\title{
评述
}

\section{铈基氧化物催化燃烧柴油机炭烟颗粒的性能及 机理研究进展}

彭超 ${ }^{1}$, 于迪 $^{1}$, 王斓懿 ${ }^{2}, 弓$ 春雷 $^{1}$, 于学华 $^{1^{*}}$, 赵震 ${ }^{1,2^{*}}$

1. 沈阳师范大学化学化工学院, 能源与环境催化研究所, 沈阳 110034

2. 中国石油大学(北京), 重质油国家重点实验室, 北京 102249

*通讯作者, E-mail: yuxuehua1986@163.com; zhenzhao@cup.edu.cn, zhaozhen1586@163.com

收稿日期: 2021-04-15; 接受日期: 2021-05-31; 网络版发表日期: 2021-06-11

国家科技部重点研发计划项目(编号: 2017YFE0131200)、国家自然科学基金(编号: 22072095, U1908204, 21761162016)、辽宁省自然基金面 上项目(编号：2019-MS-284)、移动源污染排放控制技术国家工程实验室开放基金(编号：NELMS2018A04)、沈阳师范大学创新团队支持计 划、沈阳师范大学重大捊化项目(编号: ZD201901)资助项目

摘要随着环保法规的日益严格和人们环保意识的提高, 柴油车尾气污染物中的炭烟颗粒对环境的严重污染 引起了人们广泛的关注. 利用催化净化技术实现炭烟颗粒的消除是目前最有效的途径之一, 其中高活性催化剂的 研发是决定该技术广泛应用的关键因素之一。近年来, 铈基氧化物催化剂因其良好的氧化还原性能、适当的表面 酸性以及较高的储/释氧容量而被广泛用于柴油机尾气炭烟颗粒的催化燃烧领域. 研究铈基氧化物催化剂在炭烟 催化燃烧反应高活性的本质, 有助于了解炭烟颗粒催化燃烧过程的基本原理, 为现有催化剂的优化和新型催化剂 的设计提供科学指导. 本文总结了近年来铈基氧化物催化剂材料在催化柴油机炭烟燃烧中的研究进展, 主要包括 单一氧化铈催化剂和稀土金属、过渡金属、碱(碱土)金属及贵金属改性的铈基氧化物催化剂。同时，对上述催化 剂的反应机理进行了总结. 最后, 提出了铈基氧化物催化剂在催化柴油机炭烟燃烧中存在的问题并对其发展前景 进行了展望.

关键词铈基氧化物, 催化剂, 柴油机, 炭烟颗粒

\section{1 引言}

在现代社会中柴油发动机被认为是高效耐用的内 燃动力，已经在中、重型机动车以及大型机械，如船 舶、起重机等领域内得到了广泛应用 ${ }^{[1,2]}$. 但是，柴油 车排放的污染物, 如炭烟颗粒 $(\mathrm{PM})$ 、氮氧化物 $\left(\mathrm{NO}_{x}\right)$ 、 碳氢化合物 $(\mathrm{HC})$ 、一氧化碳 $(\mathrm{CO})$ 等, 特别是炭烟颗粒 会对环境造成严重的危害 ${ }^{[3 \sim 5]}$. 炭烟颗粒不仅是城市大
气中PM2.5主要来源, 而且表面能够吸附大量的致癌 物质如苯并萠和硝基稠环芳烃等，进入人体会导致呼 吸系统疾病, 严重危害人体健康 ${ }^{[6-9]}$. 此外, 最新国VI 排放标准尤其是国 VIb 排放标准的要求更加严格, 其 PM颗粒排放量要求低于 $3 \mathrm{mg} / \mathrm{km}$ 且额外增加了对 PN 颗粒物的排放要求 $\left(\right.$ 低于 $6 \times 10^{11}$ 颗 $\left./ \mathrm{km}\right)$. 在国五阶段, 柴油车和汽油车的排放标准有所不同, 但国VI标准中 采用了燃料中性原则，即无论采用哪种燃料其排放限

引用格式: Peng C, Yu D, Wang L, Zhang C, Yu X, Zhao Z. Recent advances in performances and mechanisms of cerium-based oxide catalysts for catalytic combustion of soot particles released from diesel engines. Sci Sin Chim, 2021, 51: 1029-1059, doi: 10.1360/SSC-2021-0093 
值是相同的. 因此, 降低炭烟颗粒的排放已经柴油车尾 气催化净化的重要任务, 开展这方面的研究具有重大 的现实和环境保护意义. 当前，控制炭烟颗粒排放的

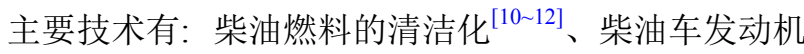
燃烧技术的改进 ${ }^{[13,14]}$ 和柴油车尾气排放后处理技 术 $^{[15,16]}$. 其中, 柴油车尾气排放后处理技术是去除炭烟 颗粒最为有效的方式之一，即利用颗粒过滤捕集器 (DPF)对炭烟颗粒进行捕集再进行燃烧，而这一技术 的核心是催化剂的研发 ${ }^{[17 ~ 19]}$. 近年来, 研究人员开发 了多种催化剂应用于柴油机尾气炭烟颗粒的催化净化 中, 如: 贵金属催化剂, 碱金属催化剂, 过渡金属催化剂 和稀土金属催化剂等。贵金属催化剂虽然具有耐高 温、抗氧化和催化活性高等优点，但因价格昂贵、资 源有限、抗中毒能力差，在实际应用中受到了极大限 制 ${ }^{[20,21]}$. 碱金属催化剂具有导热性能好、表面流动性 强等优点，但低碱金属熔点、沸点低，高温容易流 失 ${ }^{[22]}$ 。过渡金属(如 $\mathrm{Cu} 、 \mathrm{Cr} 、 \mathrm{Ni}$ 等)催化剂, 催化活性 差、起燃温度高、易中毒等缺点 ${ }^{[23]}$. 稀土金属催化剂 经济性高、使用寿命长，作为催化剂的活性组分有着 良好的抗中毒能力, 使其成为优异的催化应用替代品.

稀土金属氧化物由于具有未充满电子的 $4 \mathrm{f}$ 轨道和 镧系收缩等特征, 表现出独特的性能. 研究表明, 稀土 组分的存在可以有效地调节催化剂的表面酸碱性、修 饰催化活性中心的结构、提高催化剂的储/释氧能 力、增强其结构稳定性和提高活性组分的分散度 等 ${ }^{[24-27]}$. 在众多稀土金属氧化物中，铈基氧化物催化 剂因其具有强的储放氧的能力和优异的氧化还原能 力，被认为是最有应用前景的稀土金属催化剂且在多

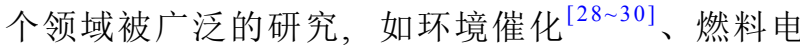
池 ${ }^{[31]}$ 、生物医学 ${ }^{[32,33]} 、 \mathrm{UV}$ 吸收剂 ${ }^{[34]}$ 和抛光剂 ${ }^{[35]}$ 等. 在环境催化领域, 铈基氧化物材料主要用于多相催化, 如, 汽车三效催化剂 $(\mathrm{TWC})^{[36 \sim 38]} 、 \mathrm{VOCs}$ 氧化催化

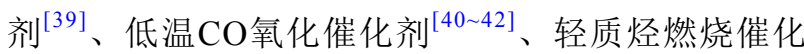
剂 ${ }^{[43,44]}$ 等. 近年来, 研究发现铈基氧化物在柴油机尾气 炭烟燃烧反应中显示出优异的催化性能. 为了进一步 优化铈基氧化物催化剂的催化性能，研究人员还利用 不同手段改善铈基氧化物催化剂，如利用不同形貌， 特定载体或制备复合氧化物等方面提高催化剂活性, 这使得铈基氧化物催化剂成为目前研究的热点. 目前, 多种类型的铈基氧化催化剂，如单一氧化铈催化剂和 金属改性的铈基氧化物催化剂等，已被用于炭烟颗粒
的催化净化消除研究.

对铈基氧化物催化剂在炭烟燃烧反应中的现有研 究成果进行梳理、归纳和总结, 将有助于本领域的研 究者更清楚地了解铈基组分所发挥的作用和催化反应 机理, 从而科学地设计高效催化剂体系. 因此, 本文主 要以铈基氧化物催化燃烧柴油机尾气中炭烟颗粒的最 新研究进展为主要内容, 重点介绍了单一氧化铈催化 剂，经稀土金属、过渡金属、碱(碱土)金属、贵金属 改性的铈基氧化物催化剂对炭烟颗粒的催化燃烧的最 新研究进展; 并总结了上述提及的铈基氧化物催化剂 对炭烟催化燃烧的反应机理. 最后，提出了目前有关 铈基氧化物催化剂在炭烟催化燃烧中存在的问题和未 来的发展趋势.

\section{2 铈基氧化物催化炭烟燃烧}

\section{1 单一氧化铈催化剂}

\subsection{1 单一氧化铈催化剂的晶体结构}

铈在元素周期表中位于 58 号, 属于镧系稀土元素 的一种, 主要存在独居石和氟碳铈矿中, 也存在于 铀、针、钚的裂变产物中, 在地壳中含量较为丰富位 于元素丰富序列的 25 位. 铈的电子排列形式为 $[\mathrm{Xe}]$ $4 \mathrm{f}^{1} 5 \mathrm{~d}^{1} 6 \mathrm{~s}^{2}$, 在化学反应过程中容易失去外层两个 $6 \mathrm{~s}$ 轨 道电子和一个次外层 $5 \mathrm{~d}$ 轨道上的电子形成 +3 价的离 子，洪特规则规定在同一层的电子在本层中填充为 半、全满或者全空时离子形态更加稳定，因此铈具有 被进一步氧化成 +4 较为稳定价态的趋势并呈现出优 异的氧化还原性能 ${ }^{[45 \sim 7]}$. 在不同温度和氧气压力下, 铈可以与 $\mathrm{O}_{2}$ 形成不同的晶相，如 $\mathrm{CeO}_{2} 、 \mathrm{Ce}_{2} \mathrm{O}_{3}$ 、 $\mathrm{Ce}_{6} \mathrm{O}_{11} 、 \mathrm{Ce}_{11} \mathrm{O}_{20}$ 和 $\mathrm{Ce}_{7} \mathrm{O}_{12}$ 等，其性质和结构均有差 异 ${ }^{[48 \sim 51]}$. 这些晶相中最重要的是 $\mathrm{CeO}_{2}$; 如图 $1 \mathrm{a}$ 所示, $\mathrm{CeO}_{2}$ 晶体结构为立方萤石型，它的单元晶胞呈面心立 方的原子排布, 空间群为 $F m 3 m(a=0.5411 \mathrm{~nm}, \mathrm{JCPDS}$ 34-394). 在这种结构中，氧和铈的配位数分别为 4 和 8 , 八个等价的最近相邻 $\mathrm{O}^{2-}$ 离子围绕立方体角上的每个 $\mathrm{Ce}^{4+}$ 离子配位，每个阴离子由四个 $\mathrm{Ce}^{4+}$ 离子配位形成 四面体，这种结构拥有很多的立方间隙，离子在间隙 中可以快速的移动传递因而具有较好的离子扩散速 度 ${ }^{[52,53]} . \mathrm{CeO}_{2}$ 在被还原后能够很好的维持原有的立方 体结构并且转化成具有大量氧空位的 $\mathrm{CeO}_{2-x}$, 当 $\mathrm{CeO}_{2-x}$ 经过氧化后又能重新氧化形成 $\mathrm{CeO}_{2}$ 并循环往复可以 
循环再利用 ${ }^{[54]}$. 在上述过程中伴随着发生了储存和释 放氧的反应, Ce离子的最小骨架重组, 氧空位的移动 以及铈的价态变化，这些变化并没有改变其晶体的结 构, 反而赋予了 $\mathrm{CeO}_{2}$ 在表面和主体上自发形成氧空位 的能力, 并导致非化学计量的固有缺陷进入晶格.

$\mathrm{CeO}_{2}$ 氧空位的形成与铈的4f电子定位/离域的量 子效应紧密相关. 在理想的 $\mathrm{CeO}_{2}$ 晶体中, 呈电中性的 Ce原子的四个价电子 $\left(6 \mathrm{~s}^{2} 5 \mathrm{~d}^{1} 4 \mathrm{f}^{1}\right)$ 离开主体原子并进入 氧原子的 $\mathrm{p}$ 带. 在还原性气氛下, 当 $\mathrm{O}^{2-}$ 离子将多余的电 子留在晶格中并以中性原子形式离开时, 留下的电子 将完全局限在附近的 $\mathrm{Ce}^{4+}$ 离子中，从而生成 $\mathrm{Ce}^{3+}$. 如 图1b所示, 这会在O $2 \mathrm{p}$ 价带和Ce $5 \mathrm{~d}$ 导带之间的间隙 中产生一个占据的4f状态，通过电子的这种局域性可 获得相当大的能量增益 ${ }^{[55]}$. DFT计算结果表明, 在纯 $\mathrm{CeO}_{2}$ 中形成氧空位需要 $4.55 \mathrm{eV}$, 而在 $\mathrm{CeO}_{2}$ 基质中嵌入 一对 $\mathrm{Ce}^{3+}$ 离子时仅需要 $0.26 \mathrm{eV}^{[56]}$. 因此, $\mathrm{Ce}^{3+}$ 离子的存 在使得在 $\mathrm{CeO}_{2}$ 晶体中形成氧空位变得更加容易. 由于 这些特殊的晶体结构, $\mathrm{CeO}_{2}$ 表现出许多优异的理化性
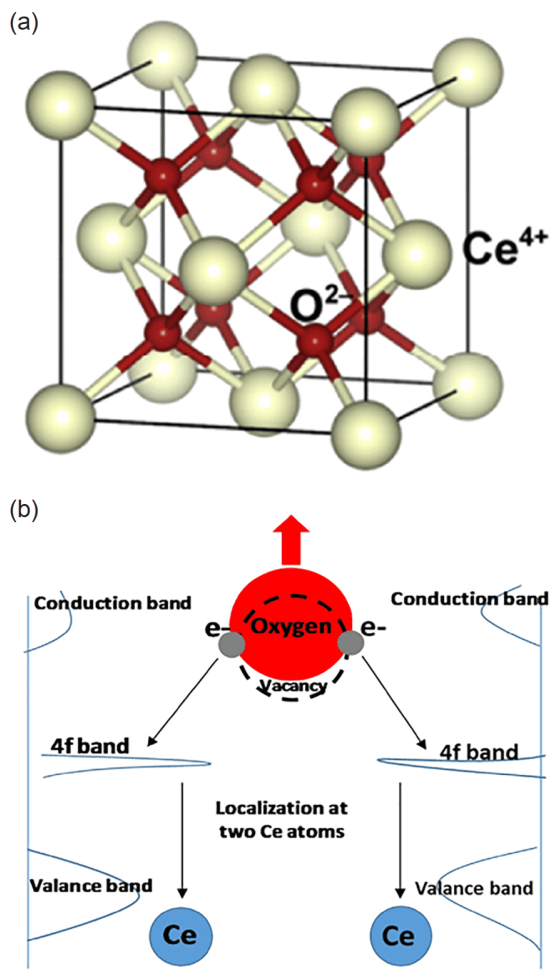

图 1 (a) $\mathrm{CeO}_{2}$ 的晶体结构 ${ }^{[53]}$; (b) 氧空位的形成与电子的局 域化 ${ }^{[55]}$ (网络版彩图)

Figure 1 (a) Crystal structure of $\mathrm{CeO}_{2}$ [53]; (b) oxygen vacancy formation and localization of the electrons [55] (color online).
质，如表面酸碱性、高储氧能力、优异的氧化还原能 力、独特的 $\mathrm{Ce}^{4+} / \mathrm{Ce}^{3+}$ 氧化还原对等, 因而其在催化领 域的研究具有重要意义和价值.

\subsection{2 纳米单一氧化铈催化剂}

柴油车尾气炭烟颗粒的催化燃烧是典型的固(炭 烟颗粒)-固(催化剂)-气 $\left(\mathrm{O}_{2}\right)$ 多相复杂催化反应，催化 剂与炭烟颗粒的接触效率是影响炭烟颗粒燃烧的重要 因素. 通过控制催化剂颗粒的尺寸，从而提高其表面 积、增加与活性中心接触效率, 能有效提高催化剂的 炭烟燃烧性能. 纳米 $\mathrm{CeO}_{2}$ 催化剂, 由于具有尺寸小, 表 面原子比例大且配位不饱和等特点, 因此在炭烟燃烧 反应中体现出比块体材料更优异的催化性能. 叶松 等 ${ }^{[57]}$ 以硝酸亚铈为原料, 氨水为沉淀剂, 采用沉淀法 制备了不同亚晶尺寸 $\mathrm{CeO}_{2}$ 颗粒用于炭烟的催化燃烧. 研究发现亚晶尺寸最小 $(8 \mathrm{~nm})$ 的 $\mathrm{CeO}_{2}$, 氧空位的数量 最多且晶格氧的流动性最强从而表现出最高的炭烟催 化活性. Huang 等 ${ }^{[58]}$ 也以硝酸亚铈为原料, 氨水为沉淀 剂，采用正、反沉淀法制备了不同晶粒尺寸的纳米 $\mathrm{CeO}_{2}$ 催化剂(7 $\mathrm{nm}-\mathrm{CeO}_{2} 、 12 \mathrm{~nm}-\mathrm{CeO}_{2} 、 20 \mathrm{~nm}-$ $\mathrm{CeO}_{2}$ ), 并通过表征方法系统研究了催化剂纳米结构 对炭烟催化活性的影响. 结果表明, 催化活性与比表 面积密切相关. 具有最大的比表面积 $\left(89 \mathrm{~m}^{2} / \mathrm{g}\right)$ 的 $20 \mathrm{~nm}-$ $\mathrm{CeO}_{2}$ 催化剂性能最好, 在炭烟燃烧反应中的起燃温度 $\left(T_{\mathrm{i}}\right)$ 和峰值温度 $\left(T_{\mathrm{m}}\right)$ 最低, 分别为 $348^{\circ} \mathrm{C}$ 和 $413^{\circ} \mathrm{C}$. Kastrinaki 等 ${ }^{[59]}$ 基于溶胶法(ABS) 和溶胶-凝胶法获得了不同 的 $\mathrm{CeO}_{2}$ 纳米颗粒催化剂用于炭烟的催化氧化. 该研究 结果发现活性最高的催化剂具有中等尺寸, 高表面积, 小晶粒尺寸, 小孔径和大孔隙率.

\subsection{3 特殊形貌单一氧化铈催化剂}

除了减小催化剂颗粒的尺寸外，通过设计和制备 具有特殊形貌和结构的 $\mathrm{CeO}_{2}$ 催化剂, 利用其特殊形貌 和结构来提高催化剂与炭烟颗粒之间的接触效率, 进 而降低炭烟燃烧温度, 提高催化剂活性. Chen等 ${ }^{[60]}$ 设 计并合成了 $\mathrm{CeO}_{2}$ 纳米棒 $(\mathrm{NR})$ 和纳米颗粒催化剂, 考察 了纳米结构与炭烟催化活性以及抗老化性之间的关 系. 研究表明, 纳米棒催化剂比纳米颗粒催化剂具有更 好的催化活性和抗老化能力. $\mathrm{CeO}_{2}(\mathrm{NR})$ 催化剂的优异 催化活性可归因于较多的氧空位, 较高的晶格氧迁移 率以及细长的棒状结构能够改善炭烟-催化剂接触. 
Zhang 等 ${ }^{[61]}$ 采用水热法和溶剂热法制备了三种不同形 貌(纳米棒、纳米粒子和片状)的 $\mathrm{CeO}_{2}$ 纳米结构, 并在 松散和紧密接触条件下测试了炭烟的燃烧性能. 实验 结果表明所制备的 $\mathrm{CeO}_{2}$ 样品均具有良好的催化活性, 其中棒状 $\mathrm{CeO}_{2}$ 表现出最佳的催化活性，在松散接触和 紧密接触条件下的炭烟燃烧的 $T_{\mathrm{m}}$ 分别为 $500^{\circ} \mathrm{C}$ 和 $368^{\circ} \mathrm{C}$. Miceli等 ${ }^{[62]}$ 采用溶液燃烧法 $(\mathrm{SCS})$ 和水热法分 别制备泡沫状和星状 $(\mathrm{SA}) \mathrm{CeO}_{2}$ 催化剂, 并用于炭烟的 燃烧反应. 与 $\mathrm{SCS}-\mathrm{CeO}_{2}$ 催化剂相比, $\mathrm{SA}-\mathrm{CeO}_{2}$ 催化剂 具有更高的微孔体积 $\left(0.04 \mathrm{~cm}^{3} / \mathrm{g}\right)$, 更大的比表面积 $\left(124 \mathrm{~m}^{2} / \mathrm{g}\right)$ 以及更小的晶粒尺寸，因此对炭烟颗粒燃烧 表现出更好的催化活性. Kumar等 ${ }^{[63]}$ 通过控制 $\mathrm{NaOH}$ 与 柠檬酸的摩尔比, 利用共沉淀法合成了具有纤维状、 束状以及鳞片状的 $\mathrm{CeO}_{2}$, 并将合成的催化剂应用于催 化燃烧炭烟颗粒的研究中. 结果表明, 纤维状的 $\mathrm{CeO}_{2}$ 具有网络状的孔道结构, 有利于炭烟与催化剂的接触 从而具有最高的催化活性. Dai等 ${ }^{[64]}$ 通过简单地调节 静电纺丝过程中的电场强度，精确地控制乙酰丙酮铈 和聚乙烯吡咯烷酮组成的纳米纤维的直径, 从而合成 柱状、芹菜状和带状 $\mathrm{CeO}_{2}$ 纳米纤维如图2所示. 与商 业样品相比, 这些新型 $\mathrm{CeO}_{2}$ 纳米纤维对炭烟燃烧具有 较低的活化能和较强的催化活性. 三种形状中，带状
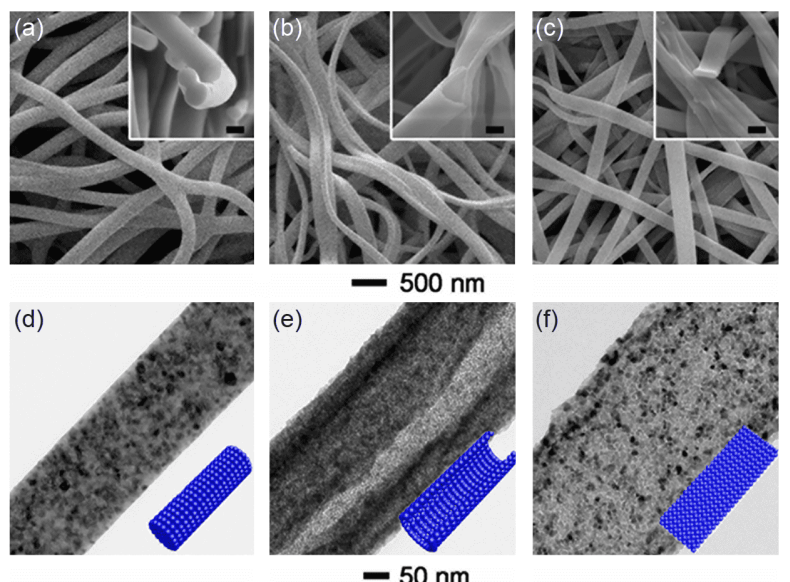

图 2 (上排)扫描电镜和(下排)透射电镜图像显示了由(a)和 (d)柱状、 (b)和 (e) 芹菜状以及 (c) 和 (f) 带状 $\mathrm{CeO}_{2}$ 纳米纤维. $(\mathrm{a} \sim \mathrm{c})$ 中的插入部分是对应的截面SEM图像, (d f $)$ 中的插入 部分是纳米纤维模型的示意图 ${ }^{[64]}$ (网络版彩图)

Figure 2 (Top row) SEM and (bottom row) TEM images of fibrous $\mathrm{CeO}_{2}$ mats made of $(\mathrm{a}, \mathrm{d})$ column-like, $(\mathrm{b}, \mathrm{e})$ celery-like and $(\mathrm{c}, \mathrm{f})$ beltlike nanofibers. The insets in (a-c) are the corresponding cross-sectional SEM images while in $(\mathrm{d}-\mathrm{f})$ are the schematic of nanofiber models, respectively [64] (color online).
$\mathrm{CeO}_{2}$ 纳米纤维的活化能最低, 为 $120.1 \mathrm{~kJ} / \mathrm{mol}$, 这是由 于炭烟和二氧化铈表面之间的最有效接触(大量的接 触点和良好的接触效率).

Bensaid等 ${ }^{[65]}$ 采用沉淀/熟化法通过调节 $\mathrm{NaOH} /$ 柠 檬酸的原料比、反应时间和反应温度合成了纤维状, 棒状和薄片状 $\mathrm{CeO}_{2}$ 催化剂. 该研究证明了纤维状是炭 烟燃烧的最佳形态，可能是由于围绕炭烟颗粒并最大 化接触点数量的纤维网络所致. Voskanyan 等 ${ }^{[66]}$ 采用 胶体二氧化硅作为模板剂, 通过胶体溶液燃烧(CSCS) 合成了孔径均匀的介孔 $\mathrm{CeO}_{2}$ 催化剂. 该催化剂具有高 的表面积, 高的孔体积, 并且对于炭烟燃烧显示出优异 的催化活性. Yang等 ${ }^{[67]}$ 以介孔二氧化硅(KIT-6)为模板 材料, 采用纳米铸造法制备了有序介孔 $\mathrm{CeO}_{2}$, 并将其 用于炭烟颗粒的燃烧. 结果表明，介孔 $\mathrm{CeO}_{2}$ 在炭烟燃 烧中表现出优异的催化性能 $T_{50}$ (炭烟转化 $50 \%$ 的温度) 为 $475^{\circ} \mathrm{C}$, 其高催化活性主要归功于其介孔结构和微晶 尺寸. 相比于介孔 $\mathrm{CeO}_{2}$, 三维有序大孔(3DOM)形貌的 贯通大孔孔道可以使反应物更容易到达活性中心，提 高催化转化效率, 而均匀的大孔孔径分布使得炭烟颗 粒的高效催化成为可能. Lee等 ${ }^{[68]}$ 研究了一系列 $\mathrm{CeO}_{2}$ 炭烟燃烧催化剂. 研究表明, 与介孔 $\mathrm{CeO}_{2}$ 催化剂相比, 大孔 $\mathrm{CeO}_{2}\left(\mathrm{M}-\mathrm{CeO}_{2}\right)$ 的炭烟燃烧活性有所提高. 这是 因为 $\mathrm{M}-\mathrm{CeO}_{2}$ 催化剂的孔径增大，使得炭烟颗粒容易 穿过催化剂的内孔, 从而增加了催化剂与炭烟的整体 接触.

\subsection{4 特殊晶面单一氧化铈催化剂}

近年来, $\mathrm{CeO}_{2}$ 催化剂的晶面效应及其独特的催化 性能引起研究者的广泛关注. 通常, $\mathrm{CeO}_{2}$ 催化剂表面 会优先暴露三个低米勒指数晶面(100)、(110)和(111) 如图3所示. $\mathrm{CeO}_{2}(110)$ 表面的电荷为零, 这是由于每个 平面上阴阳离子的化学计量平衡所致. $\mathrm{CeO}_{2}(111)$ 是每 个平面都带电的表面. 重复单元由对称配置的三个平 面组成, 因此在垂直于表面的方向上没有净偶极矩. $\mathrm{CeO}_{2}(100)$ 表面具有交替带电的平面, 重复单元只有两 个平面, 产生垂直于表面的偶极矩 ${ }^{[52]}$. 据有关报道, 各 晶面的稳定性为 $(111)>(110)>(100)$. (100) 晶面具有最 高的化学活性和氧空位浓度, 其催化活性往往高于其 它两个晶面. 通过调控 $\mathrm{CeO}_{2}$ 催化剂的形貌, 优先暴露 更多的(100)高活性晶面可大幅度提高催化剂的性能. Aneggi 等 ${ }^{[69]}$ 利用水热法制备了不同暴露晶面且不同形 

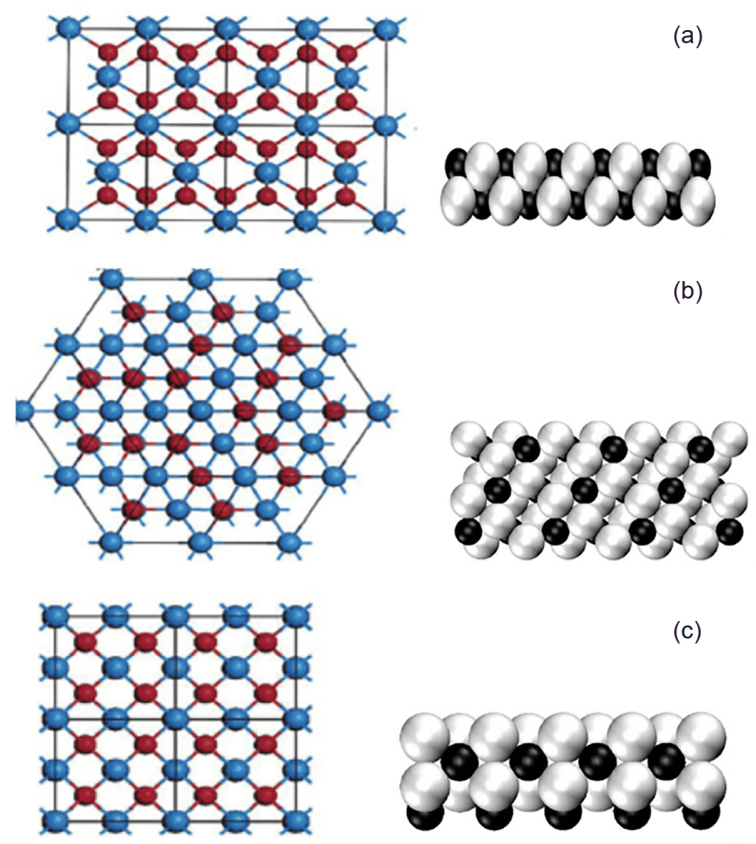

(c)

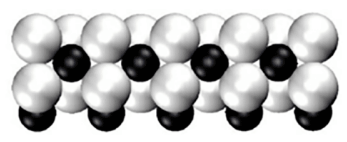

图 3 (a) $\mathrm{CeO}_{2}$ (110), (b) $\mathrm{CeO}_{2}$ (111)和(c) $\mathrm{CeO}_{2}$ (100)表面. 黑 色的球是 $\mathrm{Ce}$, 白色的球是 $\mathrm{O}^{[52]}$ (网络版彩图)

Figure 3 (a) $\mathrm{CeO}_{2}$ (110), (b) $\mathrm{CeO}_{2}$ (111) and (c) $\mathrm{CeO}_{2}$ (100) surfaces. The black spheres are $\mathrm{Ce}$ and the white spheres are $\mathrm{O}$ [52] (color online).

貌(立方体状、棒状、八面体状)的 $\mathrm{CeO}_{2}$ 催化剂如图4 所示. 其中, 立方体状的 $\mathrm{CeO}_{2}$ 暴露晶面为(100); 棒状 $\mathrm{CeO}_{2}$ 具有(100), (110)及部分的(111)晶面; 八面体状 $\mathrm{CeO}_{2}$ 的暴露晶面主要为(111)晶面. 该研究结果证明了 不同暴露晶面的 $\mathrm{CeO}_{2}$ 在炭烟颗粒的催化燃烧中展示 不同的活性. 相比于暴露(111)晶面的八面体状形貌, 暴露较多(100)和(110)晶面的立方体状和棒状 $\mathrm{CeO}_{2}$ 上 观察到更高的活性和转化率. 随后, Aneggi等 ${ }^{[70]}$ 又研究 了在不同敾烧条件下 $\mathrm{CeO}_{2}$ 形成的不同晶面对炭烟颗 粒的催化燃烧性能及活化氧在不同晶面下与炭烟的相 互作用, 以实验的方法验证了 $\mathrm{CeO}_{2}$ 自身在催化反应中 的氧化还原机制以及 $\mathrm{Ce}^{3+}$ 离子的存在. Jian等 ${ }^{[71]}$ 研究了 不同形貌的炭烟燃烧 $\mathrm{CeO}_{2}$ 催化剂上晶面的动力学行 为. 通过分析松散接触条件下的表观活化能分布函数 $\left(f\left(E_{\mathrm{a}}\right)\right)$, 发现暴露 $(100)$ 、(111)平面和非催化气体 $\mathrm{O}_{2}$ 在 炭烟燃烧过程中的表观活化能 $\left(E_{\mathrm{a}}\right)$ 分布范围分别为 60 100、100 150和150 250 kJ/mol. 与其它催化剂相 比, 在松散接触条件下 $\mathrm{CeO}_{2}$ 纳米立方体具有更高的固 有活性, 这是由于位于较低 $E_{\mathrm{a}}$ 范围的丰富的活性暴露 $(100)$ 平面具有更高的 $f\left(E_{\mathrm{a}}\right)$ 值. Sreeremya等 ${ }^{[72]}$ 采用沉淀

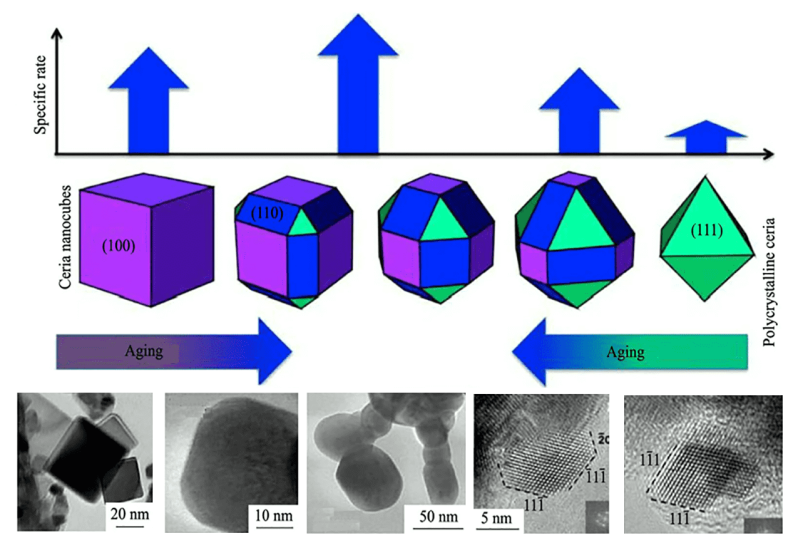

图 4 二氧化铈结构和热老化对其炭烟燃烧催化性能的影 响 ${ }^{[69]}$ (网络版彩图)

Figure 4 Influence of ceria structure and thermal ageing on their catalytic performances for soot combustion [69] (color online).

法和水热法合成了不同晶体形状和尺寸的纳米 $\mathrm{CeO}_{2}$, 并测试了炭烟的燃烧性能. 研究结果表明催化剂晶格 应变遵循单一的标度律, 随着平均晶体尺寸的增加应 变非线性减小, 并且催化剂的活性是由催化剂结晶平 面的相对分数决定的, 而不是由催化剂的比表面积决 定的.

目前, 许多单一氧化铈已被用于柴油机尾气中炭 烟颗粒的去除, 单一氧化铈对炭烟燃烧的催化性能总 结在表1中.

\section{2 不同金属改性的铈基氧化物催化剂}

单一氧化铈催化剂对炭烟燃烧表现出高活性, 但 是它有一个最主要的缺点即热稳定性差, 高温焙烧后 会严重烧结, 导致氧化还原能力急剧下降, 从而影响 其催化性能. 通过添加金属改性可提高其抗烧结能力 及催化活性. 目前, 研究人员将稀土金属、过渡金 属、贵金属以及碱(碱土)金属等引入到氧化铈中制备 了一系列改性的铈基氧化物催化剂, 与单一氧化铈相 比, 改性后的催化性能均具有明显的提升.

\subsection{1 稀土金属改性的铈基氧化物催化剂}

在稀土金属单组分氧化物中, $\mathrm{CeO}_{2}$ 的炭烟催化活 性明显高于其它稀土金属氧化物(如 $\mathrm{La}_{2} \mathrm{O}_{3} 、 \mathrm{~Tb}_{2} \mathrm{O}_{3}$ 、 $\mathrm{Sm}_{2} \mathrm{O}_{3} 、 \mathrm{Y}_{2} \mathrm{O}_{3}$ 等). 经过不同稀土金属(如La、 $\mathrm{Pr}$ 、 $\mathrm{Sm} 、 \mathrm{~Tb} 、 \mathrm{Y}$ 和 $\mathrm{Nd}$ 等)改性能够进一步提高 $\mathrm{CeO}_{2}$ 催化剂 催化燃烧炭烟的性能. 稀土金属易与铈基氧化物 $\mathrm{CeO}_{2}$ 
表 1 单一氧化铈催化剂消除炭烟的催化性能

Table 1 Reviews on catalytic performances of single cerium oxide catalyst for diesel soot removal

\begin{tabular}{|c|c|c|c|c|c|c|c|c|}
\hline 催化剂 & $\begin{array}{c}\text { 炭烟/催化剂 } \\
\text { 重量比 }\end{array}$ & $\begin{array}{l}\text { 接触 } \\
\text { 方式 }\end{array}$ & 反应物进料 & $\begin{array}{c}\text { 升温速率 } \\
\left({ }^{\circ} \mathrm{C} / \mathrm{min}\right)\end{array}$ & $\begin{array}{l}T_{10} / T_{\mathrm{i}} \\
\left({ }^{\circ} \mathrm{C}\right)\end{array}$ & $\begin{array}{c}T_{50} / T_{\mathrm{m}} \\
\left({ }^{\circ} \mathrm{C}\right)\end{array}$ & $\begin{array}{l}T_{90} \\
\left({ }^{\circ} \mathrm{C}\right)\end{array}$ & $\begin{array}{l}\text { 相关 } \\
\text { 文献 }\end{array}$ \\
\hline $7 \mathrm{~nm}-\mathrm{CeO}_{2}$ & $1 / 4$ & 松散 & 流量 $100 \mathrm{~mL} / \mathrm{min}, 12 \% \mathrm{O}_{2}+\mathrm{N}_{2}$ 平衡气 & 15 & 341 & 413 & - & {$[57]$} \\
\hline $20 \mathrm{~nm}-\mathrm{CeO}_{2}$ & $1 / 4$ & 松散 & 流量 $100 \mathrm{~mL} / \mathrm{min}, 12 \% \mathrm{O}_{2}+\mathrm{N}_{2}$ 平衡气 & 15 & 348 & 413 & - & {$[58]$} \\
\hline 棒状 $\mathrm{CeO}_{2}$ & $1 / 4$ & 紧密 & 流量 $500 \mathrm{~mL} / \mathrm{min}, 7 \% \mathrm{O}_{2}+10 \% \mathrm{H}_{2} \mathrm{O}+\mathrm{N}_{2}$ 平衡气 & 5 & 372 & 394 & 450 & {$[60]$} \\
\hline 棒状 $\mathrm{CeO}_{2}$ & $1 / 9$ & 紧密 & 流量 $80 \mathrm{~mL} / \mathrm{min}, 10 \% \mathrm{O}_{2}+1000 \mathrm{ppm} \mathrm{NO}+\mathrm{N}_{2}$ 平衡气 & 10 & 275 & 315 & 347 & {$[61]$} \\
\hline 棒状 $\mathrm{CeO}_{2}$ & $1 / 9$ & 松散 & 流量 $80 \mathrm{~mL} / \mathrm{min}, 10 \% \mathrm{O}_{2}+\mathrm{N}_{2}$ 平衡气 & 10 & 356 & 500 & 554 & [61] \\
\hline 星状 $\mathrm{CeO}_{2}$ & $1 / 9$ & 紧密 & 流量 $100 \mathrm{~mL} / \mathrm{min}, 10 \% \mathrm{O}_{2}+\mathrm{N}_{2}$ 平衡气 & 5 & 354 & 410 & - & {$[62]$} \\
\hline 纤维状 $\mathrm{CeO}_{2}$ & $1 / 10$ & 松散 & 流量 $100 \mathrm{~mL} / \mathrm{min}, 10 \% \mathrm{O}_{2}+\mathrm{N}_{2}$ 平衡气 & 5 & 241 & 400 & - & {$[63]$} \\
\hline 纤维状 $\mathrm{CeO}_{2}$ & $1 / 9$ & 紧密 & 流量 $100 \mathrm{~mL} / \mathrm{min}, 10 \% \mathrm{O}_{2}+\mathrm{N}_{2}$ 平衡气 & 5 & 317 & 372 & - & {$[65]$} \\
\hline 介孔 $\mathrm{CeO}_{2}$ & $1 / 5$ & 紧密 & 流量 $50 \mathrm{~mL} / \mathrm{min}, 4 \% \mathrm{O}_{2}+\mathrm{He}$ 平衡气 & 10 & - & 295 & - & {$[66]$} \\
\hline 介孔 $\mathrm{CeO}_{2}$ & $1 / 4$ & 紧密 & 流量 $100 \mathrm{~mL} / \mathrm{min}$, 空气 & 10 & - & 475 & - & {$[67]$} \\
\hline $3 \mathrm{DOM} \mathrm{CeO}_{2}$ & $1 / 10$ & 松散 & 流量 $100 \mathrm{~mL} / \mathrm{min}, 20 \% \mathrm{O}_{2}+5 \% \mathrm{H}_{2} \mathrm{O}+\mathrm{Ar}$ 平衡气 & 5 & - & 540 & - & {$[68]$} \\
\hline 立方体 $\mathrm{CeO}_{2}$ & $1 / 10$ & 松散 & 流量 $100 \mathrm{~mL} / \mathrm{min}, 10 \% \mathrm{O}_{2}+\mathrm{N}_{2}$ 平衡气 & 5 & - & 459 & 554 & {$[71]$} \\
\hline 八面体 $\mathrm{CeO}_{2}$ & $1 / 10$ & 松散 & 流量 $100 \mathrm{~mL} / \mathrm{min}, 10 \% \mathrm{O}_{2}+\mathrm{N}_{2}$ 平衡气 & 5 & - & 541 & 606 & [71] \\
\hline 介孔 $\mathrm{CeO}_{2}$ & $1 / 9$ & 紧密 & 流量 $100 \mathrm{~mL} / \mathrm{min}, 10 \% \mathrm{O}_{2}+\mathrm{N}_{2}$ 平衡气 & 5 & 374 & 464 & 510 & [73] \\
\hline $\mathrm{CeO}_{2}$ 纳米颗粒 & $1 / 9$ & 紧密 & 流量 $100 \mathrm{~mL} / \mathrm{min}, 10 \% \mathrm{O}_{2}+\mathrm{N}_{2}$ 平衡气 & 5 & 364 & 413 & 456 & [74] \\
\hline
\end{tabular}

形成固溶体结构，导致其晶格畸变产生大量的氧空穴 缺陷，从而提高催化剂的氧化还原特性和储氧能力 (OSC). 此外, 铈基氧化物催化剂中固溶体结构的生成 能够有效抑制催化剂晶粒的长大，提高催化剂的高温 热稳定性.

在铈基氧化物晶格中掺入La不仅能增加催化剂在 低温下的氧解吸作用，而且也增加了其氧空位的产生, 从而提高了炭烟燃烧活性. 因此, La改性的铈基氧化物 被大量的研究. Bueno-López等 ${ }^{[75]}$ 研究了 $\mathrm{CeO}_{2}$ 和不同 含量 $\mathrm{La}^{3+}$ 掺杂的 $\mathrm{CeO}_{2}$ 催化剂对 $\mathrm{O}_{2}$ 氧化炭烟的催化性 能. 在松散和紧密接触条件下, 掺 $5 \% \mathrm{La}^{3+}$ 的 $\mathrm{CeO}_{2}$ 催化 剂 $\left(\mathrm{CeO}_{2}-5 \mathrm{La}\right)$ 的催化活性最好. 作者将这种改善归因 于掺杂 $\mathrm{La}^{3+}$ 引起的BET比表面积的增加和 $\mathrm{CeO}_{2}$ 催化剂 氧化还原性能的改变有关. Anantharaman等 ${ }^{[76]}$ 利用 EDTA-柠檬酸盐法合成了二元金属氧化物 $\mathrm{Ce}_{0.9} \mathrm{M}_{0.1} \mathrm{O}_{2-\delta}$ $(\mathrm{M}=\mathrm{Gd} 、 \mathrm{Sm}$ 和 $\mathrm{La})$ ，并对其炭烟燃烧活性进行了研究. 结果发现催化剂催化活性的关键参数是掺杂性质(离 子的半径和氧化态)、反应(200)和(220)晶面和表面氧 空位. 与 $\mathrm{Ce}_{0.9} \mathrm{Sm}_{0.1} \mathrm{O}_{2-\delta}\left(T_{50}=490^{\circ} \mathrm{C}\right)$ 和 $\mathrm{Ce}_{0.9} \mathrm{Gd}_{0.1} \mathrm{O}_{2-\delta}$ $\left(T_{50}=480^{\circ} \mathrm{C}\right)$ 相比, 氧空位较高的 $\mathrm{Ce}_{0.9} \mathrm{La}_{0.1} \mathrm{O}_{2-\delta}$ 催化剂具 有更高的炭烟燃烧活性 $\left(T_{50}=450^{\circ} \mathrm{C}\right)$. Nascimento 等 ${ }^{[77]}$
研究了低温炭烟燃烧过程中 $\mathrm{La}$ 负载量对 $\mathrm{Ce}-\mathrm{Zn}$ 复合氧 化物物化性能和催化性能的影响. 研究表明 $\mathrm{Ce} / \mathrm{Zn} / \mathrm{La}$ 原子比为 $2: 1: 0.5$ 的 $\mathrm{Ce}-\mathrm{Zn}-\mathrm{La}$ 三元复合氧化物催化剂 在 $390^{\circ} \mathrm{C}$ 以下具有最高的催化活性, 并促进了炭烟的燃 烧. $\mathrm{Ce}-\mathrm{Zn}-\mathrm{La}$ 样品中存在的大量氧空位和晶格缺陷, 这是影响催化剂稳定性和氧化还原性能的关键参数.

相比于 $\mathrm{La}$ 元素, $\mathrm{Pr}$ 具有更小的离子半径. $\mathrm{CeO}_{2}$ 晶 体中引入离子半径更小的掺杂剂, 能够促进催化剂缺陷 位的形成降低光学带隙, 改善表面氧空位浓度, 从而显 著降低了氧空位形成能，增强炭烟燃烧活性. GuillénHurtado等 ${ }^{[78]}$ 研究了不同 $\mathrm{Ce} / \mathrm{Pr}$ 摩尔比的 $\mathrm{Ce}_{x} \mathrm{Pr}_{1-x} \mathrm{O}_{2-\delta}$ $(0<x<1)$ 催化剂对炭烟燃烧催化活性的影响. 结果表明: $\mathrm{Pr}$ 的引入能够提高氧在 $\mathrm{CeO}_{2}$ 表面和氧化骨架上的迁 移率, 从而显著改善的炭烟燃烧催化性能. 在所制备的 催化剂中, $\mathrm{Ce}_{0.5} \mathrm{Pr}_{0.5} \mathrm{O}_{2-\delta}$ 催化剂表现出最高的催化活性, $T_{50}$ 为 $477^{\circ} \mathrm{C}$. 此外, Guillén-Hurtado 等 ${ }^{[79]}$ 还采用反向微 乳液和共沉淀法制备了 $\mathrm{Ce}_{x} \mathrm{Pr}_{1-x} \mathrm{O}_{2}$ 和 $\mathrm{Ce}_{x} \mathrm{Zr}_{1-x} \mathrm{O}_{2} \quad(x=$ $0.8 、 0.5$ )催化剂. 研究发现 Ce-Pr比Ce-Zr催化剂更具 活性, 如图5所示催化剂粒径与炭烟燃烧呈线性关系, 催化剂的粒径越小炭烟燃烧温度越低, 其中具有最大 比表面积 $\left(125 \mathrm{~m}^{2} / \mathrm{g}\right.$ ) 和最小粒径尺寸 $(7 \mathrm{~nm})$ 的 $\mathrm{Ce}_{0.5} \mathrm{Pr}_{0.5} \mathrm{O}_{2}$ 


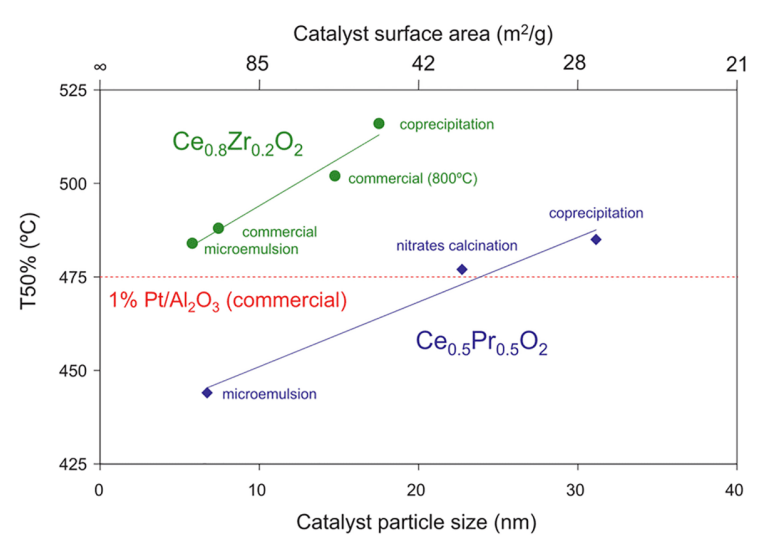

图 $5 \mathrm{NO}_{x}+\mathrm{O}_{2}+\mathrm{N}_{2}$ 混合气中炭烟燃烧能力与铈基催化剂粒 径/表面积的关系 ${ }^{[79]}$ (网络版彩图)

Figure 5 Relationship between soot combustion capacity in a $\mathrm{NO}_{x}+\mathrm{O}_{2}$ $+\mathrm{N}_{2}$ gas mixture and particle size/surface area of ceria-based catalysts [79] (color online).

催化剂表现出最好的炭烟燃烧活性. Krishna等 ${ }^{[80]}$ 研究 了 $\mathrm{La} 、 \mathrm{Pr} 、 \mathrm{Sm}$ 和Y元素改性的 $\mathrm{CeO}_{2}$ 催化剂的物理化 学性质, 并在 $\mathrm{O}_{2} / \mathrm{NO}$ 氛围中对催化剂的炭烟燃烧活性 进行了相关性研究. 研究结果表明, 稀土改性的 $\mathrm{CeO}_{2}$ 催化剂炭烟燃烧活性的提高与中/微孔体积的增加和 外表面积的稳定有关. 相比于La、Sm和Y改性, 经Pr修 饰的 $\mathrm{CeO}_{2}$ 催化剂具有更强的炭烟燃烧活性.

除了 $\mathrm{La} 、 \operatorname{Pr}$ 外, Eu、Nd、Sm、Tb和Y改性的铈基 氧化物催化剂也能提高催化燃烧炭烟的性能. Vinodkumar等 ${ }^{[81]}$ 通过共沉淀方法制备了 $\mathrm{Zr}^{4+} 、 \mathrm{La}^{3+}$ 和 $\mathrm{Eu}^{3+}$ 掺 杂的 $\mathrm{CeO}_{2}(\mathrm{CZ} 、 \mathrm{CL}$ 和 $\mathrm{CE})$. 与纯 $\mathrm{CeO}_{2}$ 相比, 掺杂后的 $\mathrm{CeO}_{2}$ 催化剂使炭烟燃烧温度 $T_{50}$ 降低了 $158^{\circ} \mathrm{C}$, 这归因 于掺杂剂物种和 $\mathrm{CeO}_{2}$ 之间的协同作用. 在合成的纳米 催化剂中, $\mathrm{CE}$ 样品由于存在更多的氧空位, 高的比表 面积和易还原性从而表现出更好的性能. Patil等 ${ }^{[82}$ 利 用甘氨酸-硝酸法(GNP)成功地合成了 $\mathrm{Nd}$ 掺杂的 $\mathrm{CeO}_{2}$ $(x \mathrm{NDC}, x=0 、 1 \% 、 3 \% 、 5 \% 、 10 \% 、 20 \%$ 和 $30 \% \mathrm{Nd})$ 催化剂, 并对其炭烟燃烧活性进行了测试. 与其它 $\mathrm{NDC}$ 催化剂相比, $1 \% \mathrm{NDC}$ 催化剂显示出较高的 $\mathrm{Ce}^{3+}$ 浓 度和表面活性氧种类，因此产生了更好的炭烟燃烧活 性. Rangaswamy等 ${ }^{[83]}$ 采用简单的沉淀法成功地将三 价稀土掺杂剂 $(\mathrm{Sm}$ 和 $\mathrm{La})$ 引入 $\mathrm{CeO}_{2}$ 中, 并研究了它们对 炭烟燃烧的催化效率. 研究结果表明, 与纯 $\mathrm{CeO}_{2}$ 和 $\mathrm{CeO}_{2}-\mathrm{La}_{2} \mathrm{O}_{3}$ 相比, $\mathrm{CeO}_{2}-\mathrm{Sm}_{2} \mathrm{O}_{3}$ 催化剂具有较高的炭烟 燃烧活性, 其原因在于 $\mathrm{CeO}_{2}-\mathrm{Sm}_{2} \mathrm{O}_{3}$ 催化剂具有许多有 利的催化性能, 如较小的微晶尺寸、较大的比表面
积、丰富的氧空位和优越的还原性. Małecka等 ${ }^{[84]}$ 报 道了 $\mathrm{CeLnO}_{x}$ 混合氧化物 $(\mathrm{Ln}=\mathrm{Pr} 、 \mathrm{~Tb}$ 和 $\mathrm{Lu})$ 在炭烟燃烧 中的结构和活性研究结果. 发现所制备的复合氧化物 均为 $\mathrm{CeO}_{2}$ 的萤石结构, 具有较强的低温还原能力和良 好的热稳定性. 其中, $\mathrm{CeTbO}_{x}$ 催化剂, 具有最好的催化 性能, 即 $T_{10} 、 T_{50} 、 T_{90}$ 值分别为 $399^{\circ} \mathrm{C} 、 486^{\circ} \mathrm{C} 、 558^{\circ} \mathrm{C}$. Zhang等 ${ }^{[85}$ 通过共沉淀法合成了一系列具有不同钇掺 杂含量(0、1、3、6和10 wt. $\%$ ) 的 $\mathrm{MnO}_{x}-\mathrm{CeO}_{2}-\mathrm{Y}_{2} \mathrm{O}_{3}$ 催 化剂. 随着钇含量增多, 催化燃烧炭烟颗粒活性降低. 但是，在 $800^{\circ} \mathrm{C}$ 下热老化 $12 \mathrm{~h}$ 后，钇能够有效的缓解催 化剂的失活. 通过添加 6\% 10\%的钇， $T_{\mathrm{m}}$ 仅增加 $34 \sim 35^{\circ} \mathrm{C}$, 与 $183^{\circ} \mathrm{C}$ 的 $\mathrm{MnO}_{x}-\mathrm{CeO}_{2}$ 相比, 这是一个显着 的改善. 热稳定性的提高归因于 $\mathrm{MnO}_{x}-\mathrm{CeO}_{2}$ 微晶的烧 结抑制, 并保留了 $\mathrm{Mn}^{4+}$ 和活性氧的高表面含量.

通常，两种或多种稀土金属改性的铈基氧化物会 表现出比单一稀土金属改性的铈基氧化物更好的炭烟 催化性能. Vinodkumar等 ${ }^{[86]}$ 制备了一系列 $\mathrm{Ce}_{0.8} \mathrm{Eu}_{0.1^{-}}$ $\mathrm{M}_{0.1} \mathrm{O}_{2-\delta}(\mathrm{M}=\mathrm{Zr} 、 \mathrm{Hf} 、 \mathrm{La}$ 和 Sm) 纳米氧化物, 并测试了 其对柴油机炭烟燃烧的性能. 研究表明, 与单组分掺杂 铈基材料相比, 共掺杂铈基材料显示出更高的活性; 经 过两种掺杂剂改性后, 催化剂的氧化还原性能和氧缺 陷浓度显着提高, 从而促进了炭烟的燃烧. 如图6所示, 制备的材料的催化活性顺序为 $\mathrm{Ce}_{0.8} \mathrm{Eu}_{0.1} \mathrm{La}_{0.1} \mathrm{O}_{2-\delta}$ $(\mathrm{CEL})>\mathrm{Ce}_{0.8} \mathrm{Eu}_{0.1} \mathrm{Sm}_{0.1} \mathrm{O}_{2-\delta}(\mathrm{CES})>\mathrm{Ce}_{0.8} \mathrm{Eu}_{0.1} \mathrm{Hf}_{0.1} \mathrm{O}_{2-\delta}$ $(\mathrm{CEH})>\mathrm{Ce}_{0.8} \mathrm{Eu}_{0.1} \mathrm{Zr}_{0.1} \mathrm{O}_{2-\delta} \quad(\mathrm{CEZ})>\mathrm{Ce}_{0.8} \mathrm{Eu}_{0.1} \mathrm{O}_{2-\delta} \quad(\mathrm{CE})>$ $\mathrm{CeO}_{2}$. Devaiah等 ${ }^{[87]}$ 通过简便的共沉淀法合成了掺Y的 二氧化铈-氧化锆 $\left(\mathrm{Ce}_{0.8} \mathrm{Zr}_{0.12} \mathrm{Y}_{0.08} \mathrm{O}_{2-\delta}, \mathrm{CZY}\right)$ 和二氧化 铈-镧系元素 $\left(\mathrm{Ce}_{0.8} \mathrm{La}_{0.12} \mathrm{Y}_{0.08} \mathrm{O}_{2-\delta}, \mathrm{CLY}\right)$ 三元氧化物固 溶体. 结果表明 $\mathrm{Y}$ 掺杂到 CZ和CL样品中后炭烟的燃烧 性能得到了极大的改善. 特别CLY样品, 由于氧空位 多, 还原性好以及表面积大从而显示出最佳的催化活 性. Piumetti等 ${ }^{[88}$ 通过水热法和溶液燃烧法首次合成 了 $\mathrm{Pr}$ 和 $\mathrm{Zr}$ 共同掺杂的铈纳米立方体, 并测试了催化剂 的炭烟燃烧活性. 实验证实了在纳米结构催化剂上Pr 和Zr对炭烟燃烧反应具有积极作用. Deng 等 ${ }^{[89]}$ 采用不 同的沉淀剂控制结晶速率，合成了一系列具有不同晶 粒尺寸、结构性能和热稳定性的纳米 $\mathrm{CeO}_{2}-\mathrm{ZrO}_{2}-$ $\mathrm{Y}_{2} \mathrm{O}_{3}-\mathrm{La}_{2} \mathrm{O}_{3}$ 材料, 并将其用于炭烟催化氧化. 研究表明 总催化剂表面可用氧(TSAO)值与表面积呈线性关系, 决定了炭烟的燃烧活性.

稀土金属改性的铈基氧化物催化剂在柴油机炭烟 


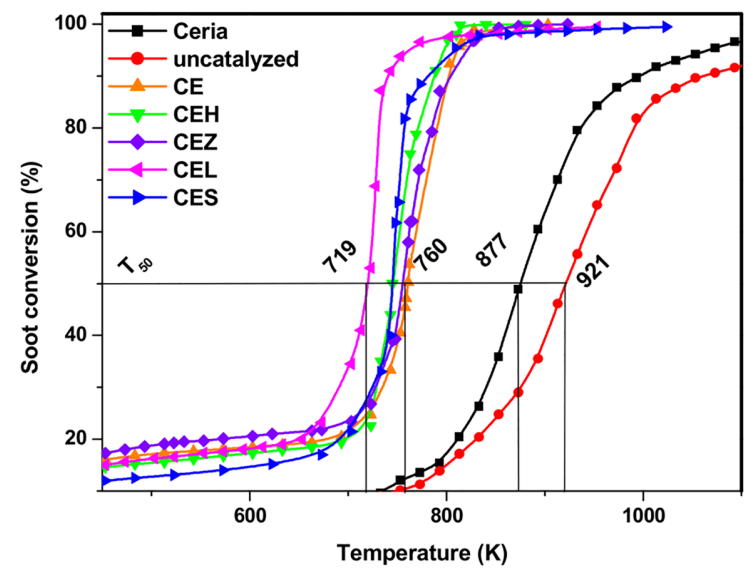

图 6 合成材料及未催化炭烟的转化规律 ${ }^{[86]}$ (网络版彩图) Figure 6 Soot conversion profiles over synthesized materials along with uncatalyzed soot [86] (color online).

颗粒的脱除中起着重要作用. 用少量稀土元素对铈基 氧化物进行改性，可以提高其氧化还原特性，储氧能 力和热稳定性. 但是, 通常柴油机尾气排放口的温度 为 $150 \sim 450^{\circ} \mathrm{C}$ ，大部分稀土金属改性的铈基氧化物催 化剂起燃温度仍然较高，离实际应用还有一定的差距. 因此，如何提升稀土金属改性的铈基氧化物催化剂的 低温活性，降低催化燃烧炭烟颗粒的起燃温度依然是 研究的重点问题.

\subsection{2 过渡金属改性的铈基氧化物催化剂}

过渡金属由于具有未充满的价层 $\mathrm{d}$ 轨道, 基于十八 电子规则, 性质与其它元素有明显差别. 大部分过渡金 属元素的电子构型中都存在不少单电子，较容易失去， 所以这些金属都有多变的价态，表现出良好的氧化还 原能力，可作为催化燃烧炭烟的活性成分．当过渡金 属掺入到氧化铈晶格中，整个体系的电荷发生不平衡. 为了补偿负电荷, $\mathrm{Ce}^{4+}$ 转化为 $\mathrm{Ce}^{3+}$, 并且在晶格中形成 氧空位，这表明过渡金属的加入形成了更多的表面反 应位点和表面活性氧物种 ${ }^{[00-92]}$ ，此外，过渡金属价格 低廉．因此，将过渡金属引入铈基氧化物中已成为一 类备受研究者们关注的炭烟燃烧催化剂.

Co作为一种常见的过渡金属元素，将其引入铈基 氧化物中可以提高氧离子的迁移率，并增强催化体系 中的氧存储与释放, 从而提高 $\mathrm{Co}^{3+}-\mathrm{Co}^{2+}$ 和 $\mathrm{Ce}^{3+}-\mathrm{Ce}^{4+}$ 氧 化还原对的效率 ${ }^{[93]}$. 因此Co改性铈基氧化物在炭烟颗 粒催化燃烧中成为研究的热点. Sudarsanam等 ${ }^{[94]}$ 发现
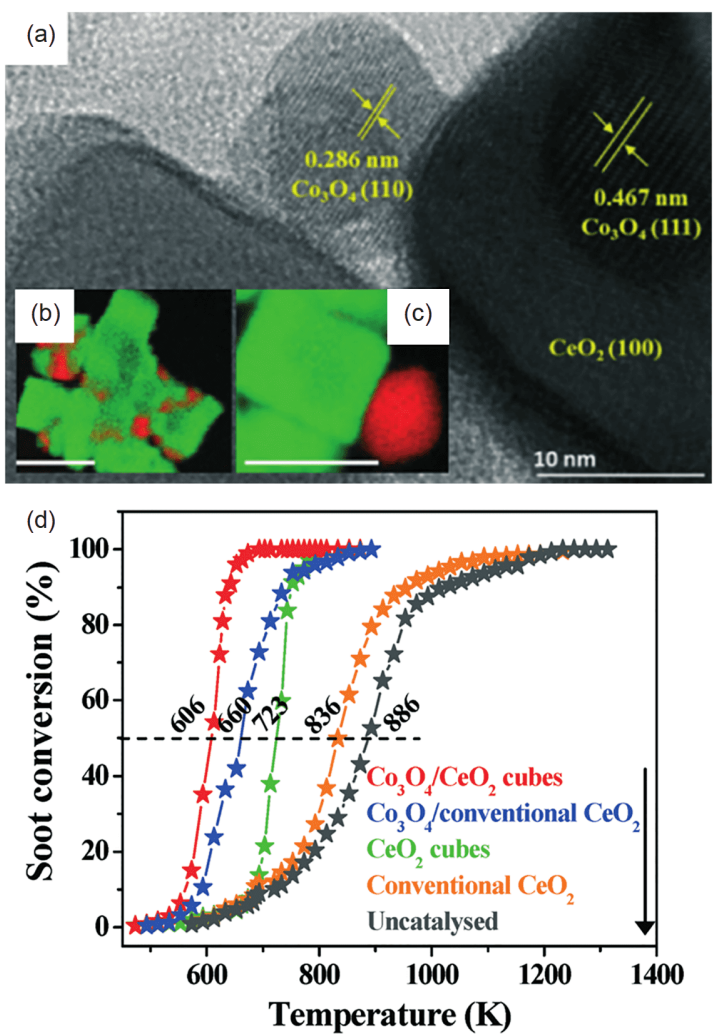

图 7 (a) HRTEM和(b, c) $\mathrm{CoO}_{x} / \mathrm{CeO}_{2}$ 样品的STEM-EELS图 像:绿色 $(\mathrm{Ce})$ 和红色 $(\mathrm{Co})$ (标尺为 $20 \mathrm{~nm}$ ). (d) $\mathrm{CeO}_{2}$ 立方体, $\mathrm{Co}_{3}$ $\mathrm{O}_{4} / \mathrm{CeO}_{2}$ 立方体, $\mathrm{Co}_{3} \mathrm{O}_{4} /$ 常规 $\mathrm{CeO}_{2}$, 常规 $\mathrm{CeO}_{2}$ 和无催化剂的样 品的炭烟转换率 ${ }^{[94]}$ (网络版彩图)

Figure 7 (a) HRTEM and (b, c) STEM-EELS elemental mapping images of the $\mathrm{CoO}_{x} / \mathrm{CeO}_{2}$ sample: green (Ce) and red (Co) (scale bar is $20 \mathrm{~nm}$ ). (d) Soot conversion (\%) versus temperature for $\mathrm{CeO}_{2}$ cubes, $\mathrm{Co}_{3} \mathrm{O}_{4} / \mathrm{CeO}_{2}$ cubes, $\mathrm{Co}_{3} \mathrm{O}_{4} /$ conventional $\mathrm{CeO}_{2}$, conventional $\mathrm{CeO}_{2}$ and uncatalysed samples [94] (color online).

$\mathrm{Co}_{3} \mathrm{O}_{4}$ 促进的 $\mathrm{CeO}_{2}$ 纳米立方体在低温下 $\left(T_{50}=333^{\circ} \mathrm{C}\right)$ 对 柴油机炭烟的燃烧表现出优异的催化活性, 如图7所 示. 他们把这一显著的性能归功于 $\mathrm{CeO}_{2}$ 优越的可还原 性质, $\mathrm{CeO}_{2}$ (100)和 $\mathrm{Co}_{3} \mathrm{O}_{4}$ (110)面的优先暴露以及铈和 钴氧化物的协同作用. Zhai 等 ${ }^{[95]}$ 首次用胶体晶体模板 法制备了 $\mathrm{Co} / \mathrm{Ce}$ 摩尔比可控的 $3 \mathrm{DOM} \mathrm{Co}_{3} \mathrm{O}_{4}-\mathrm{CeO}_{2}$ 催化 剂, 并将其用于 $\mathrm{NO}_{\mathrm{x}}$ 辅助炭烟燃烧. 对催化剂的详细表 征结果表明，炭烟燃烧活性的提高源于其独特的 $3 \mathrm{DOM}$ 骨架所产生的大孔效应、与更多的 $\mathrm{Co}^{3+}$ 反应位 点相关的化学性质、 $\mathrm{Ce}$ 物种的表面富集以及氧化还 原性能的改善所产生的协同促进作用. Xing 等 ${ }^{[96]}$ 采用 水热法和浸渍法在整体泡沫镍上合成了 $\mathrm{Co}_{3} \mathrm{O}_{4} / \mathrm{CeO}_{2}$ 纳 米片 $(\mathrm{Co} / \mathrm{Ce}-\mathrm{NS})$. 所构建的分级介孔-大孔纳米结构, 
增加了炭烟与催化剂的接触效率，促进了催化炭烟燃 烧过程中气态反应物和产物的传质. $\mathrm{Co}_{3} \mathrm{O}_{4}$ 纳米颗粒 沉积在 $\mathrm{CeO}_{2}$ 纳米片上, 增强了催化剂的氧化还原性能, Co-Ce相互作用产生了活跃的表面吸附氧种, 有利于 炭烟燃烧.

与其它过渡金属改性的铈基氧化物催化剂相比, 锰改性的铈基氧化物催化剂具有氧化性能强、氧化态 多等优点, 在催化炭烟颗粒燃烧应用中表现出优异的 催化性能. 目前, 在Mn改性的铈基氧化物催化剂中, $\mathrm{MnO}_{x}-\mathrm{CeO}_{2}$ 混合氧化物 ${ }^{[97 ~ 103]} 、 \mathrm{Mn}_{x} \mathrm{Ce}_{1-x} \mathrm{O}_{2}$ 固溶 体 ${ }^{[104,105]}$ 以及负载型 $\mathrm{MnO}_{x} / \mathrm{CeO}_{2}$ 氧化物 ${ }^{[106,107]}$ 被证明是 有效的 $\mathrm{NO}_{x}$ 辅助氧化炭烟的催化剂. Wang 等 ${ }^{[108]}$ 通过水 热法合成了过渡金属 $(\mathrm{Mn}$ 和 $\mathrm{Fe}$ ) 掺杂的 $\mathrm{Ce}-\mathrm{Sn}$ 纳米棒催 化剂. 清楚地发现, 掺锰的 $\mathrm{Ce}-\mathrm{Sn}$ 催化剂表现出最高的 催化活性, 其 $\Delta T_{10} 、 \Delta T_{50}$ 和 $\Delta T_{90}$ 值分别为 $56^{\circ} \mathrm{C} 、 56.2^{\circ} \mathrm{C}$ 和 $45.4^{\circ} \mathrm{C}$. 同时, 如图 8 所示, $\mathrm{Ce}^{3+}$ 浓度与表面活性氧含 量, 表面活性氧与炭烟燃烧活性, 表面活性氧与 $\mathrm{NO}_{2}$ 利 用效率, $\mathrm{NO}_{2}$ 利用效率与炭烟燃烧活性均呈线性关系. 掺杂 $\mathrm{Mn}$ 有助于更多的 $\mathrm{Ce}^{3+}$ 和表面氧空位的生成以及 增强表面活性氧 $\mathrm{NO}_{2}$ 的利用效率, 从而提高了炭烟的 燃烧活性. 与表面氧空位有关, 表面氧空位有利于加 速表面活性氧的形成. 本课题组Cheng等 ${ }^{[109]}$ 成功合成
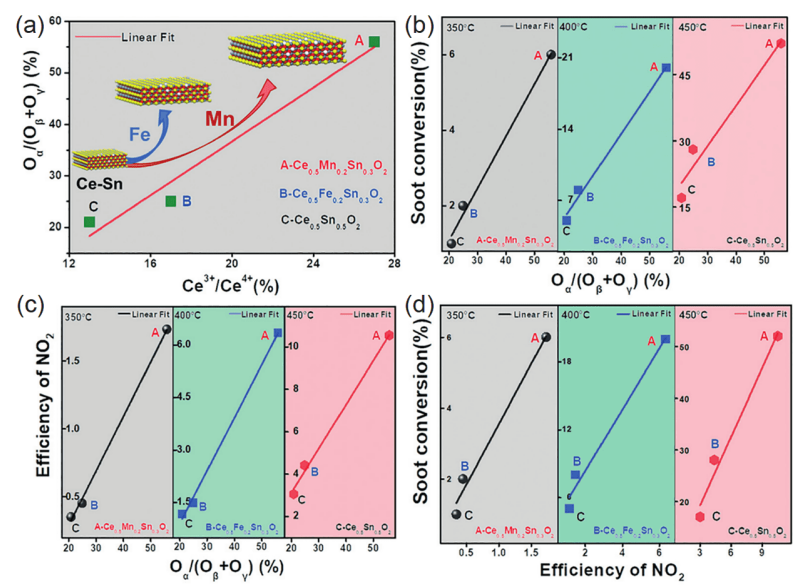

图 8 (a) 表面活性氧与 $\mathrm{Ce}^{3+} / \mathrm{Ce}^{4+}$ 比值的关系, (b) 表面活性 氧与炭烟燃烧活性的关系, (c)表面活性氧与 $\mathrm{NO}_{2}$ 利用效率的 关系, (d) $\mathrm{NO}_{2}$ 利用效率与炭烟燃烧活性的关系 ${ }^{[108]}$ (网络版 彩图)

Figure 8 (a) Relationship between the surface active oxygen and the $\mathrm{Ce}^{3+} / \mathrm{Ce}^{4+}$ ratio, (b) relationship between the surface-active oxygen and soot combustion activity, (c) relationship between the surface-active oxygen and the utilization efficiency of $\mathrm{NO}_{2}$, and (d) relationship between the utilization efficiency of $\mathrm{NO}_{2}$ and soot combustion activity [108] (color online).
了 $3 \mathrm{DOM} \mathrm{Ce}_{0.8} \mathrm{Mn}_{0.1} \mathrm{Zr}_{0.1} \mathrm{O}_{2}$ 催化剂, 在空速为 $25000 / \mathrm{h}$, 催化剂与炭烟松散接触的条件下催化炭烟颗粒燃烧. 三维有序大孔结构有效地增加了催化剂与炭烟颗粒的 接触面积, 较低的 $E_{\mathrm{a}}$ 值 $(86.4 \mathrm{~kJ} / \mathrm{mol})$, 高 $\mathrm{Ce}^{3+} / \mathrm{Ce}^{4+}$ 比率 和化学吸附的氧种类, 加强了催化剂的氧化还原能力, 从而提高催化剂的活性, 该催化剂在 $402^{\circ} \mathrm{C}$ 的 $\mathrm{PM}$ 燃烧 中提供最大的 $\mathrm{CO}_{2}$ 浓度. 除了单独的 $\mathrm{Mn}$ 改性外, $\mathrm{Mn}$ 还 能与其它过渡金属 $(\mathrm{Co} 、 \mathrm{Cu})$ 共同改性铈基氧化物催化 剂. Rao 等 ${ }^{[110]}$ 通过简单的共沉淀法制备了纳米 $\mathrm{Mn}$ 和 $\mathrm{Co}$ 共掺杂 $\mathrm{CeO}_{2}$ 的 $\mathrm{Ce}_{0.8} \mathrm{Mn}_{0.1} \mathrm{Co}_{0.1} \mathrm{O}_{2-\delta}$ 固溶体催化剂, 并对 其对柴油机炭烟燃烧活性进行了研究. 催化活性结果 表明, 在紧密接触条件下, $\mathrm{Ce}_{0.8} \mathrm{Mn}_{0.1} \mathrm{Co}_{0.1} \mathrm{O}_{2-\delta}$ 具有比纯 $\mathrm{CeO}_{2}\left(T_{50}=601^{\circ} \mathrm{C}\right)$ 更好的活性 $\left(T_{50}=363^{\circ} \mathrm{C}\right)$. 更大的表面 积, 容易的氧化还原行为和高浓度的表面吸附氧被认 为是催化活性增强的关键因素. Ali等 ${ }^{[111]}$ 采用简单的 共沉淀法和焙烧法制备了一系列花状 $\mathrm{Cu}_{x} \mathrm{Mn}_{y} \mathrm{Ce}_{z}$ 混合 氧化物催化剂. 这些三元混合氧化物催化剂均具有较 好的炭烟燃烧性能, 特别是 $\mathrm{Cu}_{1} \mathrm{Mn}_{1} \mathrm{Ce}_{1}$ 催化剂在 $\mathrm{NO}$ $+\mathrm{O}_{2}$ 和 $\mathrm{O}_{2}$ 气氛下对炭烟的燃烧活性显著提高. 不同金 属 $(\mathrm{Cu} 、 \mathrm{Mn} 、 \mathrm{Ce})$ 在混合氧化物中的协同作用、电荷 转移和独特的花状形貌, 降低了催化剂的氧化还原电 位, 增加了大量的表面活性氧, 从而促进炭烟燃烧.

在过渡金属改性的铈基氧化物中, 除Co和Mn改性 外, $\mathrm{Cu}$ 改性的铈基氧化物催化剂因其成本相对较低且 具有优异的催化活性常被应用于催化炭烟颗粒燃烧反 应中. Cui等 ${ }^{[112]}$ 采用聚乙烯吡咯烷酮(PVP)辅助共沉淀 法制备了 $\mathrm{CeO}_{2}-\mathrm{NF}$ 和 $\mathrm{Cu}_{x} \mathrm{Ce}_{1-x} \mathrm{O}_{2}-\mathrm{NF}(x=0.1 、 0.2 、 0.3$ 和0.4)纳米片, 并在 $\mathrm{NO}_{x}$ 辅助的紧密接触模式下测试了 炭烟燃烧的活性. 研究表明, $\mathrm{Cu}_{x} \mathrm{Ce}_{1-x} \mathrm{O}_{2}-\mathrm{NF}$ 催化剂表 现出比 $\mathrm{CeO}_{2}-\mathrm{NF}$ 更好的活性, 其中 $\mathrm{Cu}_{0.2} \mathrm{Ce}_{0.8} \mathrm{O}_{2}-\mathrm{NF}$ 具 有更高的催化活性, $\mathrm{Cu}$ 的掺杂加速了活性氧的迁移率 在紧密接触模式下, $T_{50}$ 低至 $312^{\circ} \mathrm{C}$. Sudarsanam等 ${ }^{[113]}$ 研 究了 $\mathrm{CuO}_{x}$ 改性的 $\mathrm{CeO}_{2}$ 纳米立方体的结构-活性特性, 并详细考察了 $\mathrm{CuO}_{x} / \mathrm{CeO}_{2}$ 纳米界面在柴油机炭烟催化 氧化中的作用. 发现在“松散”和“紧密”接触条件下, 与 原始 $\mathrm{CeO}_{2}$ 纳米立方体相比, 用 $\mathrm{CuO}_{x}$ 改性的 $\mathrm{CeO}_{2}$ 纳米立 方体显示出更高的炭烟催化氧化性能. XPS、Raman 和STEM-EELS研究证明, $\mathrm{CuO}_{x} / \mathrm{CeO}_{2}$ 异质结构纳米催 化剂具有较高的催化性能, 其主要原因是 $\mathrm{CuO}_{x}-\mathrm{CeO}_{2}$ 纳米界面存在大量的 $\mathrm{Ce}^{3+}$ 离子和丰富的氧空位. 此外, Sudarsanam等 ${ }^{[114]}$ 还报道了异质结构铜-铈和铁-铈纳 
米棒的氧化还原和酸性质在柴油机炭烟催化燃烧中的 作用. 相比于 $\mathrm{Fe}_{2} \mathrm{O}_{3} / \mathrm{CeO}_{2}$ 纳米棒, $\mathrm{CuO} / \mathrm{CeO}_{2}$ 纳米棒中 存在大量的实质性扰动，从而提高了整体氧化铈的还 原性并形成丰富的Lewis酸中心，在紧密接触 $\left(T_{50}=358^{\circ} \mathrm{C}\right)$ 和松散接触 $\left(T_{50}=419^{\circ} \mathrm{C}\right)$ 均具有良好的炭烟 活性. 催化剂的氧化还原(氧空位)和酸性质在炭烟燃 烧中均起到具有提高活性作用: $\mathrm{CuO} / \mathrm{CeO}_{2}$ 的氧空位有 助于形成活性氧, 而酸位则促进炭烟颗粒转化为活性 氧阳离子自由基, 可被活性氧有效地氧化.

在铈中掺杂过渡金属离子已被证明是改善其热性 能、氧化还原性能和催化氧化性能的有效方法. 在比 较了 $\mathrm{Ce}_{1-x} \mathrm{M}_{x} \mathrm{O}_{2-\delta}(\mathrm{M}=\mathrm{Zr} 、 \mathrm{Ti} 、 \mathrm{Pr} 、 \mathrm{Y}$ 和Fe $)$ 等5种典型 铈基氧化物后, Singh等发现 $\mathrm{Ce}_{1-x} \mathrm{Fe}_{x} \mathrm{O}_{2-\delta}$ 材料具有更高 的储氧能力和更活泼的晶格氧 ${ }^{[115]}$. 同样, Zhai等 ${ }^{[16]}$ 也 研究了不同过渡金属 $(\mathrm{Mn}, \mathrm{Cr}, \mathrm{Fe}, \mathrm{Cu})$ 改性的 $\mathrm{CeO}_{2}$ $\mathrm{ZrO}_{2}$, 发现 $\mathrm{Fe}$ 改性的 $\mathrm{CeO}_{2}-\mathrm{ZrO}_{2}$ 固溶体具有最高的氧 气储存能力, 如图9所示. 结果证明, Fe改性的铈基氧 化物是一种性能优良的炭烟燃烧催化剂. 此外, Aneggi 等 ${ }^{[117]}$ 比较了 $\mathrm{CeO}_{2}-\mathrm{ZrO}_{2}$ 和 $\mathrm{CeO}_{2}-\mathrm{Fe}_{2} \mathrm{O}_{3}$ 两类复合氧化 物的催化炭烟燃烧活性. 结果发现, $\mathrm{CeO}_{2}-\mathrm{Fe}_{2} \mathrm{O}_{3}$ 催化剂 显示出了明显高于 $\mathrm{CeO}_{2}-\mathrm{ZrO}_{2}$ 催化剂的催化活性. $\mathrm{CeO}_{2}-\mathrm{Fe}_{2} \mathrm{O}_{3}$ 催化剂的高活性可归因于两方面: (1) $\mathrm{Ce}-\mathrm{Fe}$ 固溶体的形成提高了材料的氧迁移能力; (2) $\mathrm{Ce}-\mathrm{Fe}$ 复 合材料表面的无定型 $\mathrm{Fe}_{2} \mathrm{O}_{3}$ 以及其与 $\mathrm{Ce}-\mathrm{Fe}$ 固溶体紧密 接触而产生的界面层可作为活性位，提高了材料对 $\mathrm{O}_{2}$ 和PM的吸附能力.

除上述 $\mathrm{Co} 、 \mathrm{Mn} 、 \mathrm{Cu}$ 和Fe过渡金属改性的铈基氧 化物外，还存在其它过渡金属(如Zr、V、Cr、Ni等)改 性的铈基氧化物，这些氧化物也常被应用于催化炭烟 颗粒燃烧反应中. Neelapala等 ${ }^{[18]}$ 以葡萄糖和果糖为有 机添加剂，通过溶胶-凝胶合成法制备了 $\mathrm{Cr}$ 掺杂的
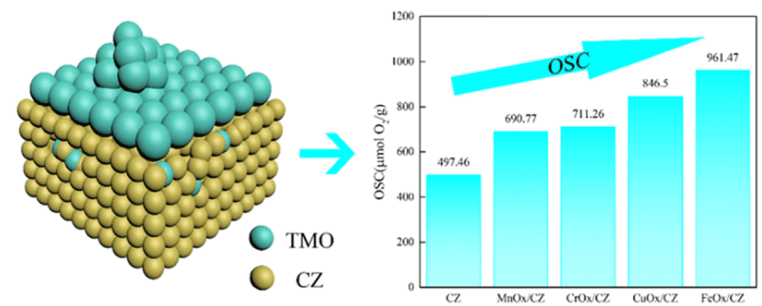

图 9 不同过渡金属氧化物的 $\mathrm{CeO}_{2}-\mathrm{ZrO}_{2}$ 固溶体的氧气储存 能力 ${ }^{[116]}$ (网络版彩图)

Figure 9 The oxygen storage capacity of $\mathrm{CeO}_{2}-\mathrm{ZrO}_{2}$ solid solution loaded with different transition metal oxid [116] (color online).
$\mathrm{CeO}_{2}$ 催化剂 $\left(\mathrm{Ce}_{1-x} \mathrm{Cr}_{x} \mathrm{O}_{2-\delta}, x=0.05\right.$ 至0.25). 与未催化的 炭烟 $\left(600^{\circ} \mathrm{C}\right)$ 相比, $\mathrm{Cr}$ 掺杂的催化剂可以将炭烟燃烧温 度 $\left(T_{50}\right)$ 大幅降低至 $450^{\circ} \mathrm{C}$ (平均值), 可用于制作能耗较 低的高效DPF再生系统. Cousin等 ${ }^{[19]}$ 研究了一系列V$\mathrm{Ce}$ 催化剂炭烟催化性能, 发现 $\mathrm{V}$ 改性可以以降低催化 活性为代价来明显提高催化剂的热稳定性. SellersAnton等 ${ }^{[120]}$ 研究了 $\mathrm{Ni}$ 掺杂 $3 \mathrm{DOM} \mathrm{CeO}_{2}$ 对炭烟燃烧的 物理化学性质和催化活性的影响. 结果证明, $\mathrm{Ni}$ 参与 了 $\mathrm{NO}$ 向 $\mathrm{NO}_{2}$ 的催化氧化, 有利于催化剂活性氧的产生 和储氧能力的提高, 从而增强 $3 \mathrm{DOM} \mathrm{CeO}_{2}$ 的催化活性. 同时, $\mathrm{Ni}$ 的掺入方式对其理化和催化性能显著影响, 通 过在固体模板中连续渗透引入 $\mathrm{Ni}$, 能够减小 $\mathrm{CeO}_{2}$ 的晶 粒尺寸, 改善Ni的分散性和提高催化剂的还原性. 锆离 子 $\left(\mathrm{Zr}^{4+}\right)$ 掺入 $\mathrm{CeO}_{2}$ 晶格中, 可以显著提高其氧化还原性 能和储放氧能力. 同时, 经过 $\mathrm{Zr}$ 的改性铈基氧化物催化 剂的氧化还原稳定性以及长期热形态得以增强，因此 被广泛应用于炭烟燃烧反应中. Yang 等 ${ }^{[121]}$ 利用溶剂 热法合成了具有立方-四方界面的 $\mathrm{CeO}_{2}-\mathrm{ZrO}_{2}(\mathrm{C}-\mathrm{T})$ 固 溶体催化剂. 与商用 $\mathrm{CeZrLaPrO}_{x}$ 和 $\mathrm{CeO}_{2}-\mathrm{ZrO}_{2}$ 催化剂 相比, $\mathrm{CeO}_{2}-\mathrm{ZrO}_{2}(\mathrm{C}-\mathrm{T})$ 具有更好的炭烟燃烧活性, 催 化剂中的立方-四方界面能够促进结构缺陷的产生(氧 空位)和 $\mathrm{CeO}_{2}$ 中表面晶格氧的释放. Zhou等 ${ }^{[122]}$ 人比较 了 $\mathrm{Al}_{2} \mathrm{O}_{3}, \mathrm{TiO}_{2}$ 和 $\mathrm{ZrO}_{2}$ 改性 $\mathrm{MnO}_{x}-\mathrm{CeO}_{2}$ 之间的热稳定 性. 结果发现, 催化剂经过热老化后, $\mathrm{ZrO}_{2}$ 改性催化剂 的失活显著减轻. $\mathrm{ZrO}_{2}$ 改性成功地保持了 $\mathrm{MnO}_{x}-\mathrm{CeO}_{2}$ 的表面积. 此外, 它还防止了 $\mathrm{MnO}_{x}-\mathrm{CeO}_{2}$ 的相分离, 保 留了超氧化物和过氧化物的生成.

上述大量有关过渡金属改性的铈基氧化物催化剂 的研究表明，Co、 $\mathrm{Mn} 、 \mathrm{Cu}$ 和Fe改性的铈基氧化物表 现出较好的炭烟颗粒燃烧活性. 一般来说，过渡金属 通过掺杂或负载的方式与铈基氧化物产生协同作用. 一方面铈基氧化物可以稳定过渡金属，使其高度分散 在其表面上，另一方面过渡金属氧化物具有调控铈基 氧化物储放氧能力, 进一步提高催化活性. 然而, 由于 炭烟燃烧过程为放热反应，高活性的铈基催化剂的稳 定性以及抗水耐硫性都对其实际应用有一定的制约. 因此，如何提高过渡金属改性的铈基氧化物催化剂的 稳定性和抗水耐硫性是当前研究的重点.

\subsection{3 贵金属改性的铈基氧化物催化剂}

贵金属催化剂，如Pt、Ag、 $\mathrm{Au} 、 \mathrm{Pd} 、 \mathrm{Ru} 、 \mathrm{Rh}$ 等， 
物理和化学性质稳定、能够高效转化气态氧变成具有 高活性的活性氧物种，从而有效氧化柴油机尾气炭烟 颗粒. 因此，贵金属催化剂对柴油机排气炭烟的催化 燃烧具有明显的促进作用. 此外，贵金属催化剂之间 存在协同作用，组合使用可以使催化反应的活性大大 增加，同时贵金属还可以和一般金属形成不同含量比 例和不同颗粒尺寸的催化剂，提高炭烟燃烧反应的选 择性和催化剂的寿命. 将贵金属与铈基氧化物结合, 不仅能够实现贵金属的高分散以提高其利用效率，而 且贵金属粒子和载体之间的相互作用会改变其表面的 性质(几何结构和表面电子), 加速反应呈现高的催化 活性, 有助于二者共同发挥炭烟催化性能.

在众多贵金属催化剂中，Pt基催化剂由于其较高 的催化活性(尤其是在 $\mathrm{NO}_{x}$ 存在的情况下更为显著)和 耐久性而有望成为商业化应用炭烟颗粒催化燃烧的催 化剂. 铈基氧化物经过Pt改性能够较大程度提高它的 催化活性以热稳定性，因此Pt改性的铈基氧化物催化 剂成为目前研究热点. Andana等 ${ }^{[123]}$ 采用溶液燃烧法 制备了纳米立方体 $\mathrm{CeO}_{2}-\mathrm{NC}$ 并通过湿法浸渍将质量 分数为 $1 \%$ 的 $\mathrm{P}$ 纳米颗粒担载到 $\mathrm{CeO}_{2}-\mathrm{NC}$ 载体上合成 $\mathrm{Pt} / \mathrm{CeO}_{2}-\mathrm{NC}$ 催化剂. 研究表明活性金属Pt纳米颗粒和 反应性 $\mathrm{CeO}_{2}-\mathrm{NC}$ 载体的协同作用会增加比表面积, 改 善的电子性能，提高低温下的氧化还原性能，最终显 著提高催化剂催化燃烧炭烟的活性. Azambre等 ${ }^{[124]}$ 研 究了不同氧化气氛 $\left(20 \% \mathrm{O}_{2}\right.$ 或 $\left.10 \% \mathrm{O}_{2}+700 \mathrm{ppm} \mathrm{NO}_{2}\right)$ 下 $\mathrm{Pt} / \mathrm{Ce}_{0.68} \mathrm{Zr}_{0.32} \mathrm{O}_{2}$ 催化剂对柴油机炭烟颗粒氧化的影 响. 结果表明: 无论使用何种气氛, 该催化剂均能显着 降低炭烟的着火温度, 当 $\mathrm{NO}_{x}$ 辅助氧化过程时催化作 用更加明显. 这主要归因于两种催化剂组分(贵金属和 铈锆氧化物材料) 在循环炭烟被 $\mathrm{NO}_{2}$ 侵蚀后释放的 $\mathrm{NO}$ 循环方面的效率本课题组 $\mathrm{Yu}^{[125]}$ 等利用胶体晶体模板 法成功合成了 $3 \mathrm{DOM}$ 铈锰复合氧化物，考察了不同铈 锰摩尔比对催化剂结构和性能的影响. 其中 $\mathrm{Mn}_{0.5} \mathrm{Ce}_{0.5}$ $\mathrm{O}_{2-\delta}$ 催化活性最高, $T_{50}$ 为 $358^{\circ} \mathrm{C}$. 为了进一步提高三维 有序大孔铈锰复合氧化物对炭烟颗粒催化燃烧的能 力, 将Pt金属负载到三维有序大孔铈锰催化剂上, 合成 了 3 wt.\% Pt $/ \mathrm{Mn}_{0.5} \mathrm{Ce}_{0.5} \mathrm{O}_{2-\delta}$ 催化剂. 高度分散的铂纳米 颗粒提高了催化剂将 $\mathrm{NO}$ 氧化成 $\mathrm{NO}_{2}$ 的能力, 大孔结构 为固体反应物(炭烟)提供了理想的反应场所, 增加了 催化剂的可用活性位点的数量. 两者结合, 从而提高 了催化剂催化炭烟的能力 $\left(T_{50}\right.$ 降低到 $342^{\circ} \mathrm{C}, S_{\mathrm{CO}_{2}}^{\mathrm{m}}$ 提高
到 $96.7 \%$ ). $\mathrm{Li}^{\text {等 }}{ }^{[126]}$ 利用胶体晶体模板法和沉淀法合 成了一系列的3DOM $\mathrm{Pt}_{1.0} @ \mathrm{CeO}_{2-x} / \mathrm{ZrO}_{2}-x(x=\mathrm{Pt} / \mathrm{Ce}$ 摩 尔比)催化剂, 并应用于炭烟的催化燃烧反应. 研究表 明强Pt- $\mathrm{CeO}_{2-x}$ 相互作用的 $\mathrm{Pt} @ \mathrm{CeO}_{2-x}$ 核-壳纳米粒子 可导更多的活性氧物种的产生. 具有最高浓度的活性 $\mathrm{O}^{2-}$ 物种 $(15.7 \%)$ 和最大数量的活性氧化还原位点 $\left(8.63 \times 10^{-5} \mathrm{~mol} / \mathrm{g}\right)$ 的 $3 \mathrm{DOM} \mathrm{Pt}_{1.0} @ \mathrm{CeO}_{2-x} / \mathrm{ZrO}_{2}-1$ 催化剂 显示出最高的炭烟燃烧催化活性， $T_{10} 、 T_{50}$ 和 $T_{90}$ 分别 为 $275 、 328$ 和 $365^{\circ} \mathrm{C}$.

与Pt改性的铈基氧化物催化剂类似，Au改性的铈 基氧化物催化剂也被认为是良好的炭烟燃烧催化剂. Jin等 ${ }^{[127]}$ 使用还原沉积法制备 $\mathrm{Au} / \mathrm{CeO}_{2} / 3 \mathrm{DOM} \mathrm{Al} \mathrm{O}_{3}$ 催 化剂, 并将上述催化剂用于炭烟催化燃烧的活性评价. 研究发现 $\mathrm{CeO}_{2} / 3 \mathrm{DOM} \mathrm{Al}_{2} \mathrm{O}_{3}$ 载体中的 $\mathrm{Al}-\mathrm{Ce}-\mathrm{O}$ 固溶体 能够形成大量氧空位, 改善了氧的输送性能. $\mathrm{Au}$ 与 $\mathrm{CeO}_{2}$ 之间强烈的金属-载体相互作用增加了 $\mathrm{Au}$ 纳米粒 子表面的活性氧含量, 从而促进了炭烟的燃烧. Wei 等 ${ }^{[128]}$ 采用鼓泡辅助膜还原 $(\mathrm{GBMR})$ 法将 $\mathrm{Au}$ 纳米颗粒 负载到主要暴露面分别为(110)、(100)和(111)的棒, 立 方体和多面体 $\mathrm{CeO}_{2}$ 上, 用于炭烟的催化燃烧. 研究结 果表明 $\mathrm{Au}$ 和 $\mathrm{CeO}_{2}$ 的最佳活性晶面之间的强相互作用 对于调节活化 $\mathrm{O}_{2}$ 的活性位点密度至关重要. 如图 10 所 示, 与其它晶体面相比, $\mathrm{Au}$ 和 $\mathrm{CeO}_{2}(110)$ 晶面的协同作 用具有最大的活性位点密度. 因此, 在炭烟燃烧过程 中, 棒状 $\mathrm{Au} / \mathrm{CeO}_{2}$ 催化剂的催化活性最高 $\left(T_{50}=350^{\circ} \mathrm{C}\right.$, $\mathrm{TOF}=0.18 / \mathrm{h})$, 表观活化能最低 $(72 \mathrm{~kJ} / \mathrm{mol})$. 此外, Wei 等 ${ }^{[129 ~ 131]}$ 还成功合成了一系列三维有序大孔(3DOM) $\mathrm{Au} / \mathrm{Ce}_{1-x} \mathrm{Zr}_{x} \mathrm{O}_{2} 、 \mathrm{Au} @ \mathrm{CeO}_{2} / \mathrm{ZrO}_{2}$ 和 $\mathrm{Au}_{n} \mathrm{Pt}_{m} / \mathrm{Ce}_{1-x} \mathrm{Zr}_{x} \mathrm{O}_{2}$ 催

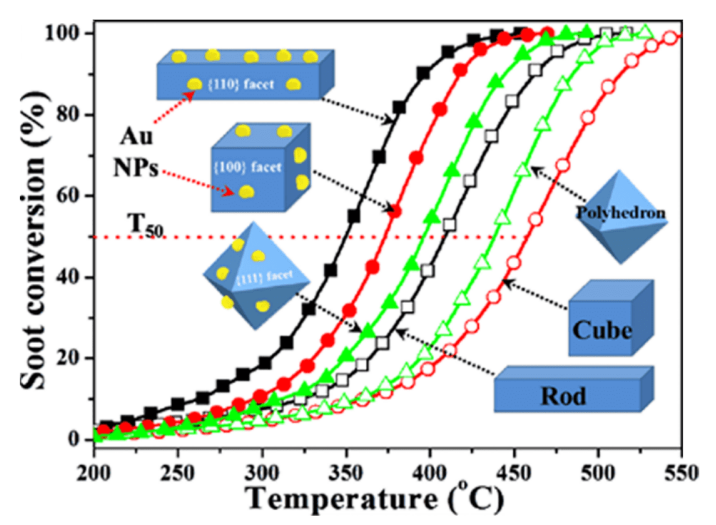

图 10 炭烟转化率与反应温度的关系 ${ }^{[128]}$ (网络版彩图) Figure 10 Profiles of the soot conversion rate vs. the reaction temperature [128] (color online). 
化剂，发现这些催化剂在松散接触方式下具有较低下 炭烟起燃温度.

银是一种较便宜的贵金属，在低温下表现出优异 的氧解离吸附能力. 此外, 金属银还表现出显著的迁 移率, 这与碱金属(如钾)一样, 有利于炭烟和催化剂在 较低温度下的接触. 因此, $\mathrm{Ag}$ 改性的铈基氧化物催化 剂在实际应用中具有降低成本和保持高活性的优势. Wang 等 ${ }^{[132]}$ 将质量分数为 $1 \%$ 的 $\mathrm{Ag}$ 分别负载到 $\mathrm{CeO}_{2}$ 纳 米立方体 $(\mathrm{C})$ 、纳米棒 $(\mathrm{R})$ 和纳米八面体 $(\mathrm{O})$ 中, 研究了 $\mathrm{Ag} / \mathrm{CeO}_{2}$ 的形貌对炭烟燃烧的影响. 实验发现经过 $\mathrm{Ag}$ 改性后的 $\mathrm{CeO}_{2}$ 催化剂，其催化活性和抗水性得到大幅 度提升．其中暴露大量(100)晶面的 $\mathrm{Ag} / \mathrm{CeO}_{2}-\mathrm{C}$ 催化剂 的催化活性明显优于暴露(110)、(100)晶面的 $\mathrm{Ag} /$ $\mathrm{CeO}_{2}-\mathrm{R}$ 催化剂和暴露(111)晶面的 $\mathrm{Ag} / \mathrm{CeO}_{2}-\mathrm{O}$ 催化剂. Lee等 ${ }^{[133]}$ 采用静电纺丝法制备了直径241 253 nm 的 $\mathrm{CeO}_{2}$ 纳米纤维. 然后将其用作 $\mathrm{Ag}$ 纳米颗粒的新型载体 材料, 并评价了它们作为柴油机炭烟燃烧催化剂的性 能. 实验结果表明纤维状 $\mathrm{Ag} / \mathrm{CeO}_{2}$ 是很有前途的炭烟 燃烧催化剂, $\mathrm{CeO}_{2}$ 的大表面积和高含量的 $\mathrm{Ag}$ 金属物种 可以促进炭烟燃烧活性. 此外, Lee等 ${ }^{[134]}$ 还将 $\mathrm{Ag}$ 纳米 颗粒担载到静电纺丝法制备的具有分级结构的纳米纤 维网状 $\mathrm{Ce}-\mathrm{ZrO}_{2}$ 固溶体表面如图11所示，并用于炭烟 的催化氧化. 发现 $\mathrm{Ag} / \mathrm{Ce}_{0.67} \mathrm{Zr}_{0.33} \mathrm{O}_{2}$ 催化剂分别比 $\mathrm{Ag} /$ $\mathrm{Ce}_{0.5} \mathrm{Zr}_{0.5} \mathrm{O}_{2}$ 和 $\mathrm{Ag} / \mathrm{Ce}_{0.33} \mathrm{Zr}_{0.67} \mathrm{O}_{2}$ 催化剂更具炭烟燃烧活
性. Zou等 ${ }^{[135]}$ 通过柠檬酸络合成功制备了用作炭烟催 化材料的高性能复合氧化物 $x \mathrm{Ag} / \mathrm{Co}_{0.93} \mathrm{Ce}_{0.07} \quad(x=\mathrm{Ag} /$ $(\mathrm{Co}+\mathrm{Ce})$ 摩尔比), 研究了 $\mathrm{Ag}$ 在炭烟燃烧过程中产生的 物质对炭烟燃烧性能的影响. 研究表明催化剂在 $\mathrm{O}_{2}$ 气 氛下生成的表面银氧化物通过参与炭烟和氧化银之间 的氧化还原循环而促进炭烟燃烧, 而在富含 $\mathrm{NO}_{x}$ 的大 气中形成的 $\mathrm{AgNO}_{3}$ 则有助于在较低温度下起燃炭烟.

除Pt、Au、Ag改性外，Pd、Ru、Rh等贵金属改 性的铈基氧化物也可以产生具有较好的炭烟燃烧活性 的催化剂. Homsi等 ${ }^{[136]}$ 报道了向不同的 $\mathrm{Ce}_{x} \mathrm{Zr}_{1-x} \mathrm{O}_{2}$ $(0 \leq x \leq 1)$ 载体中添加 $\mathrm{Rh}$ 对炭烟颗粒氧化的影响. 催化 剂在 $600{ }^{\circ} \mathrm{C}$ 煅烧后会形成不同反应性的氧化钉物质. 催化活性随载体中铈含量的增加而增加, $\mathrm{Ru} / \mathrm{CeO}_{2}$ 是性能最好的催化剂. Xiong 等 ${ }^{[137]}$ 通过鼓泡辅助膜 还原沉淀法 $(\mathrm{GBMR} / \mathrm{P})$ 精心合成了三维有序介大孔 $\mathrm{Ce}_{0.3} \mathrm{Zr}_{0.7} \mathrm{O}_{2}$ 负载的 $\mathrm{PdAu} @ \mathrm{CeO}_{2}$ 核壳纳米粒子的高效 $\mathrm{PdAu} @ \mathrm{CeO}_{2} / 3 \mathrm{DOMM}-\mathrm{Ce}_{0.3} \mathrm{Zr}_{0.7} \mathrm{O}_{2}$ 催化剂, 如图12所 示. 研究表明 $\mathrm{Pd}-\mathrm{Au}-\mathrm{CeO}_{2}$ 三元组分的协同作用可以提 高活性氧的密度, 进而提高催化炭烟燃烧, 其TOF值在 $290^{\circ} \mathrm{C}$ 时为 $2.51 / \mathrm{h}$ 是 $3 \mathrm{DOMM}-\mathrm{Ce}_{0.3} \mathrm{Zr}_{0.7} \mathrm{O}_{2}$ 氧化物的 5 倍 以上, $T_{10}, T_{50}, T_{90}$ 分别为 $276^{\circ} \mathrm{C} 、 363^{\circ} \mathrm{C} 、 404^{\circ} \mathrm{C}$. Lee 等 ${ }^{[138]}$ 研究了不同贵金属改性 $(\mathrm{M}=\mathrm{Ag}, \mathrm{Au}, \mathrm{Pd}, \mathrm{Pt}$ 和Rh) $\mathrm{CeO}_{2}$ 催化剂对炭烟燃烧活性的影响, 结果发现 $\mathrm{M} / \mathrm{CeO}_{2}$ 催化剂的炭烟燃烧活性优于 $\mathrm{CeO}_{2}$, 且活性顺序依次为 (a)
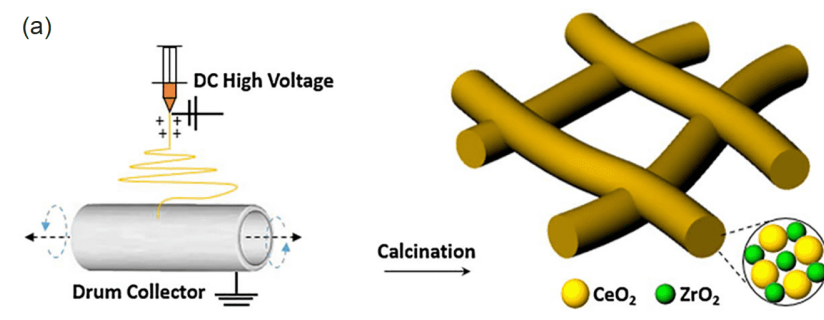

Electrospinning process

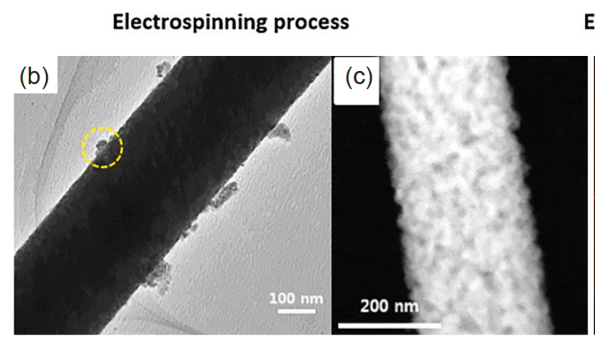

Electrospun $\mathrm{Ce}-\mathrm{ZrO}_{2}$ web
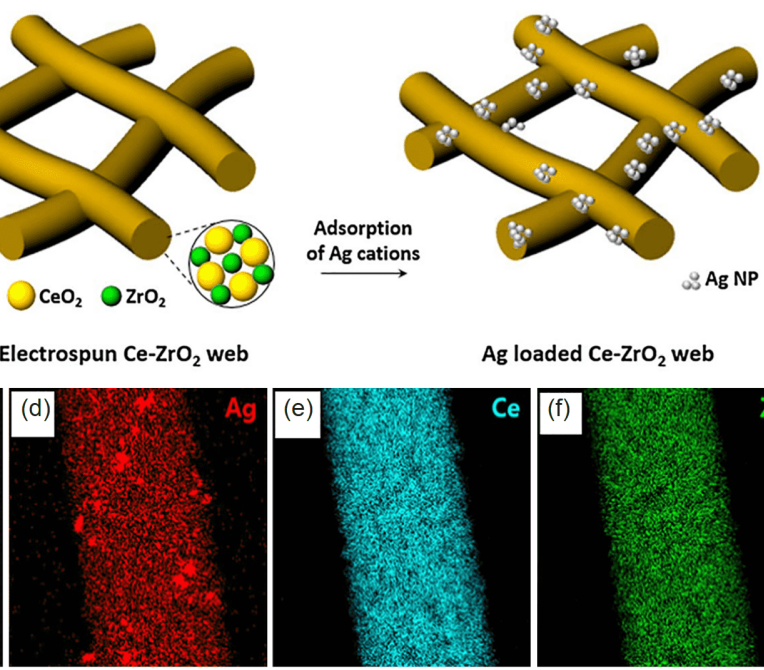

Ag loaded $\mathrm{Ce}-\mathrm{ZrO}_{2}$ web

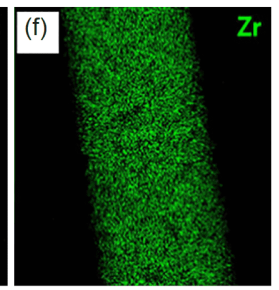

图 11 (a) 通过典型的静电纺丝和沉积工艺制备 $\mathrm{Ag} / \mathrm{Ce}-\mathrm{Zr}$ 纤维网的流程. 负载4.5 wt.\% $\mathrm{Ag}$ 后, $\mathrm{Ag} / \mathrm{Ce}_{0.67} \mathrm{Zr}_{0.33}$ 网的(b) $\mathrm{HR}-\mathrm{TEM}$ 和(c f) EDS图像 ${ }^{[134]}$ (网络版彩图)

Figure 11 (a) Overall procedure to prepare $\mathrm{Ag} / \mathrm{Ce}-\mathrm{Zr}$ fibrous webs via typical electrospinning and deposition processes. (b) HR-TEM and (c-f) EDS mapping images of $\mathrm{Ag} / \mathrm{Ce}_{0.67} \mathrm{Zr}_{0.33}$ webs after 4.5 wt.\% $\mathrm{Ag}$ loading [134] (color online). 


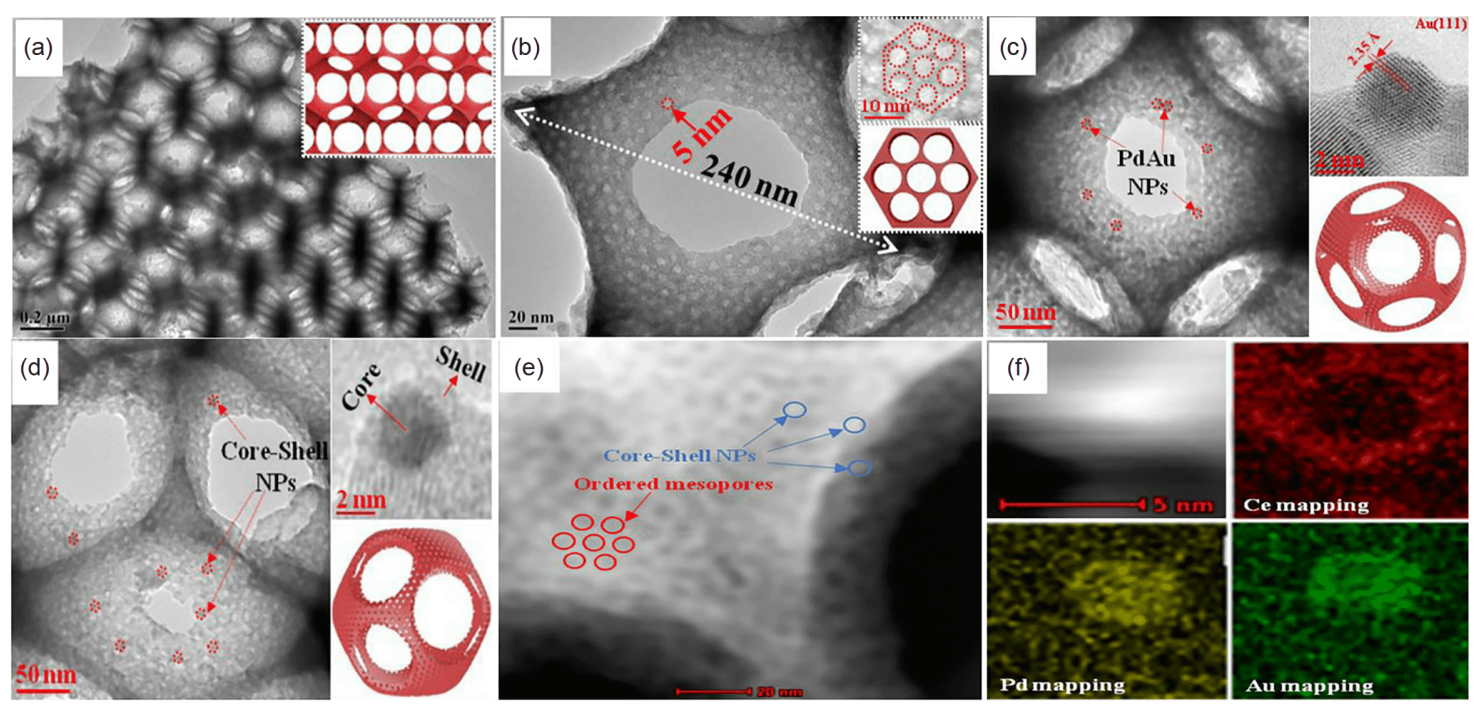

图 12 DOMM-CZ (a, b), PdAu/3DOMM-CZ (c)和PdAu@CeO $/ 3 D O M M-C Z$ (d f)催化剂的TEM, HRTEM和HAADF-STEM 图像. (f)图像显示了 $\mathrm{PdAu} @ \mathrm{CeO}_{2}$ 核-壳及其HAADF-STEM-EDX元素分析, $\mathrm{Ce}$ (红色), $\mathrm{Pd}$ (黄色)和 $\mathrm{Au}$ (绿色) ${ }^{[137]}$ (网络版彩图) Figure 12 TEM, HRTEM and HAADF-STEM images of 3DOMM-CZ (a-b), PdAu/3DOMM-CZ (c) and PdAu@CeO $2 / 3$ DOMM-CZ (d-f) catalysts. The (f) image shows a HR-STEM image of one PdAu@CeO 2 core-shell NP and its HAADF-STEM-EDX element-mapping analysis of Ce (red), Pd (yellow) and $\mathrm{Au}$ (green) [137] (color online).

$\mathrm{Rh} / \mathrm{CeO}_{2}>\mathrm{Ag} / \mathrm{CeO}_{2}>\mathrm{Pt} / \mathrm{CeO}_{2}>\mathrm{Au} / \mathrm{CeO}_{2}>\mathrm{Pd} / \mathrm{CeO}_{2}>\mathrm{CeO}_{2}$. $\mathrm{Rh} / \mathrm{CeO}_{2}$ 催化剂优异的炭烟燃烧性能可归因于其具有 较多的氧空位, 较强的氧吸附和电子转移能力.

贵金属改性的铈基氧化物催化剂具有催化活性 高、抗氧化强、选择性好等优点，贵金属改性的铈基 氧化物催化剂在柴油机炭烟颗粒燃烧中扮演着重要的 角色. 但贵金属易受柴油机尾气中的硫 $(\mathrm{S}) 、$ 铅 $(\mathrm{Pb})$ 、 磷 $(\mathrm{P})$ 等元素的影响而中毒失活，同时贵金属的引入也 使其催化剂的成本增加. 因此如何提高贵金属改性铈 基氧化物催化剂的抗中毒能力，最大程度地提高贵金 属利用效率，尽可能节约成本，是贵金属改性的铈基 氧化物催化剂的研究热点.

\subsection{4 碱(碱土)金属改性的铈基氧化物催化剂}

催化剂的熔点与其对炭烟催化燃烧的性能之间存 在良好的对应关联. 催化剂的熔点低, 表面原子的移动 性强; 催化剂与炭烟接触的能力就强, 从而降低炭烟燃 烧的温度. 碱(碱土)金属元素具有低的溶点、沸点, 强 的还原性强等特点, 这使其具有良好的催化炭烟燃烧 性能. 将碱(碱土)金属引入铈基氧化物中, 一方面保持 了铈基氧化物的还原性能，提高催化剂/炭烟与碱金属 接触; 另一方面碱(碱土)金属对 $\mathrm{NO}_{x}$ 具有良好储存能
力, 有利于氮氧化物充分利用以提高炭烟的燃烧能力.

由于碱金属具有较好的流动性, 引入碱金属可以 增加催化剂与炭烟的有效接触面积, 因而有利于炭烟 的催化燃烧. 在各种碱金属中 $\mathrm{K}$ 和 $\mathrm{Cs}$ 被认为是改性铈 基氧化物炭烟燃烧催化剂最有效的碱金属添加剂. 在 早期研究，根据碱金属离子的电负性，炭烟燃烧活性

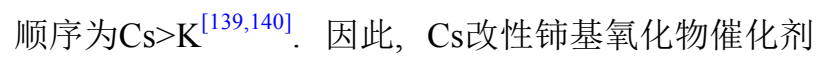
引起研究者的青睐. $\mathrm{Li}^{\text {等 }}{ }^{[141]}$ 研究发现 $\mathrm{Cs}-$ 负载型氧化 物 $\left(\mathrm{Cs} / \mathrm{MgO} 、 \mathrm{Cs} / \mathrm{CeO}_{2}\right.$ 和 $\left.\mathrm{Cs} / \mathrm{ZrO}_{2}\right)$ 的催化炭烟燃烧活性 均优于 $\mathrm{K}$-负载型氧化物, 炭烟在 $\mathrm{Cs}$ 表面的化学吸附比 在 $\mathrm{K}$ 表面通过炭烟边缘的含氧基团的化学吸附更容易 激活, 导致更多的电子由Cs向炭烟供能. Sui等 ${ }^{[142]}$ 采用 溶胶凝胶法制备了不同 $\mathrm{Cs}$ 掺杂量的Cs-Ce-Zr催化剂, 并对其组成以及接触条件对炭烟催化活性的影响进行 了研究. 实验证明: 紧密接触条件下该催化剂的催化活 性优于松散接触条件下的催化活性. 催化活性主要取 决于 $\mathrm{Cs}$ 的相对含量, 在紧密接触条件下, 具有 $51.80 \%$ Cs含量的催化剂的炭烟的 $T_{\mathrm{i}}$ 为 $294^{\circ} \mathrm{C}$, 与松散接触条件 相比, 降低了约 $50^{\circ} \mathrm{C}$. Wang 等 ${ }^{[143]}$ 将 $\mathrm{Cs}$ 掺杂到 $3 \% \mathrm{Co} /$ $\mathrm{Ce}_{0.5} \mathrm{Sn}_{0.5} \mathrm{O}_{2}$ 中开发了具有优异性能的 $10 \% \mathrm{Cs} / 3 \% \mathrm{Co} /$ $\mathrm{Ce}_{0.5} \mathrm{Sn}_{0.5} \mathrm{O}_{2}$ 炭烟催化燃烧催化剂. 研究表明, 在 $\mathrm{H}_{2} \mathrm{O} /$ $\mathrm{O}_{2} / \mathrm{N}_{2}$ 气氛和疏松接触条件下, 掺杂 $\mathrm{Cs}$ 使催化剂的 $\mathrm{T}_{50}$ 
降低了 $163^{\circ} \mathrm{C} . \mathrm{Cs}$ 的加入, 表面活性氧的解吸量增加了 10 倍以上，同时催化剂与炭烟颗粒的接触度(DC)显著 提高(图13a, b). 此外Cs的引入还导致了更多的氧缺陷 的形成(图13c，d), 有利于表面化学反应氧的活化, 进 而提高催化剂的催化性能.

虽然 $\mathrm{Cs}$ 在改性铈基氧化物催化剂中表现出异常 优异的性能, 但是在实际的应用中, 铯元素的价格要远 远高于钾元素, 所以综合考虑, 钾元素要比铯元素更具 有应用前景. Salinas 等 ${ }^{\left[{ }^{[44}\right]}$ 报道了一系列担载 $\mathrm{K}$ 的 $\mathrm{K} /$ $\mathrm{CeO}_{2}-\mathrm{Al}_{2} \mathrm{O}_{3}$ 催化剂在炭烟燃烧中的催化活性. 证实了 在炭烟燃烧中使用 $\mathrm{K}$ 活性相作为催化剂的重要性. 不 同的钾前驱体的应用对 $\mathrm{K} / \mathrm{CeO}_{2}$ 的催化活性有显著影 响. Neyertz等 ${ }^{[145]}$ 研究了堇青石负载的 $\mathrm{K} / \mathrm{CeO}_{2}$ 催化剂 进行柴油机炭烟燃烧反应。结果表明催化剂活性取决 于所用的钾前体，以 $\mathrm{KNO}_{3}>\mathrm{K}_{2} \mathrm{CO}_{3}>\mathrm{KOH}$ 的顺序降低. 钾的不同前体引起的结构效应决定了材料的活性。 Shan等 ${ }^{[146]}$ 评价了负载 $\mathrm{KNO}_{3} / \mathrm{K}_{2} \mathrm{CO}_{3}$ 的 $\mathrm{CeO}_{2}$ 催化剂对 炭烟燃烧的催化活性和稳定性. 当 $\mathrm{K}$ 以 $\mathrm{K}_{2} \mathrm{CO}_{3}$ 形式存在 时(由于 $\mathrm{K}_{2} \mathrm{CO}_{3}$ 的具有较高熔点、碱度以及在炭烟燃 烧过程中生成的 $\mathrm{CeO}_{2}$ 不可逆地吸附)催化剂的活性和 稳定性低于 $\mathrm{KNO}_{3} / \mathrm{CeO}_{2}$.
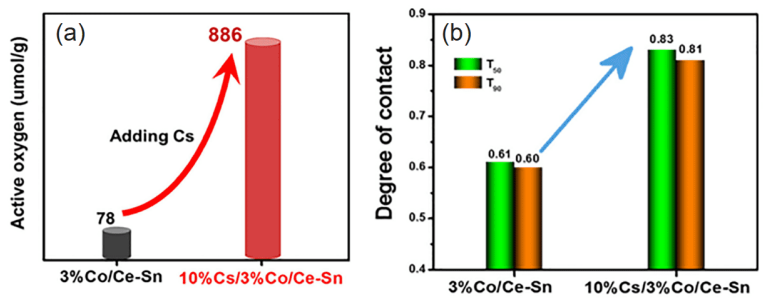

(d)

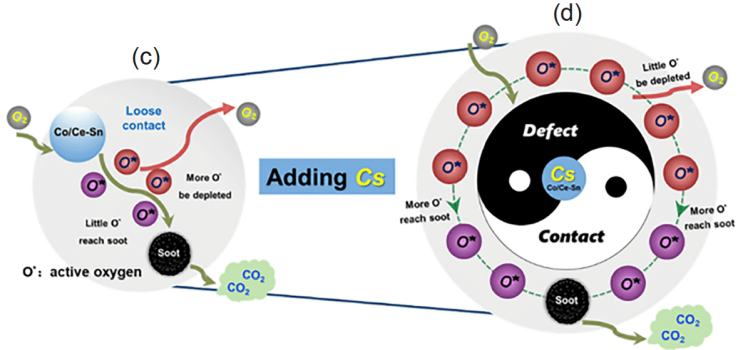

图 13 (a) 制备催化剂的 $\mathrm{O}_{2}$ 解吸量和(b) $T_{50}$ 与 $T_{90}$ 的接触效 率，炭烟燃烧过程示意图: (c) $3 \% \mathrm{Co} / \mathrm{Ce}_{0.5} \mathrm{Sn}_{0.5} \mathrm{O}_{2}$; (d) $10 \%$ $\mathrm{Cs} / 3 \% \mathrm{Co} / \mathrm{Ce}_{0.5} \mathrm{Sn}_{0.5} \mathrm{O}_{2}{ }^{[143]}$ (网络版彩图)

Figure 13 (a) $\mathrm{O}_{2}$ desorption amounts and (b) the contact efficiency of $T_{50}$ and $T_{90}$ of the as-prepared catalysts. Schematic illustration of soot combustion process: (c) $3 \% \mathrm{Co} / \mathrm{Ce}_{0.5} \mathrm{Sn}_{0.5} \mathrm{O}_{2} ;$ (d) $10 \% \mathrm{Cs} / 3 \% \mathrm{Co} /$ $\mathrm{Ce}_{0.5} \mathrm{Sn}_{0.5} \mathrm{O}_{2}$ [143] (color online).
在过渡金属及贵金属改性的铈基氧化物中引入碱 金属可以得到高效的炭烟燃烧三元/多元催化剂. Huang 等 ${ }^{[147]}$ 采用溶胶-凝胶法合成了掺杂 $\mathrm{K}$ 的 $\mathrm{K}_{z}-\mathrm{Ce}_{0.5} \mathrm{Mn}_{0.5} \mathrm{O}_{2}$ $(z=0.1 、 0.2 、 0.3)$ 催化剂. 考察了不同掺钾量对催化剂 的结构和催化性能的影响. 研究结果表明:在一系列掺 钾催化剂中, $\mathrm{K}_{0.2}-\mathrm{Ce}_{0.5} \mathrm{Mn}_{0.5} \mathrm{O}_{2}$ 表现出最好的炭烟催 化活性， $T_{\mathrm{i}}$ 和 $T_{\mathrm{m}}$ 分别为 278 和 $323^{\circ} \mathrm{C}$. $\mathrm{K}$ 的掺杂改变了 锰和铈之间的结构平衡，导致氧空位数量的变化，增 加催化剂表面氧物种的迁移，促进了炭烟的催化燃 烧. Alinezhadchamazketi等 ${ }^{[148]}$ 采用凝胶燃烧法合成了 一系列 $\mathrm{M}-\mathrm{Ce}-\mathrm{Zr} \quad(\mathrm{M}=\mathrm{Mn} 、 \mathrm{Cu} 、 \mathrm{Fe} 、 \mathrm{~K} 、 \mathrm{Ba} 、 \mathrm{Sr})$ 和 $\mathrm{K}_{x}-\mathrm{Mn}-\mathrm{Ce}-\mathrm{Zr}(x=0 、 5 、 10 、 20$ wt.\%)混合金属氧化 物, 并对其炭烟燃烧的催化活性进行了研究. 结果表 明， K-Ce-Zr在松散接触条件下对炭烟燃烧具有最高 的催化活性，其原因是炭烟与催化剂的接触增强. 在 紧密接触条件下, Mn-Ce- $\mathrm{Zr}$ 纳米复合材料具有较高的 炭烟燃烧活性, 与非催化炭烟燃烧相比, 炭烟TPO峰值 温度降低了约 $280^{\circ} \mathrm{C}$. 此外, 在 $\mathrm{Mn}-\mathrm{Ce}-\mathrm{Zr}$ 中加入高达 10 wt.\%的氧化钾可提高其催化活性，并在松散接触条件 下进一步降低炭烟TPO峰值温度约 $40{ }^{\circ} \mathrm{C}$. Cooper等 ${ }^{[149]}$ 采用湿法浸渍、初湿法和化学蒸汽浸渍等方法制备了 $\mathrm{K}$ 改性的 $\mathrm{AgK} / \mathrm{CeO}_{2}-\mathrm{ZrO}_{2}-\mathrm{Al}_{2} \mathrm{O}_{3}$ 催化剂, 研究了制备方 法对催化剂活性的影响. 研究发现在 $80^{\circ} \mathrm{C}$ 下, 上述三种 方法制备的催化剂能够在低温下利用原位形成的 $\mathrm{N}_{2} \mathrm{O}$ 氧化炭烟. 制备方法的不同影响了催化剂产生和使用 $\mathrm{N}_{2} \mathrm{O}$ 作为炭烟燃烧剂的能力. 将 $\mathrm{K}$ 引入到 $\mathrm{Ag} / \mathrm{CeO}_{2}-$ $\mathrm{ZrO}_{2}-\mathrm{Al}_{2} \mathrm{O}_{3}$ 中可以极大地改善炭烟的燃烧活性，特别 是对于通过湿法浸渍制备的催化剂.

对于碱土金属而言, 尽管 $\mathrm{CaO} 、 \mathrm{MgO}$ 和 $\mathrm{CaO}-\mathrm{MgO}$ 等其它物种也被证明对 $\mathrm{NO}_{x}$ 辅助炭烟燃烧是有效的, 但到目前为止，只有Ba改性的铈基氧化物催化剂被大 量研究过用于炭烟的燃烧. $\mathrm{Ba}$ 被广泛认为是硝酸盐的 储存材料. 在 $\mathrm{NO}_{x}$ 辅助的炭烟燃烧反应中, $\mathrm{NO}_{2}$ 的产生 主要在 $<350^{\circ} \mathrm{C}$ 的温度范围内，但发生炭烟燃烧的最佳 释放温度约为 $350 \sim 450^{\circ} \mathrm{C}$. 这种温度的不匹配导致 $\mathrm{NO}_{2}$ 不能充分利用能够通过将钡引入铈基氧化物来克服. $\mathrm{Wu}$ 等 ${ }^{[150]}$ 研究了 $\mathrm{Ba}$ 改性的 $\mathrm{MnO}_{x}-\mathrm{CeO}_{2}$ 氧化物催化剂在 $\mathrm{NO}_{x}$ 存在条件下的炭烟燃烧性能. 研究发现 $\mathrm{Ba}$ 的添加 不能防止 $\mathrm{MnO}_{x}-\mathrm{CeO}_{2}$ 固溶体的相分离, 但能有效地抑 制了固溶体微晶的烧结, 确保了老化的 $\mathrm{Ba} / \mathrm{Mn}-\mathrm{Ce}$ 催化 剂具有很高的NO氧化活性，促进炭烟燃烧. Lin等 ${ }^{[151]}$ 
将硝酸钡浸渍在溶胶-凝胶法制备的 $\mathrm{CuO}_{x}-\mathrm{CeO}_{2}$ 混合 氧化物上制备了 $\mathrm{Ba}-\mathrm{Cu}-\mathrm{Ce}$ 催化剂, 并在松散接触条件 下, $1000 \mathrm{ppm} \mathrm{NO} / 10 \% \mathrm{O}_{2} / \mathrm{N}_{2}$ 气氛中评估了炭烟燃烧催 化剂的活性. 研究结果表明 $\mathrm{Ba}$ 的引入显著提高催化剂 在 $\mathrm{NO}+\mathrm{O}_{2}$ 存在下的炭烟燃烧活性，特别是在低 $\mathrm{NO}$ 含 量气氛下. $\mathrm{Ba}$ 的最佳负载量为 $\mathrm{Cu}+\mathrm{Ce}$ 的 $6 \sim 10 \mathrm{~mol} . \%$, 所制得的催化剂 $T_{\mathrm{i}}\left(376^{\circ} \mathrm{C}\right)$ 低于 $\mathrm{CuCe}\left(417^{\circ} \mathrm{C}\right)$. Guan 等 ${ }^{[152]}$ 研究了向 $\mathrm{FeCeO}_{2-\delta}$ 中引入 $\mathrm{Ba}$ 对炭烟燃烧的促进 作用. 结果发现 $\mathrm{Ba}(10 \%) \mathrm{FeCe}$ 在 $\mathrm{NO}$ 的存在下表现出最 佳的催化性能, 并具有最低的炭烟着火温度 $282^{\circ} \mathrm{C}$, 如 图14a所示. $\mathrm{FeCeO}_{2-\delta}$ 中 Ba的负载显着提高了 $\mathrm{NO}_{x}$ 的吸 附和解吸能力, 如图 $14 \mathrm{~b}$ 所示. $\mathrm{NO}_{x}$ 吸附在催化剂表面 形成亚硝酸盐和硝酸盐，而 $\mathrm{BaFeCeO}_{2-\delta}$ 上相应的硝酸 盐在高温下稳定，这对炭烟的燃烧起到至关重要的 作用.

碱金属的引入能够增强催化剂与炭烟颗粒接触,
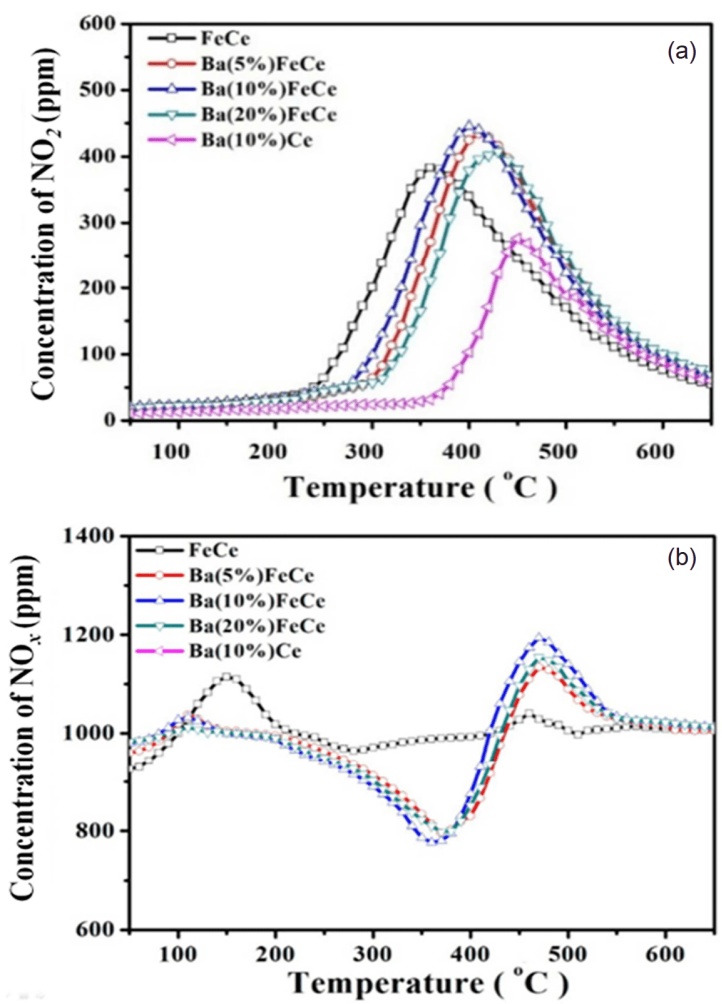

图 14 在由 $10 \% \mathrm{O}_{2} 、 1000 \mathrm{ppm} \mathrm{NO}$ 和 $\mathrm{N}_{2}$ 平衡气体组成的混 合气体中进行NO-TPD测试期间, $\mathrm{NO}_{2}(\mathrm{a})$ 和 $\mathrm{NO}(\mathrm{b})$ 的逸出 ${ }^{[152]}$ (网络版彩图)

Figure 14 Evolutions of $\mathrm{NO}_{2}$ (a) and $\mathrm{NO}_{x}$ (b) during the NO-TPO tests in the gas mixture consisting of $10 \% \mathrm{O}_{2}, 1000 \mathrm{ppm} \mathrm{NO}$, and $\mathrm{N}_{2}$ balanced gas [152] (color online).
碱土金属的引入能够提高 $\mathrm{NO}_{x}$ 的利用效率，从而提高 炭烟颗粒催化燃烧活性. 然而, 由于碱(碱土)金属表面 原子的移动性强，它们表现出较弱的热稳定性. 因此, 如何提高碱(碱土)金属改性的铈基氧化物催化剂的热 稳定性是目前以及未来的研究重点.

当前，大量不同金属改性的铈基氧化物催化剂已 被用于柴油机尾气中炭烟颗粒的去除，各种铈基氧化 物催化剂对炭烟燃烧的催化性能总结在表2中.

\section{3 铈基氧化物催化燃烧炭烟机理的研究}

不同铈基氧化物催化剂对炭烟的催化燃烧性能存 在显著差异, 而导致这些差异的产生主要原因是由于 催化剂的结构性质和催化机理不同. 铈基氧化物催化 剂的结构特性(比表面积、尺寸、组成和形貌)可能会 改变炭烟与催化剂之间的接触, 从而影响催化剂上活 性中心的利用程度. 此外, 每个催化剂活性中心对炭 烟的催化燃烧通常具有不同的催化机理. 通过对催化 机理的详细研究, 可以更好地了解铈基氧化物催化剂 在炭烟燃烧反应中发挥的作用, 为制备与设计更高效 催化剂提供一定的理论指导.

\section{1 单一氧化铈催化炭烟燃烧机理}

如上所述, 单一氧化铈催化剂由于其能够在 $\mathrm{Ce}^{3+}$ 和 $\mathrm{Ce}^{4+}$ 状态之间切换, 具有较高的氧存储性能, 因此对 炭烟燃烧具有显著的活性. 当尾气中含氧量大时, 氧化 铈由 $\mathrm{Ce}_{2} \mathrm{O}_{3}$ 向 $\mathrm{CeO}_{2}$ 转变, 发生氧化反应: $\mathrm{Ce}_{2} \mathrm{O}_{3}+1 / 2 \mathrm{O}_{2} \rightarrow$ $2 \mathrm{CeO}_{2}$, 将尾气中的 $\mathrm{O}_{2}$ 存储起来; 当尾气中 $\mathrm{O}_{2}$ 不足时, 由 $\mathrm{CeO}_{2}$ 向 $\mathrm{Ce}_{2} \mathrm{O}_{3}$ 转变, 发生还原反应: $2 \mathrm{CeO}_{2} \rightarrow \mathrm{Ce}_{2} \mathrm{O}_{3}+$ $1 / 2 \mathrm{O}_{2}, \mathrm{O}_{2}$ 又可以放出来, 从而提高了催化剂的催化性 能 $^{[185]}$. 在柴油机尾气中, 几种含氧的气体分子 $(\mathrm{NO}$ 、 $\mathrm{SO}_{2} 、 \mathrm{CO} 、 \mathrm{CO}_{2} 、 \mathrm{O}_{2}$ 和 $\mathrm{H}_{2} \mathrm{O}$ ) 都可能会与炭烟颗粒反 应. 其中, $\mathrm{SO}_{2} 、 \mathrm{CO} 、 \mathrm{H}_{2} \mathrm{O} 、 \mathrm{CO}_{2}$ 和 $\mathrm{NO}$ 对炭烟反应性 低, 无法在柴油机尾气的排放温度 $\left(150 \sim 450^{\circ} \mathrm{C}\right)$ 下直接 与炭烟反应. 因此, 在某些条件下, $\mathrm{O}_{2}$ 被认为是唯一能 够氧化柴油机炭烟颗粒的反应性气体. 此外, NO可以 被催化氧化为 $\mathrm{NO}_{2}$, 它比 $\mathrm{NO}$ 和 $\mathrm{O}_{2}$ 更具反应性. 因此, 在 实际的DPF过滤器中, 柴油机炭烟颗粒的燃烧主要被 $\mathrm{NO}_{2}$ 和/或 $\mathrm{O}_{2}$ 氧化. 而在不同的反应气氛中, 单一铈基 氧化物催化剂的反应机理各不相同.

Bueno-López等 ${ }^{[186]}$ 人认为, 单一氧化铈催化燃烧 
表 2 不同金属改性铈基氧化物催化剂消除炭烟颗粒的催化性能

Table 2 Reviews on catalytic performances of cerium-based oxide catalysts modified by different metals for removal of soot particles

\begin{tabular}{|c|c|c|c|c|c|c|c|c|}
\hline 催化剂 & $\begin{array}{c}\text { 炭烟/催 } \\
\text { 化剂重 } \\
\text { 量比 }\end{array}$ & $\begin{array}{c}\text { 炭烟与催 } \\
\text { 化剂的接 } \\
\text { 触方式 }\end{array}$ & 反应物进料 & $\begin{array}{l}\text { 升温速率 } \\
\left({ }^{\circ} \mathrm{C} / \mathrm{min}\right)\end{array}$ & $\begin{array}{l}T_{10} / T_{\mathrm{i}} \\
\left({ }^{\circ} \mathrm{C}\right)\end{array}$ & $\begin{array}{l}T_{50} / T_{\mathrm{m}} \\
\left({ }^{\circ} \mathrm{C}\right)\end{array}$ & $\begin{array}{l}T_{90} \\
\left({ }^{\circ} \mathrm{C}\right)\end{array}$ & $\begin{array}{l}\text { 相关 } \\
\text { 文献 }\end{array}$ \\
\hline $\mathrm{Ce}-\mathrm{Zn}-\mathrm{La}$ & $1 / 9$ & 松散 & 流量 $75 \mathrm{~mL} / \mathrm{min}, 20 \% \mathrm{O}_{2}+\mathrm{N}_{2}$ 平衡气 & 10 & 295 & 389 & - & [77] \\
\hline $\mathrm{Ce}_{0.5} \operatorname{Pr}_{0.5} \mathrm{O}_{2-\delta}$ & $1 / 4$ & 松散 & 流量 $500 \mathrm{~mL} / \mathrm{min}, 5 \% \mathrm{O}_{2}+500 \mathrm{ppm} \mathrm{NO}+\mathrm{N}_{2}$ 平衡气 & 10 & - & 477 & - & [78] \\
\hline $\mathrm{CePrO}_{x}$ & $1 / 4$ & 紧密 & 流量 $100 \mathrm{~mL} / \mathrm{min}, 10 \% \mathrm{O}_{2}+600 \mathrm{ppm} \mathrm{NO}+\mathrm{Ar}$ 平衡气 & 15 & - & 378 & 422 & {$[80]$} \\
\hline $1 \% \mathrm{NDC}$ & $1 / 10$ & 紧密 & 流量 $50 \mathrm{~mL} / \mathrm{min}$, 空气 & 10 & - & 427 & - & [82] \\
\hline $\mathrm{CeO}_{2}-\mathrm{Sm}_{2} \mathrm{O}_{3}$ & $1 / 4$ & 紧密 & 流量 $50 \mathrm{~mL} / \mathrm{min}$, 空气 & 10 & - & 417 & - & [83] \\
\hline $\mathrm{MnO}_{x}-\mathrm{CeO}_{2}-\mathrm{Y}_{2} \mathrm{O}_{3}$ & $1 / 10$ & 松散 & 流量 $500 \mathrm{~mL} / \mathrm{min}, 10 \% \mathrm{O}_{2}+800 \mathrm{ppm} \mathrm{NO}_{x}+\mathrm{N}_{2}$ 平衡气 & 10 & - & 434 & - & [85] \\
\hline $\mathrm{Ce}_{0.8} \mathrm{La}_{0.12} \mathrm{Y}_{0.08} \mathrm{O}_{2-\delta}$ & $1 / 4$ & 紧密 & 流量 $100 \mathrm{~mL} / \mathrm{min}$, 空气 & 10 & - & 459 & - & [87] \\
\hline 立方体状 $\mathrm{Ce}_{0.8} \mathrm{Zr}_{0.1} \mathrm{Pr}_{0.1} \mathrm{O}_{2}$ & $1 / 9$ & 紧密 & 流量 $100 \mathrm{~mL} / \mathrm{min}, 10 \% \mathrm{O}_{2}+\mathrm{N}_{2}$ 平衡气 & 5 & 382 & 419 & 453 & [88] \\
\hline $\mathrm{Ce}_{0.5} \mathrm{Pr}_{0.5} \mathrm{O}_{2-\delta}$ & $1 / 9$ & 松散 & 流量 $100 \mathrm{~mL} / \mathrm{min}, 50 \% \mathrm{O}_{2}+\mathrm{N}_{2}$ 平衡气 & 5 & 441 & 527 & 608 & [153] \\
\hline $\mathrm{Ce}_{0.5} \operatorname{Pr}_{0.5} \mathrm{O}_{2-\delta}$ & $1 / 9$ & 紧密 & 流量 $100 \mathrm{~mL} / \mathrm{min}, 50 \% \mathrm{O}_{2}+\mathrm{N}_{2}$ 平衡气 & 5 & 360 & 408 & 441 & [153] \\
\hline $\mathrm{Ce}_{0.3}(\mathrm{Zr}+\mathrm{Y})_{0.7} \mathrm{O}_{2-\delta}$ & $1 / 9$ & 松散 & 空气 & - & 347 & 393 & 433 & {$[154]$} \\
\hline $\mathrm{Ce}_{0.8} \mathrm{Eu}_{0.1} \mathrm{La}_{0.1} \mathrm{O}_{2-\delta}$ & $1 / 4$ & 紧密 & 流量 $100 \mathrm{~mL} / \mathrm{min}$, 空气 & 10 & - & 446 & - & {$[155]$} \\
\hline $\mathrm{Ce}_{0.8} \mathrm{Zr}_{0.1} \mathrm{Pr}_{0.1} \mathrm{O}_{2}$ & $1 / 9$ & 紧密 & 流量 $100 \mathrm{~mL} / \mathrm{min}, 50 \%$ 空气 $+50 \% \mathrm{~N}_{2}$ & 5 & 388 & 444 & 503 & [156] \\
\hline $\mathrm{Ce}_{0.9} \mathrm{Gd}_{0.1} \mathrm{O}_{2}$ & $1 / 4$ & 紧密 & 流量 $100 \mathrm{~mL} / \mathrm{min}$, 空气 & 10 & - & 468 & - & {$[157]$} \\
\hline $\mathrm{Mn}_{x} \mathrm{Ce}_{1-x-0.1} \mathrm{Nd}_{0.1} \mathrm{O}_{2}$ & $1 / 10$ & 松散 & $\begin{array}{c}\text { 流量 } 500 \mathrm{~mL} / \mathrm{min}, 10 \% \mathrm{O}_{2}+1000 \mathrm{ppm} \\
\mathrm{NO}+\mathrm{He} \text { 平衡气 }\end{array}$ & 5 & 274 & 307 & - & [158] \\
\hline $3 \mathrm{DOM} \mathrm{Co} \mathrm{Co}_{4}-\mathrm{CeO}_{2}$ & $1 / 10$ & 松散 & 流量 $80 \mathrm{~mL} / \mathrm{min}, 5 \% \mathrm{O}_{2}+0.25 \% \mathrm{NO}+\mathrm{N}_{2}$ 平衡气 & 2 & - & 406 & - & [95] \\
\hline $0.6 \mathrm{Co} / \mathrm{Ce}-\mathrm{NS}$ & $1 / 5$ & 松散 & 流量 $100 \mathrm{~mL} / \mathrm{min}, 10 \% \mathrm{O}_{2}+600 \mathrm{ppm} \mathrm{NO}+\mathrm{N}_{2}$ 平衡气 & 2 & 319 & 380 & - & [96] \\
\hline $\mathrm{MnO}_{x}-\mathrm{CeO}_{2}$ & $1 / 9$ & 松散 & 流量 $100 \mathrm{~mL} / \mathrm{min}, 10 \% \mathrm{O}_{2}+\mathrm{Ar}$ 平衡气 & - & 254.5 & 299.0 & 359.4 & [101] \\
\hline 花状 $20 \% \mathrm{Mn}_{3} \mathrm{O}_{4} / \mathrm{CeO}_{2}$ & $1 / 9$ & 松散 & 流量 $100 \mathrm{~mL} / \mathrm{min}$, 空气: $\mathrm{Ar}=1: 1$ & 5 & 322 & 382 & 478 & [107] \\
\hline $3 \mathrm{DOM}-\mathrm{Ce}_{0.8} \mathrm{Mn}_{0.1} \mathrm{Zr}_{0.1} \mathrm{O}_{2}$ & $1 / 10$ & 松散 & 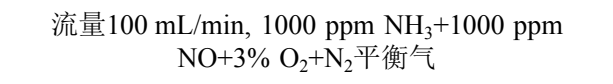 & 3 & - & 402 & - & [109] \\
\hline 花状 $\mathrm{Cu}_{x} \mathrm{Mn}_{y} \mathrm{Ce}_{z}$ & $1 / 10$ & 松散 & $500 \mathrm{ppm} \mathrm{NO}$ 和 $10 \% \mathrm{O}_{2}$ & 10 & - & 347 & - & [111] \\
\hline $\mathrm{Cu}_{0.2} \mathrm{Ce}_{0.8} \mathrm{O}_{2}-\mathrm{NF}$ & $1 / 10$ & 松散 & 流量 $50 \mathrm{~mL} / \mathrm{min}, 5 \% \mathrm{O}_{2}+0.1 \% \mathrm{NO}+\mathrm{N}_{2}$ 平衡气 & 2 & - & 360 & - & [112] \\
\hline 立方体状 $\mathrm{CuO}_{x} / \mathrm{CeO}_{2}$ & $1 / 4$ & 松散 & 流量 $100 \mathrm{~mL} / \mathrm{min}$, 空气 & 10 & 342 & 471 & - & [113] \\
\hline 棒状 $\mathrm{CuO} / \mathrm{CeO}_{2}$ & $1 / 4$ & 松散 & 流量 $100 \mathrm{~mL} / \mathrm{min}$, 空气 & 10 & - & 419 & - & {$[114]$} \\
\hline $\mathrm{Ce}_{0.95} \mathrm{Cr}_{0.05} \mathrm{O}_{2-\delta}$ & $1 / 4$ & 紧密 & 流量 $100 \mathrm{~mL} / \mathrm{min}$, 空气 & 10 & - & 425 & - & [118] \\
\hline$(\mathrm{Ni}-\mathrm{Ce})-3 \mathrm{DOM}$ & $1 / 4$ & 松散 & 流量 $50 \mathrm{~mL} / \mathrm{min}, 5 \% \mathrm{O}_{2}+500 \mathrm{ppm} \mathrm{NO}+\mathrm{N}_{2}$ 平衡气 & 10 & - & 530 & - & [120] \\
\hline $\mathrm{CeO}_{2}-\mathrm{ZrO}_{2}(\mathrm{C}-\mathrm{T})$ & $1 / 9$ & 紧密 & 流量 $100 \mathrm{~mL} / \mathrm{min}, 10 \% \mathrm{O}_{2}+7 \% \mathrm{H}_{2} \mathrm{O}+\mathrm{N}_{2}$ 平衡气 & 5 & 325 & 366 & 406 & [121] \\
\hline $\mathrm{CoCeO}_{2}-\mathrm{NRS}$ & $1 / 10$ & 紧密 & 流量 $50 \mathrm{~mL} / \mathrm{min}, 13 \% \mathrm{O}_{2}+1000 \mathrm{ppm} \mathrm{NO}+\mathrm{He}$ 平衡气 & 5 & - & 321 & - & [159] \\
\hline 空心纤维状 $\mathrm{Co}_{3} \mathrm{O}_{4}-\mathrm{CeO}_{2}$ & $1 / 20$ & 松散 & 流量 $20 \mathrm{~mL} / \mathrm{min}, 18 \% \mathrm{O}_{2}+0.1 \% \mathrm{NO}+\mathrm{He}$ 平衡气 & 5 & - & 380 & - & [160] \\
\hline $3 \mathrm{DOM} \mathrm{Co} \mathrm{Ce}_{1-x} \mathrm{O}_{2-\delta}$ & $1 / 10$ & 松散 & 流量 $500 \mathrm{~mL} / \mathrm{min}, 10 \% \mathrm{O}_{2}+\mathrm{N}_{2}$ 平衡气 & 5 & 367 & 452 & - & [161] \\
\hline $\mathrm{Ag} / \mathrm{Co}_{3} \mathrm{O}_{4} @ \mathrm{CeO}_{2}$ & $1 / 10$ & 紧密 & 流量 $500 \mathrm{~mL} / \mathrm{min}, 1 \% \mathrm{O}_{2}+\mathrm{N}_{2}$ 平衡气 & 5 & - & 277 & - & [162] \\
\hline $\mathrm{Mn} / \mathrm{CZ}$ & $1 / 10$ & 紧密 & 流量 $600 \mathrm{~mL} / \mathrm{min}, 10 \% \mathrm{O}_{2}+600 \mathrm{ppm} \mathrm{NO}+\mathrm{N}_{2}$ 平衡气 & 10 & 281 & 360 & - & [163] \\
\hline $3 \mathrm{DOM} \mathrm{Ce} \mathrm{Ce}_{0.7} \mathrm{Fe}_{0.2} \mathrm{Ti}_{0.1} \mathrm{O}_{2}$ & $1 / 10$ & 松散 & $\begin{array}{c}\text { 流量 } 100 \mathrm{~mL} / \mathrm{min}, 3 \% \mathrm{O}_{2}+1000 \mathrm{ppm} \mathrm{NH}_{3}+1000 \mathrm{ppm} \\
\mathrm{NO}+\mathrm{N}_{2} \text { 平衡气 }\end{array}$ & 3 & - & 385 & - & [164] \\
\hline $\mathrm{Ce}_{0.92} \mathrm{Zr}_{0.08} \mathrm{O}_{2}$ & $1 / 10$ & 紧密 & 流量 $50 \mathrm{~mL} / \mathrm{min}, 10 \% \mathrm{O}_{2}+\mathrm{N}_{2}$ 平衡气 & 2 & - & 355 & - & [165] \\
\hline $\mathrm{Ce}_{0.8} \mathrm{Zr}_{0.2} \mathrm{O}_{2}$ & $1 / 10$ & 松散 & 流量 $50 \mathrm{~mL} / \mathrm{min}, 5 \% \mathrm{O}_{2}+1000 \mathrm{ppm} \mathrm{NO}+\mathrm{He}$ 平衡气 & 2 & 385 & 469 & - & {$[166]$} \\
\hline $\mathrm{Co} / \mathrm{Ce}_{0.75} \mathrm{Zr}_{0.25} \mathrm{O}_{2}$ & $1 / 10$ & 紧密 & 流量 $50 \mathrm{~mL} / \mathrm{min}, 10 \% \mathrm{O}_{2}+\mathrm{N}_{2}$ 平衡气 & 10 & 344 & 431 & - & [167] \\
\hline
\end{tabular}


中国科学: 化学 2021 年 第 51 卷 第 8 期

\begin{tabular}{|c|c|c|c|c|c|c|c|c|}
\hline 催化剂 & $\begin{array}{c}\text { 炭烟/催 } \\
\text { 化剂重 } \\
\text { 量比 }\end{array}$ & $\begin{array}{c}\text { 炭烟与催 } \\
\text { 化剂的接 } \\
\text { 触方式 }\end{array}$ & 反应物进料 & $\begin{array}{l}\text { 升温速率 } \\
\left({ }^{\circ} \mathrm{C} / \mathrm{min}\right)\end{array}$ & $\begin{array}{l}T_{10} / T_{\mathrm{i}} \\
\left({ }^{\circ} \mathrm{C}\right)\end{array}$ & $\begin{array}{l}T_{50} / T_{\mathrm{m}} \\
\left({ }^{\circ} \mathrm{C}\right)\end{array}$ & $\begin{array}{l}T_{90} \\
\left({ }^{\circ} \mathrm{C}\right)\end{array}$ & $\begin{array}{l}\text { 相关 } \\
\text { 文献 }\end{array}$ \\
\hline 多孔纳米片状 $\mathrm{CoCe}$ & $1 / 10$ & 紧密 & 流量 $50 \mathrm{~mL} / \mathrm{min}, 5 \% \mathrm{O}_{2}+\mathrm{N}_{2}$ 平衡气 & 2 & - & 311 & 352 & [168] \\
\hline 梯形 $\mathrm{CeO}_{2} @ \mathrm{MnO}_{2}$ & $1 / 9$ & 松散 & 流量 $100 \mathrm{~mL} / \mathrm{min}, 5 \% \mathrm{O}_{2}+\mathrm{N}_{2}$ 平衡气 & 2 & - & 403 & - & [169] \\
\hline $\mathrm{CeO}_{2}-\mathrm{ZrO}_{2}-\mathrm{MnO}_{x}$ & $1 / 10$ & 紧密 & 流量 $50 \mathrm{~mL} / \mathrm{min}, 0.5 \% \mathrm{O}_{2}+\mathrm{N}_{2}$ 平衡气 & 10 & - & 340 & 396 & {$[170]$} \\
\hline $\mathrm{Ce}_{0.95} \mathrm{Mn}_{0.025} \mathrm{Cu}_{0.025}$ & $1 / 9$ & 紧密 & 流量 $100 \mathrm{~mL} / \mathrm{min}, 50 \%$ 空气 $+50 \% \mathrm{~N}_{2}$ & 5 & 441 & 516 & 552 & {$[171]$} \\
\hline 棒状 $\mathrm{MnO}_{x}-\mathrm{CeO}_{2}$ & $1 / 9$ & 松散 & 流量 $100 \mathrm{~mL} / \mathrm{min}, 10 \% \mathrm{O}_{2}+\mathrm{N}_{2}$ 平衡气 & 3 & 314 & 346 & 383 & [102] \\
\hline $\mathrm{CuO}-\mathrm{CeO}_{2}$ & $1 / 20$ & 紧密 & $10 \% \mathrm{O}_{2}+500 \mathrm{ppm} \mathrm{NO}+\mathrm{N}_{2}$ 平衡气 & 10 & - & 383 & - & {$[172]$} \\
\hline $\mathrm{Pt} / \mathrm{CeO}_{2}-\mathrm{NC}$ & $1 / 9$ & 松散 & 流量 $100 \mathrm{~mL} / \mathrm{min}, 10 \% \mathrm{O}_{2}+\mathrm{N}_{2}$ 平衡气 & 5 & 500 & 571 & 619 & [123] \\
\hline 3 wt. $\% \mathrm{Pt} / \mathrm{Mn}_{0.5} \mathrm{Ce}_{0.5} \mathrm{O}_{2-\delta}$ & $1 / 10$ & 松散 & 流量 $50 \mathrm{~mL} / \mathrm{min}, 10 \% \mathrm{O}_{2}+0.2 \% \mathrm{NO}+\mathrm{Ar}$ 平衡气 & 2 & 290 & 342 & 373 & [125] \\
\hline 3DOM Pt $1.0 @ \mathrm{CeO}_{2-x} / \mathrm{ZrO}_{2}-1$ & $1 / 10$ & 松散 & 流量 $50 \mathrm{~mL} / \mathrm{min}, 10 \% \mathrm{O}_{2}+0.2 \% \mathrm{NO}+\mathrm{Ar}$ 平衡气 & 2 & 275 & 328 & 365 & [126] \\
\hline $\mathrm{Au} / \mathrm{CeO}_{2} / 3 \mathrm{DOM} \mathrm{Al}{ }_{2} \mathrm{O}_{3}$ & $1 / 10$ & 松散 & 流量 $50 \mathrm{~mL} / \mathrm{min}, 10 \% \mathrm{O}_{2}+0.2 \% \mathrm{NO}+\mathrm{Ar}$ 平衡气 & 2 & 273 & 364 & 412 & [127] \\
\hline $\mathrm{Au} / \mathrm{CeO}_{2}-\mathrm{R}$ & $1 / 10$ & 松散 & 流量 $50 \mathrm{~mL} / \mathrm{min}, 10 \% \mathrm{O}_{2}+0.2 \% \mathrm{NO}+\mathrm{Ar}$ 平衡气 & 2 & 259 & 350 & 398 & [128] \\
\hline $3 \mathrm{DOM} \mathrm{Au} \mathrm{Pt}_{2} / \mathrm{Ce}_{0.8} \mathrm{Zr}_{0.2} \mathrm{O}_{2}$ & $1 / 10$ & 松散 & 流量 $50 \mathrm{~mL} / \mathrm{min}, 10 \% \mathrm{O}_{2}+0.2 \% \mathrm{NO}+\mathrm{Ar}$ 平衡气 & 2 & 236 & 345 & 397 & [131] \\
\hline $\mathrm{Ag} / \mathrm{CeO}_{2}-\mathrm{C}$ & $1 / 9$ & 紧密 & 流量 $200 \mathrm{~mL} / \mathrm{min}, 8 \% \mathrm{O}_{2}+\mathrm{Ar}$ 平衡气 & 5 & - & 334 & - & [132] \\
\hline 纤维状 $\mathrm{Ag} / \mathrm{CeO}_{2}$ & - & 紧密 & 流量 100 mL/min, 空气 & 10 & 292 & 429 & 495 & {$[133]$} \\
\hline $\mathrm{Ag} / \mathrm{Ce}_{0.67} \mathrm{Zr}_{0.33} \mathrm{O}_{2}$ & $1 / 19$ & 松散 & 流量 $100 \mathrm{~mL} / \mathrm{min}$, 空气 & 10 & 451 & 481 & 511 & [134] \\
\hline $\mathrm{PdAu} @ \mathrm{CeO}_{2} / \mathrm{CZ}$ & $1 / 10$ & 松散 & 流量 $50 \mathrm{~mL} / \mathrm{min}, 5 \% \mathrm{O}_{2}+0.2 \% \mathrm{H}_{2} \mathrm{O}+\mathrm{Ar}$ 平衡气 & 2 & 276 & 363 & 404 & [137] \\
\hline $\mathrm{Pt} / \mathrm{Ce}_{0.6} \mathrm{Zr}_{0.4} \mathrm{O}_{2}$ & $1 / 10$ & 松散 & 流量 $500 \mathrm{~mL} / \mathrm{min}, 10 \% \mathrm{O}_{2}+1000 \mathrm{ppm} \mathrm{NO}+\mathrm{N}_{2}$ 平衡气 & 10 & - & 430 & - & [173] \\
\hline $\begin{array}{c}\mathrm{OMMM} \\
\mathrm{Pt}-\mathrm{KMnO}_{x} / \mathrm{Ce}_{0.25} \mathrm{Zr}_{0.75} \mathrm{O}_{2}\end{array}$ & $1 / 10$ & 松散 & 流量 $50 \mathrm{~mL} / \mathrm{min}, 10 \% \mathrm{O}_{2}+2000 \mathrm{ppm} \mathrm{NO}+\mathrm{Ar}$ 平衡气 & 2 & 273 & 330 & 385 & {$[126]$} \\
\hline $\mathrm{AgCe}$ & $1 / 9$ & 松散 & 流量 50 mL/min, 空气 & 10 & 386.5 & 431 & 472.5 & {$[174]$} \\
\hline 立方体状 $\mathrm{Ag} / \mathrm{CeO}_{2}$ & $1 / 4$ & 紧密 & 流量 $500 \mathrm{~mL} / \mathrm{min}, 1 \% \mathrm{O}_{2}+\mathrm{N}_{2}$ 平衡气 & 5 & - & 376 & - & {$[175]$} \\
\hline $\mathrm{Ag} / \mathrm{CeO}_{2}-\mathrm{ZrO}_{2}$ & $1 / 19$ & 松散 & 流量 $50 \mathrm{~mL} / \mathrm{min}, 4.8 \% \mathrm{O}_{2}+5 \% \mathrm{H}_{2} \mathrm{O}+\mathrm{N}_{2}$ 平衡气 & 2 & 254 & 286 & 317 & {$[176]$} \\
\hline $\mathrm{Ag} / \mathrm{CeO}_{x} / \mathrm{FeO}_{y} /$ 堇青石 & $1 / 9$ & 松散 & 流量 $75 \mathrm{~mL} / \mathrm{min}$, 空气 & 10 & 235 & 334 & - & {$[177]$} \\
\hline $5 \mathrm{Ag}_{1}-\mathrm{Cu}_{0.1} / \mathrm{SBA}-15$ & $1 / 10$ & 松散 & 流量 $50 \mathrm{~mL} / \mathrm{min}, 5 \% \mathrm{O}_{2}+\mathrm{Ar}$ 平衡气 & 10 & 225 & 285 & - & {$[178]$} \\
\hline $\mathrm{Ru} / \mathrm{ZnO}: \mathrm{CeO}_{2}$ & $1 / 9$ & 松散 & 流量 $75 \mathrm{~mL} / \mathrm{min}, 20 \% \mathrm{O}_{2}+\mathrm{N}_{2}$ 平衡气 & - & 243 & 360 & - & [179] \\
\hline $10 \% \mathrm{Cs} / 3 \% \mathrm{Co} / \mathrm{Ce}_{0.5} \mathrm{Sn}_{0.5} \mathrm{O}_{2}$ & $1 / 10$ & 松散 & 流量 $500 \mathrm{~mL} / \mathrm{min}, 10 \% \mathrm{O}_{2}+5 \% \mathrm{H}_{2} \mathrm{O}+\mathrm{N}_{2}$ 平衡气 & 10 & - & 393 & - & {$[143]$} \\
\hline $\mathrm{K} / 3 \% \mathrm{CeO}_{2}-\mathrm{Al}_{2} \mathrm{O}_{3}$ & $1 / 4$ & 紧密 & 流量 $180 \mathrm{~mL} / \mathrm{min}, 12 \% \mathrm{O}_{2}+\mathrm{Ar}$ 平衡气 & 10 & - & 480 & - & [144] \\
\hline $\mathrm{K}_{0.2}-\mathrm{Ce}_{0.5} \mathrm{Mn}_{0.5} \mathrm{O}_{2}$ & $1 / 4$ & 紧密 & 流量 $100 \mathrm{~mL} / \mathrm{min}, 12 \% \mathrm{O}_{2}+\mathrm{N}_{2}$ 平衡气 & 15 & 278 & 323 & - & [147] \\
\hline $\mathrm{Ba} / \mathrm{Mn}-\mathrm{Ce}$ & $1 / 10$ & 松散 & 流量 $500 \mathrm{~mL} / \mathrm{min}, 10 \% \mathrm{O}_{2}+1000 \mathrm{ppm} \mathrm{NO}+\mathrm{N}_{2}$ 平衡气 & 10 & - & 405 & - & {$[150]$} \\
\hline $\mathrm{Ba}-\mathrm{Cu}-\mathrm{Ce}$ & $1 / 10$ & 松散 & $\begin{array}{c}\text { 流量 } 1000 \mathrm{~mL} / \mathrm{min}, 10 \% \mathrm{O}_{2}+1000 \mathrm{ppm} \\
\mathrm{NO}+\mathrm{N}_{2} \text { 平衡气 }\end{array}$ & 20 & 376 & 400 & - & {$[151]$} \\
\hline $\mathrm{Ba}(10 \%) \mathrm{FeCe}$ & $1 / 10$ & 松散 & 流量 $500 \mathrm{~mL} / \mathrm{min}, 10 \% \mathrm{O}_{2}+1000 \mathrm{ppm} \mathrm{NO}+\mathrm{N}_{2}$ 平衡气 & 5 & 282 & 429 & 506 & {$[152]$} \\
\hline $\mathrm{K} / \mathrm{CeO}_{2}-\mathrm{ZrO}_{2}$ & $1 / 10$ & 松散 & 流量 $500 \mathrm{~mL} / \mathrm{min}, 10 \% \mathrm{O}_{2}+1000 \mathrm{ppm} \mathrm{NO}+\mathrm{N}_{2}$ 平衡气 & 2 & - & 428 & - & {$[180]$} \\
\hline $\mathrm{K} / \mathrm{CuO}_{x}-\mathrm{CeO}_{2}$ & $1 / 10$ & 松散 & 流量 $500 \mathrm{~mL} / \mathrm{min}, 10 \% \mathrm{O}_{2}+1000 \mathrm{ppm} \mathrm{NO}+\mathrm{N}_{2}$ 平衡气 & 2 & - & 338 & - & {$[181]$} \\
\hline $\mathrm{K} / \mathrm{La}_{0.8} \mathrm{Ce}_{0.2} \mathrm{CoO}_{3}$ & $1 / 9$ & 紧密 & 流量 $50 \mathrm{~mL} / \mathrm{min}, 20 \% \mathrm{O}_{2}+\mathrm{N}_{2}$ 平衡气 & 10 & - & 380 & - & [182] \\
\hline $\mathrm{K}-\mathrm{Mn} / \mathrm{La}_{0.8} \mathrm{Ce}_{0.2} \mathrm{FeO}_{3}$ & $1 / 9$ & 松散 & 流量 $50 \mathrm{~mL} / \mathrm{min}, 5 \% \mathrm{O}_{2}+1000 \mathrm{ppm} \mathrm{NO}+\mathrm{N}_{2}$ 平衡气 & 2 & 349 & 409 & 462 & {$[183]$} \\
\hline $\mathrm{K} / \mathrm{Ce}_{0.65} \mathrm{Zr}_{0.35} \mathrm{O}_{2} /$ 堇青石 & - & 松散 & 流量 $20 \mathrm{~mL} / \mathrm{min}, 18 \% \mathrm{O}_{2}+0.1 \% \mathrm{NO}+\mathrm{He}$ 平衡气 & 5 & - & 435 & - & [184] \\
\hline
\end{tabular}

炭烟颗粒的反应机理主要分为两种: (1) 活性氧辅助机 理, 该机理具有两个关键步骤, 即活性氧的产生和活性
氧从催化剂到炭烟颗粒的转移, 催化剂与气相 $\mathrm{O}_{2}$ 之间 存在直接的氧交换; (2) $\mathrm{NO}_{2}$ 辅助机理, 利用了较高的 
温度会导致 $\mathrm{NO}$ 氧化为 $\mathrm{NO}_{2}$, 并吸附在催化剂表面形成 表面吸附物种, 随后迁移到催化剂与炭烟的固-固界面 处进行炭烟的燃烧．通常，由于活性氧的稳定性低于 $\mathrm{NO}_{2}$, 因此活性氧辅助机理在接触良好的炭烟催化剂 体系中可能会很好地发挥作用。同时，他们还利用同 位素 ${ }^{18} \mathrm{O}_{2}$ 进行产物瞬时分析(TAP)研究, 观察到炭烟的 燃烧是通过Mars-van-Krevelen机制发生的，即在炭烟 燃烧反应过程中，气态 $\mathrm{O}_{2}$ 不直接与炭烟发生反应。相 反，氧化铈的前几个表面层中的晶格氧被转移到炭烟 上(式1), 并且气态的 $\mathrm{O}_{2}$ 填充了氧化物上产生的氧空位 (式2), 其机理反应过程如下 ${ }^{[187]}$ :

$n \mathrm{Ce}^{16} \mathrm{O}_{2}+\mathrm{C} \rightarrow n \mathrm{Ce}^{16} \mathrm{O}_{2-2 / n}+\mathrm{C}^{16} \mathrm{O}_{2}$

$n \mathrm{Ce}^{16} \mathrm{O}_{2-2 / n}{ }^{18} \mathrm{O}_{2} \rightarrow n \mathrm{Ce}^{16} \mathrm{O}_{2-2 / n}{ }^{18} \mathrm{O}_{2 / n}$

Soler等 ${ }^{[188]}$ 研究了 $\mathrm{CeO}_{2}$ 作为催化剂催化燃烧炭烟 颗粒的性能, 并提出了更加具体的活性氧辅助机理, 如 图15所示. $\mathrm{CeO}_{2}$ 首先在炭烟颗粒和 $\mathrm{CeO}_{2}$ 表面之间的界 面被炭烟还原并释放 $\mathrm{CO}_{2}$ (路径 $1 ， 2$ ), 然后还原的 $\mathrm{CeO}_{2}$ 表面与气体氧反应填补氧空位，生成过氧化物/超氧化 物物种(路径3，4), 这些活性氧物种迁移到炭烟表面并 以低得多的能源成本有效地反应形成 $\mathrm{CO}_{2}$ (路径 5,6$)$. 最终炭烟和 $\mathrm{CeO}_{2}$ 表面之间建立了新的接触点, 并且循 环再次开始. 这与 Gross 等 ${ }^{[189]}$ 人提出的在二氧化铈上 催化柴油机尾气燃烧的机理一致. Guillén-Hurtado 等 ${ }^{[190]}$ 以松散接触方式制备的氧化铈一炭烟颗粒混合物 为材料，在 $\mathrm{NO}$ 存在的条件下用标记过的 ${ }^{18} \mathrm{O}_{2}$ 进行脉冲 技术研究了二氧化铈催化氧化炭烟的机理. 研究证明
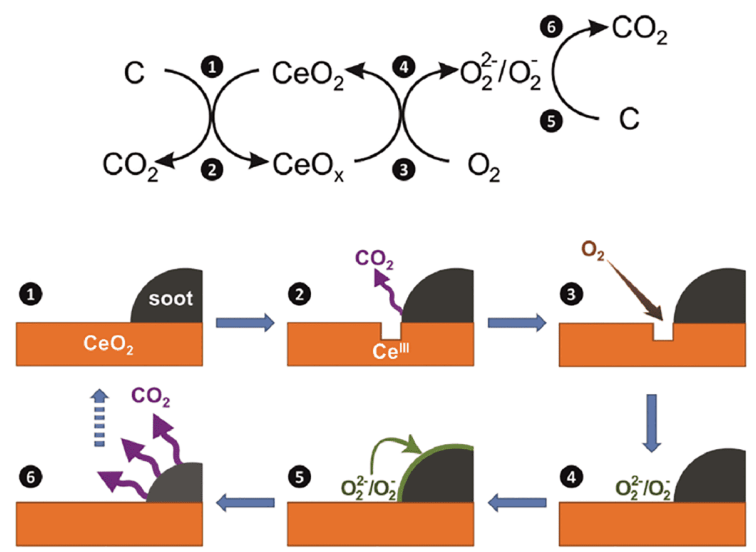

图 15 氧化铈催化剂上炭烟燃烧机理示意图 ${ }^{[188]}$ (网络版彩 图)

Figure 15 Schematic diagram of soot combustion mechanism on ceria catalysts [188] (color online).
即使在没有 ${ }^{18} \mathrm{O}_{2}$ 的情况下，二氧化铈也会将 $\mathrm{NO}$ 氧化为 $\mathrm{NO}_{2}$. 用二氧化铈的晶格氧氧化 $\mathrm{NO}$ 会使二氧化铈上产 生氧空位, 一旦 ${ }^{18} \mathrm{O}_{2}$ 被脉冲化, 这些空位就会被气相氧 填满. 通过以下反应分别描述了氧化铈氧对 $\mathrm{NO}$ 的氧化 (式3)和 ${ }^{18} \mathrm{O}_{2}$ 对氧化铈的再氧化(式4):

$n \mathrm{CeO}_{2}+2 \mathrm{NO} \rightarrow n \mathrm{CeO}_{2-2 / n}+2 \mathrm{NO}_{2}$

$n \mathrm{CeO}_{2-2 / n}+{ }^{18} \mathrm{O}_{2} \rightarrow\left[(n-1) \mathrm{CeO}_{2}\right]-\mathrm{Ce}^{18} \mathrm{O}_{2}$

\section{2 不同金属改性的铈基氧化物催化炭烟燃烧机理}

近年来，不同金属改性的铈基氧化物催化剂在炭 烟颗粒的催化燃烧中所展示的高活性逐渐引起人们的 注意, 为进一步设计和制备更加高活性的铈基氧化物 催化剂，越来越多的研究者对不同金属改性的铈基氧 化物催化燃烧炭烟颗粒的催化机理进行了研究. 相比 于单一氧化铈催化剂，不同金属改性的铈基氧化物催 化剂对炭烟燃烧机理更加复杂. 一般一种金属可以起 到一种或两种以上作用，因此需要根据其不同组分研 究铈基氧化物催化剂上炭烟燃烧的反应机理.

\subsection{1 稀土金属改性的铈基氧化物催化炭烟燃烧机理}

如前所述，铈基催化剂对炭烟的燃烧效率高度依 赖于其独特的性质，如氧空位缺陷和储氧能力(OSC) 等. 经过稀土金属改性的铈基氧化物催化剂会产生更 多的结构缺陷，这些缺陷会促进更多的气态氧吸附到 表面上或促进表面下的晶格氧扩散到表面，从而增强 活性氧的形成. 而改性的稀土金属不同，其铈基氧化 物催化剂产生结构缺陷数量不同, 从而导致催化剂对 炭烟催化燃烧的性能以及反应途径均有差异.

Mukherjee等 ${ }^{[191]}$ 结合相关的文献报道提出了 $\mathrm{CeO}_{2}-\mathrm{ZrO}_{2} 、 \mathrm{CeO}_{2}-\mathrm{La}_{2} \mathrm{O}_{3} 、 \mathrm{CeO}_{2}-\mathrm{Pr}_{2} \mathrm{O}_{3} 、 \mathrm{CeO}_{2}-$ $\mathrm{HfO}_{2} 、 \mathrm{CeO}_{2}-\mathrm{Fe}_{2} \mathrm{O}_{3}$ 等催化燃烧炭烟颗粒的机制. 在所 提出的机制中，催化剂参与氧化还原循环并被反复氧 化和还原, 该过程涉及以下步骤:

$\mathrm{M}_{\text {red }}+\mathrm{O}_{\text {gas }} \rightarrow \mathrm{M}_{\text {oxd }}-\mathrm{O}_{\text {ads }}$

$\mathrm{M}_{\text {oxd }}-\mathrm{O}_{\text {ads }}+\mathrm{C}_{\mathrm{f}} \rightarrow \mathrm{M}_{\text {red }}+\mathrm{SOC}$

$\mathrm{SOC} \rightarrow \mathrm{CO} / \mathrm{CO}_{2}$

$\mathrm{M}_{\mathrm{red}}$ 和 $\mathrm{M}_{\mathrm{oxd}}-\mathrm{O}_{\mathrm{ads}}$ 分别代表催化剂的还原态和氧化 态. $\mathrm{O}_{\mathrm{gas}}$ 和 $\mathrm{O}_{\mathrm{ads}}$ 分别代表气态 $\mathrm{O}_{2}$ 和表面吸附氧. $\mathrm{C}_{\mathrm{f}}$ 表示 碳表面的活性碳位或游离碳位, SOC表示表面的碳-氧 复合体. 根据这一机理, 气态氧解离吸附在金属氧化物 催化剂表面(式5)，产生的原子氧自由基攻击活性游离 
碳位 $\mathrm{C}_{\mathrm{f}}$, 得到含氧活性中间体(式6). 中间体与 $\mathrm{O}_{\mathrm{ads}}$ 或气 态 $\mathrm{O}_{2}$ 之间的反应产生 $\mathrm{CO} / \mathrm{CO}_{2}$ (式7). Katta等 ${ }^{[192]}$ 提出了 铈镧 $(C L)$ 复合氧化物催化燃烧炭烟颗粒的反应机制, 如图16所示. 该机理涉及多个步骤的组合: 首先, 炭烟 以紧密接触方式吸附在催化剂的表面; 随后 $\mathrm{La}^{3+}$ 诱导 的缺陷被气态氧填充从而形成活性氧; 最后活性氧从 催化剂表面溢出并与炭烟颗粒作用形成 $\mathrm{CO}$ 或 $\mathrm{CO}_{2}$.

当反应体系中不存在 $\mathrm{NO}_{x}$ 时，稀土金属改性的铈 基氧化物催化剂的机理与单一铈基氧化物催化机理基 本一致. 首先, 活性氧在催化剂表面产生, 然后从催化 剂转移到炭烟颗粒上进行催化燃烧炭烟颗粒，最后催 化剂的氧空位与气相 $\mathrm{O}_{2}$ 之间相互作用回到催化剂原 始状态. 当反应体系中 $\mathrm{NO}_{x}$ 存在时, 其产生的活性氧会 与 $\mathrm{NO}_{x}$ 反应产生 $\mathrm{NO}_{2}$, 反应机理转变为 $\mathrm{NO}_{2}$ 辅助催化 机理.

\subsection{2 过渡金属改性的铈基氧化物催化炭烟燃烧机理}

过渡金属在炭烟的催化燃烧中一般以其氧化物形 式起作用, 这是基于过渡金属变价特点, 经过过渡金属 改性的铈基氧化物催化剂，可以充分利用其高氧化还 原性能实现炭烟的低温氧化. 但由于过渡金属的引入, 铈基氧化物催化机理途径也变得更加复杂. 因此, 研究 炭烟在过渡金属改性的铈基氧化物催化剂上燃烧起作 用的反应途径，探讨了炭烟在其催化燃烧作用机理具 有重要意义.

近年来，研究者们基于过渡金属改性的铈基氧化

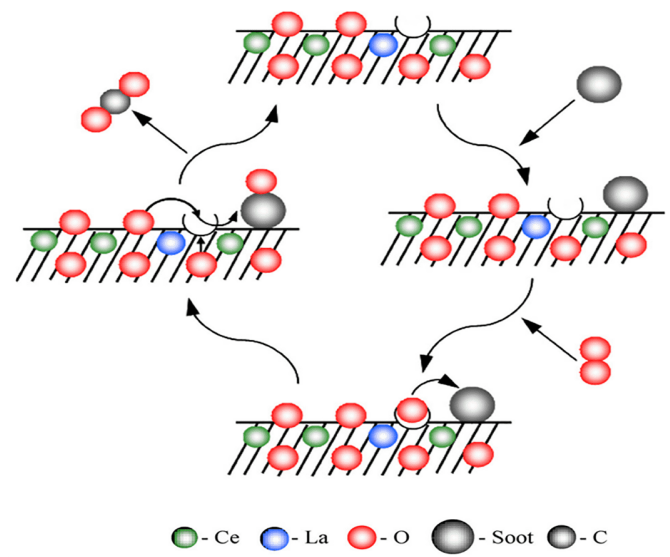

图 16 铈镧催化剂的炭烟燃烧机理示意图 ${ }^{[192]}$ (网络版彩 图)

Figure 16 Schematic diagram of soot combustion mechanism of ceria-lanthana catalysts [192] (color online).
物催化剂的研究结果对其机理进行了大量的研究. 炭 烟在 $\mathrm{Co}_{3} \mathrm{O}_{4}$ 上的氧化被认为是氧化还原机制. 同时，吸 附的氧在 $\mathrm{CeO}_{2}$ 表面上很可能被活化成活性物质(超氧 化物和过氧化物)氧化炭烟. 在许多报道中，把这一反 应机理归属于氧溢出机制 ${ }^{[193]}$. Xu等 ${ }^{[194]}$ 利用一系列实 验表征手段研究了 $\mathrm{Co}-\mathrm{CeO}_{2}$ 混合氧化物在 $\mathrm{NO}_{x}$ 辅助下 催化氧化炭烟的性能并出了反应机理. 该机理在很大 程度上取决于储存 $\mathrm{NO}_{x}$ 的能力和 $\mathrm{NO}$ 氧化为 $\mathrm{NO}_{2}$ 的催化 活性. 如图17所示, 炭烟燃烧的反应路径分为三种: 一 是活性氧物种 $\mathrm{O}_{2}{ }^{-}$和 $\mathrm{O}^{-}$直接将催化剂表面上的炭烟颗 粒催化燃烧; 二是 $\mathrm{NO}$ 在活性氧的作用下生成 $\mathrm{NO}_{2}, \mathrm{NO}_{2}$ 在催化剂表面上吸附, 随后进行迁移与炭烟颗粒作用 将炭烟颗粒氧化; 三是气相的NO吸附在催化剂表面 并与活性氧结合形成亚硝酸盐或硝酸盐的中间物种, 炭烟颗粒在中间物种的作用下进行氧化.

相比于钴氧化物，锰氧化物中锰离子具有多变价 态, 并且各氧化态之间可以相互转变, 有利于提高催 化剂的氧化还原能力. 将锰引入铈基氧化物中, 由于 $\mathrm{Ce}$ 和 $\mathrm{Mn}$ 金属氧化物的协同作用，表现出了优异的炭 烟燃烧活性，因此锰改性的铈基氧化物催化剂的反 应机理常常被研究. Mori等 ${ }^{[99]}$ 提出不同接触模式下 $\mathrm{MnO}_{x} / \mathrm{CeO}_{2}$ 的炭烟燃烧机理及其反应发生的途径. 如 图18所示, 在紧密接触模式下, $\mathrm{MnO}_{x} / \mathrm{CeO}_{2}$ 相晶格中形 成的活性氧主要是直接燃烧. $\mathrm{MnO}_{x}$ 释放的活性氧可通 过相邻 $\mathrm{CeO}_{2}$ 相中的氧空位由气态 $\mathrm{O}_{2}$ 依次补偿. 在松散 接触模式下, $\mathrm{NO}$ 辅助途径占主导, 而 $\mathrm{MnO}_{x} / \mathrm{CeO}_{2}$ 相上 潜在的活性氧直接氧化则是次要途径, 这可能是因为 活性氧不能从催化剂表面释放.

Lin等 ${ }^{[101]}$ 研究了 $\mathrm{MnO}_{x}-\mathrm{CeO}_{2}$ 混合氧化物的炭烟燃 烧机理. 该反应机理包括超氧化物, 过氧化物, O-空位

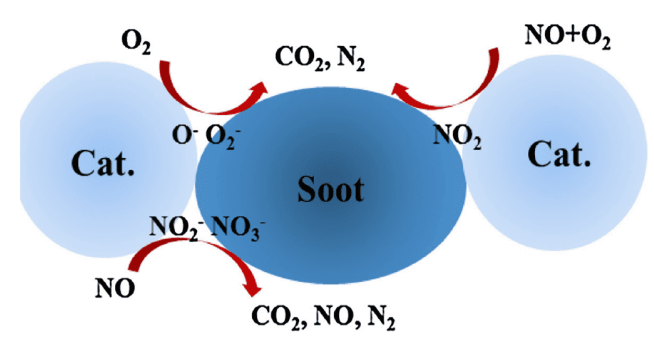

图 $17 \mathrm{Co}-\mathrm{CeO}_{2}$ 混合氧化物上炭烟燃烧的一般反应途径 ${ }^{[194]}$ (网络版彩图)

Figure 17 A general reaction pathway of soot combustion over Co$\mathrm{CeO}_{2}$ mixed oxides [194] (color online). 

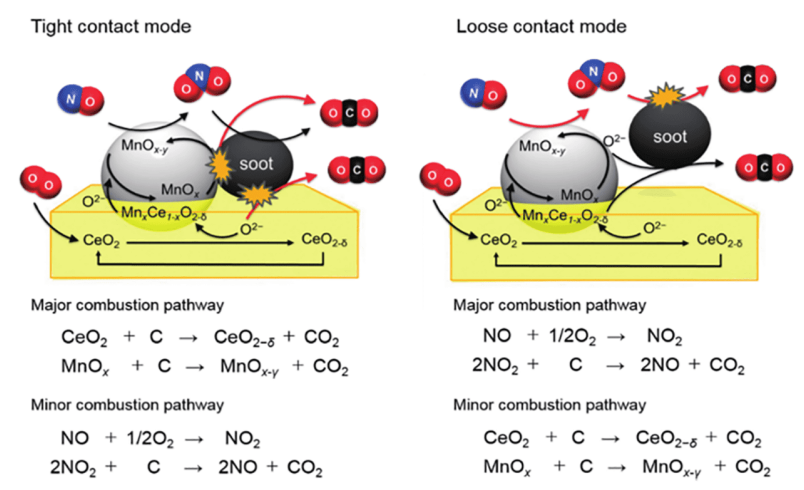

图 18 炭烟与 $\mathrm{MnCeO}$ 催化剂紧密和松散接触模式下的燃烧 机理示意图 ${ }^{[99]}$ (网络版彩图)

Figure 18 Schematic illustrations of soot combustion mechanism under tight and loose contact mode with $\mathrm{MnCeO}$ catalysts [99] (color online).

(弗伦克尔型氧空位 $\left(\mathrm{F}-\mathrm{O}_{\mathrm{V}}\right.$ 和固有氧空位 $\left.\left(\mathrm{I}-\mathrm{O}_{\mathrm{V}}\right)\right)$ 的形 成，溢出过程和再氧化过程. 如图19所示，其催化机 理如下所述: (1) 将炭烟引入系统中, 通过溢流程序并 随后形成 $\mathrm{O}$ 空位，从氧化物表面除去氧后，会生成非 化学计量的二氧化铈氧化物，同时逸出的活性氧参与 炭烟燃烧.（2）然后通过气相或地下氧气迅速填充表 面 $\mathrm{O}$ 空位. (3) 交替还原-氧化过程可按照以下方案进 行: $\mathrm{O}_{2(\mathrm{~g})} \leftrightarrow\left[\mathrm{O}_{2(\text { ads })}\right] \leftrightarrow\left[\mathrm{O}_{2}{ }^{-}\right.$(ads) $] \leftrightarrow\left[\mathrm{O}_{2}{ }^{2-}{ }_{\text {(ads) }}\right] \leftrightarrow\left[2 \mathrm{O}^{-}{ }_{\text {(ads) }}\right] \leftrightarrow$ $\left[\mathrm{O}_{2}^{-}\right.$(lattice) $]$.

除了 Mn，Co改性的铈基氧化物外，其它过渡金属 改性铈基氧化物催化剂的机理也有研究. Zhang 等 ${ }^{[98]}$ 通过动力学研究探索了 $\mathrm{Fe}$ 掺杂 $\mathrm{CeO}_{2}$ 混合氧化物对炭 烟燃烧的作用，发现催化反应是通过氧化还原机理进 行的. 在一个反应循环中, $\mathrm{Fe}$ 的作用是生成 $\mathrm{Fe}^{3+}, \mathrm{Fe}^{3+}$ 与活性氧结合并与炭烟发生反应，而还原后的 $\mathrm{Fe}^{2+}$ 在 $\mathrm{Ce}$ 的作用下很容易被氧化为 $\mathrm{Fe}^{3+}$. 因此, 活性位点是由 $\mathrm{Fe}-\mathrm{O}-\mathrm{Ce}$ 组成的. Rico-Pérez等 ${ }^{[195]}$ 根据XRD、拉曼光 谱和 $\mathrm{H}_{2}-\mathrm{TPR}$ 等多种表征结果提出了 $\mathrm{CuCePr}+\mathrm{CePr}$ 催 化剂的反应机理. 如图20所示, 该反应机理由活性氧机 制和 $\mathrm{NO}_{x}$ 辅助机制共同组成. 活性氧机制: 催化剂通过 氧交换过程充当氧化还原中心，将氧气从气相 $\mathrm{O}_{2}$ 转移 到炭烟中，并在炭烟和催化剂之间的接触/界面区域引 发催化剂还原，形成还原位点，该位点被气相 $\mathrm{O}_{2}$ 再氧 化. 从催化剂转移到炭烟的活性氧可以有效地氧化炭 烟颗粒, 使其直接接触. $\mathrm{NO}_{x}$ 辅助机制: 首先, $\mathrm{CuO}$ 有效 的吸附 $\mathrm{NO}$, 并与 $\mathrm{Ce}_{0.5} \mathrm{Pr}_{0.5} \mathrm{O}_{2-\delta}$ 载体产生的氧源在 $\mathrm{CuO}$ $\mathrm{Ce}_{0.5} \mathrm{Pr}_{0.5} \mathrm{O}_{2-\delta}$ 界面生成 $\mathrm{NO}_{2}$, 然后进行炭烟燃烧.

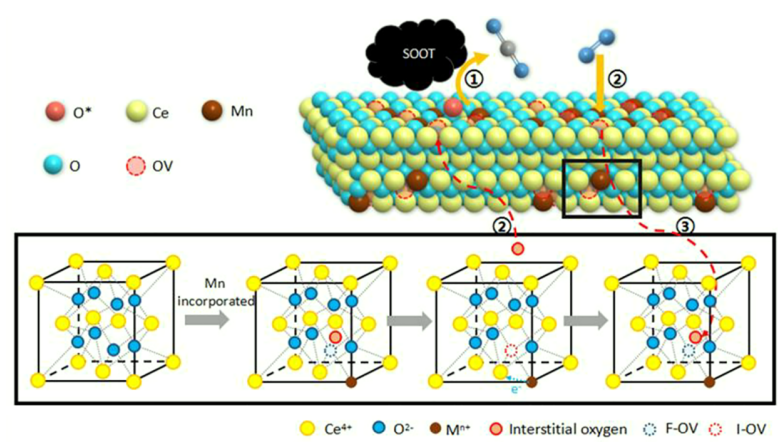

图 $19 \mathrm{MnO}_{x}-\mathrm{CeO}_{2}$ 混合氧化物的炭烟燃烧机理示意图 ${ }^{[101]}$ (网络版彩图)

Figure 19 Schematic diagram of soot combustion mechanism of $\mathrm{MnO}_{x}-\mathrm{CeO}_{2}$ mixed oxides [101] (color online).

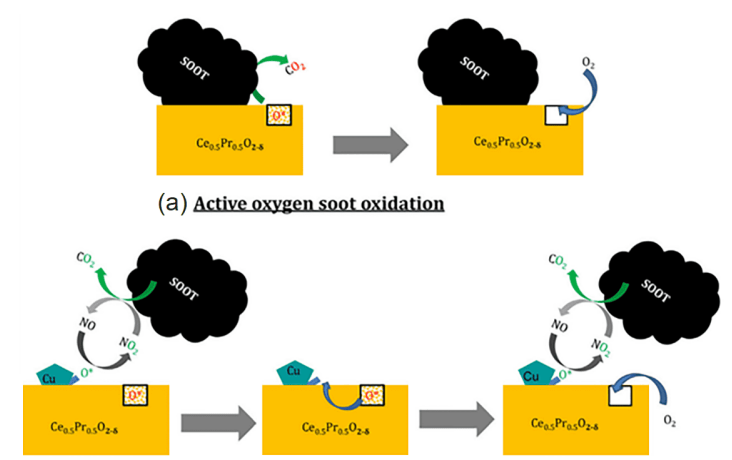

(b) $\mathrm{NO}_{2}$ assited soot oxidation

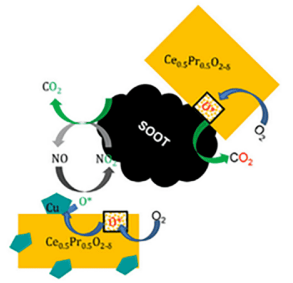

(c) General soot oxidation pathway

图 20 (a) 活性氧机理, (b) $\mathrm{NO}_{2}$ 辅助机理, (c) $\mathrm{CuCePr}+\mathrm{CePr}$ 催化剂上炭烟燃烧反应的整体机理 ${ }^{[195]}$ (网络版彩图)

Figure 20 (a) Active oxygen mechanism, (b) $\mathrm{NO}_{2}$-assisted mechanisms, (c) overall mechanism of reactions for soot combustion over $\mathrm{CuCePr}+\mathrm{CePr}$ catalysts [195] (color online).

$\mathrm{Ce}_{0.5} \mathrm{Pr}_{0.5} \mathrm{O}_{2-\delta}$ 载体中的所产生的空位由气相 $\mathrm{O}_{2}$ 填充.

Liu等 ${ }^{[165]}$ 利用Raman，XPS和 $\mathrm{O}_{2}-\mathrm{TPD}$ 等多种表征 结果提出了简化 $\mathrm{Ce}_{1-x} \mathrm{Zr}_{x} \mathrm{O}_{2}$ 催化剂在 $\mathrm{O}_{2}$ 氛围下对于炭 烟颗粒催化燃烧的机理，该机理为典型活性氧机制即 活性氧来源于催化剂的气态 $\mathrm{O}_{2}$ 和晶格 $\mathrm{O}^{2-}$ 如下所示:

$$
\begin{aligned}
& x / 2 \mathrm{O}_{2}+\mathrm{Ce}^{3+}-\mathrm{V}_{\mathrm{O}} \rightarrow \mathrm{Ce}^{4+}-\mathrm{O}_{y-x} \\
& \mathrm{Ce}^{4+}-\mathrm{O}_{y-x}+x / 2 \mathrm{C} \rightarrow x / 2 \mathrm{CO}_{2}+\mathrm{Ce}^{3+}-\mathrm{V}_{\mathrm{O}}
\end{aligned}
$$


$2 \mathrm{Ce}^{4+}-\mathrm{O}^{2-}-\mathrm{Ce}^{4+}+\mathrm{C} \rightarrow 2 \mathrm{Ce}^{3+}-\mathrm{O}^{2-}-\mathrm{Ce}^{3+}+\mathrm{CO}_{2}$

在催化剂表面上，气态 $\mathrm{O}_{2}$ 接受来自 $\mathrm{Ce}^{3+}$ 的电子并 与氧空位结合形成活性氧物种 $\left(\mathrm{O}_{2}{ }^{-}\right.$和 $\left.\mathrm{O}^{-}\right)$, 随后炭烟被 从催化剂表面溢出的活性氧氧化(式8、9). 此外, 催化 剂的晶格氧扩散到表面与自由碳原子反应，并伴随 $\mathrm{Ce}^{4+}$ 还原为 $\mathrm{Ce}^{3+}$ (式10). 此外, Atribak 等 ${ }^{[196]}$ 研究了 $\mathrm{Ce}_{0.76} \mathrm{Zr}_{0.24} \mathrm{O}_{2}$ 混合氧化物在 $\mathrm{NO}_{x} / \mathrm{O}_{2}$ 气氛中对的炭烟燃 烧的催化活性，并根据相关实验结果提出了反应机理. 如图21所示, $\mathrm{NO}$ 在整个 $\mathrm{NO}_{2}$ 形成过程中将氧从 $\mathrm{O}_{2}$ 分子 转移到炭烟表面, 并且催化剂的作用是促进 $\mathrm{NO}$ 氧化为 $\mathrm{NO}_{2}$. $\mathrm{NO}_{2}$ 启动表面氧化后, $\mathrm{O}_{2}$ 也会与炭烟反应. 催化剂 上适合于 $\mathrm{NO}$ 氧化成 $\mathrm{NO}_{2}$ 的表面位点数量取决于可用 的总面积(BET值), 这些表面位点的性质还取决于表面 上的金属分布. 同样, $\mathrm{Ai}$ 等 ${ }^{[167]}$ 也研究了 $\mathrm{Ce}-\mathrm{Zr}$ 固溶体的 反应机理. 他们发现催化剂中的晶格氧容易与炭烟反 应形成活性物质并生成 $\mathrm{CO}_{2}$, 同时在连续供气期间将 氧气供应至催化剂，填充了催化剂中的氧空位，从而 使催化剂再生.

过渡金属改性的铈基氧化物对炭烟的燃烧具有较 高的催化活性, 其催化原理主要有两种: 电子转移机理 (氧溢出机理)和氧转移机理(氧化还原机理) ${ }^{[197,198]}$. 电 子转移机理是以氧原子溢出为基础, 催化剂和碳元素 $\mathrm{p}$ 轨道上电子之间的相互作用引起 $\mathrm{C}-\mathrm{C}$ 键的减弱, 加快 了碳与分子氧之间的反应速率. 而氧转移机理这是通 过金属氧化物的氧化还原循环或增加从催化剂到催化 剂与碳表面的氧原子传递来实现.

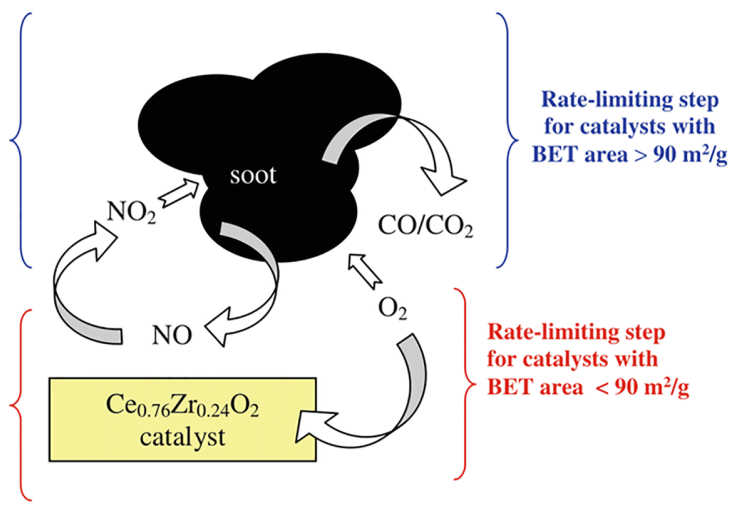

图 $21 \mathrm{Ce}_{0.76} \mathrm{Zr}_{0.24} \mathrm{O}_{2}$ 在 $\mathrm{NO}_{x} / \mathrm{O}_{2}$ 下催化炭烟燃烧的流程 ${ }^{[196]}$ (网络版彩图)

Figure 21 Scheme of the $\mathrm{Ce}_{0.76} \mathrm{Zr}_{0.24} \mathrm{O}_{2}$-catalysed soot combustion under $\mathrm{NO}_{x} / \mathrm{O}_{2}$ [196] (color online).

\subsection{3 贵金属改性的铈基氧化物催化炭烟燃烧机理}

在对贵金属改性的铈基催化剂的研究中，人们发 现铈基载体除了能够实现贵金属的高度分散，并发挥 自身储放氧能力之外，在贵金属-铈基载体的界面处还 会发生二者的相互作用，进而显著影响催化剂的性能. 这种相互作用不仅会改变贵金属状态，而且也会影响 铈基载体氧空位的形成, 进而改变催化剂的供氧能

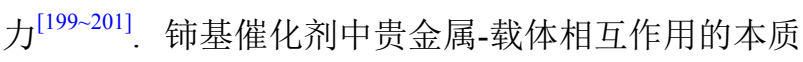
较为复杂，可将该作用定义为: 由于载体与贵金属之 间的电子转移或化学键生成, 而使得贵金属结构及电 子状态发生改变, 进而直接影响贵金属或载体的理化 性质及催化活性的作用 ${ }^{[202]}$. 近年来, 运用各种表征技 术研究炭烟在贵金属改性的铈基催化剂上燃烧的反应 机理, 证实了在炭烟催化燃烧过程中中间反应物质出 现. 随着研究的不断深入，不同贵金属改性的铈基氧 化物同的催化剂上的炭烟催化燃烧机理被研究人员 提出.

贵金属Pt和 $\mathrm{Au}$ 有利于活性氧的生成, 进而促进 $\mathrm{NO}$ 氧化为 $\mathrm{NO}_{2}$, 间接促进炭烟的燃烧. 此外, 贵金属与铈 基氧化物之间具有协同效应也能够促进 $\mathrm{NO}_{x}$ 转化为 $\mathrm{NO}_{2}$. Xiong等 ${ }^{[137]}$ 根据实验结果推测了 $\mathrm{PdAu} @ \mathrm{CeO}_{2} /$ 3DOMM-CZ催化剂可能的反应机理. 如图22所示, 有 序的分级多孔纳米结构提高了催化剂与反应物之间的 接触效率. 3DOMM-CZ载体不仅促进了反应物在催化 剂内部空间的传质，而且提供了更大的表面积来充分 分散活性位点. 其次, 由于 $\mathrm{PdAu}$ 合金核与 $\mathrm{CeO}_{2}$ 壳之间 的界面面积增加, 核壳纳米结构活性位点和氧化物壳/ 载体表现出SMSI效应增强, 提高反应过程中氧空位的 密度和氧化还原性能. 由氧空位和 $\mathrm{PdAu} @ \mathrm{CeO}_{2}$ 核壳位 点生成的活性氧有利于炭烟颗粒氧化为 $\mathrm{CeO}_{2}$ 和 $\mathrm{NO}$ 氧 化为 $\mathrm{NO}_{2}$, 其中 $\mathrm{NO}$ 氧化为 $\mathrm{NO}_{2}$ 是 $\mathrm{NO}_{2}$ 辅助催化机理中 炭烟燃烧的决定性步骤. 因此, $\mathrm{PdAu} @ \mathrm{CeO}_{2} / 3 \mathrm{DOMM}-$ $\mathrm{CZ}$ 催化剂结合了催化剂与反应物(炭烟、 $\mathrm{NO} 、 \mathrm{O}_{2}$ ) 良 好的接触效率和 $\mathrm{Pd}-\mathrm{Au}-\mathrm{CeO}_{2}$ 三元组分的氧活化协同 作用的优点, 对炭烟燃烧具有良好的催化活性和稳 定性.

Bueno-López和Andana等 ${ }^{[123,203]}$ 人认为 $\mathrm{Pt} / \mathrm{CeO}_{2}$ 催 化剂的炭烟燃烧过程在不存在 $\mathrm{NO}_{x}$ 时遵循以下三个步 骤: (1) 氧在相邻的两个 Pt位上的解离吸附; (2) 氧从 $\mathrm{Pt}$ 位转移到 $\mathrm{CeO}_{2}$ 表面(氧溢出); (3) 炭烟与从 $\mathrm{CeO}_{2}$ 表面/ 

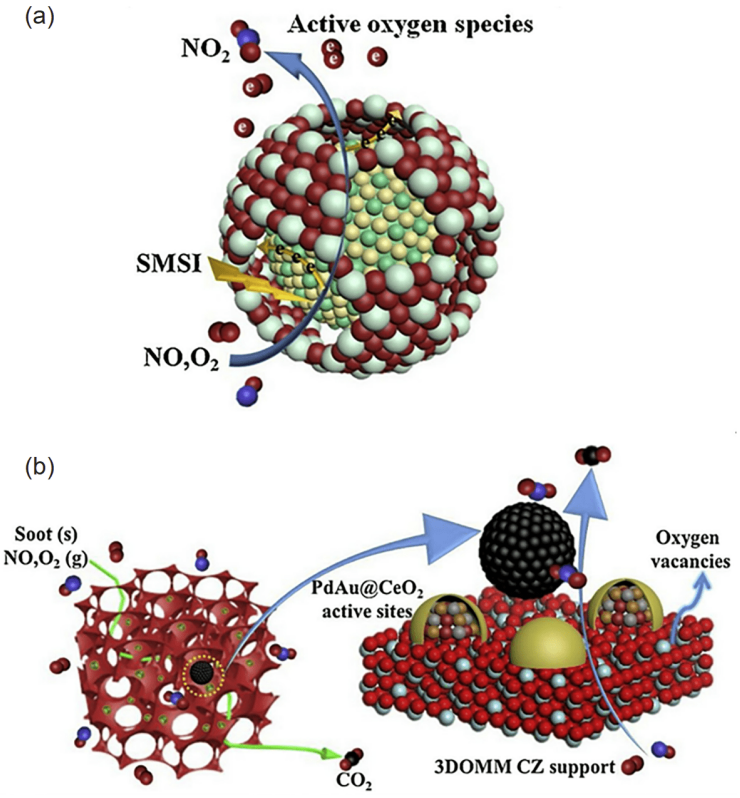

图 22 (a) $\mathrm{PdAu} @ \mathrm{CeO}_{2}$ 核壳活性中心的催化机理. (b) $\mathrm{PdAu} @ \mathrm{CeO}_{2} / 3 \mathrm{DOMM}-\mathrm{CZ}$ 催化剂在松散接触条件下燃烧炭 烟的机理 ${ }^{[137]}$ (网络版彩图)

Figure 22 (a) Catalytic mechanism of $\mathrm{PdAu} @ \mathrm{CeO}_{2}$ core-shell active sites. (b) Mechanism illustration of $\mathrm{PdAu} @ \mathrm{CeO}_{2} / 3 \mathrm{DOMM}-\mathrm{CZ}$ catalysts for soot combustion under the loose contact [137] (color online).

晶格中释放出来的所谓“活性氧物种”之间的接触. 在 这一机制中，Pt只参与了体相向 $\mathrm{CeO}_{2}$ 表面的氧捕获和 转移. 而在 $\mathrm{NO}_{x}$ 存在的情况下, 炭烟的燃烧基本上结合 了前三种反应. 该机制中 $\mathrm{NO}$ 在 $\mathrm{Pt}$ 表面上转化为 $\mathrm{NO}_{2}$, 而 $\mathrm{NO}_{2}$ 氧化性较强, 会直接与炭烟颗粒进行反应, 形成称 为“表面氧化碳”(SOC)的不稳定的碳一氧化合物. 最终, 无论是否与氧化剂 $\left(\mathrm{NO}_{2}\right.$ 和 $\left.\mathrm{O}_{2}\right)$ 反应, SOC都会进一步分 解, 生成 $\mathrm{CO} 、 \mathrm{CO}_{2}$ 和 $\mathrm{NO}$.

Wei等 ${ }^{[204]}$ 通过不同表征技术研究了 $3 \mathrm{DOM}$ $\mathrm{Pt} @ \mathrm{CeO}_{2-\delta}-\mathrm{rich} / \mathrm{Ce}_{1-x} \mathrm{Zr}_{x} \mathrm{O}_{2}$ 炭烟燃烧催化剂的性能，并 提出了该催化对炭烟燃烧的催化机理如图23所示:首 先，3DOM结构可以提高催化剂与炭烟颗粒的接触效 率. 其次, 3DOM氧化物上自组装的富含 $\mathrm{Pt} @ \mathrm{CeO}_{2-\delta}$ 的 核壳型纳米颗粒 $(\mathrm{NPs})$ 增加了 $\mathrm{O}_{2}$ 活化的活性位点 $\left(\mathrm{O}_{\mathrm{V}}\right)$ 密度. 最后, $\mathrm{Pt} @ \mathrm{CeO}_{2-\delta}$ 核壳型NPs表面的活性氧物种 可以转移到炭烟粒子表面，将其氧化为 $\mathrm{CO}_{2}$. 因此，该 催化剂结合了 $3 \mathrm{DOM}$ 氧化物与催化剂-炭烟的良好接 触和核壳结构的Pt@ $\mathrm{CeO}_{2-\delta}$ 纳米粒子的高氧空位密度 的优点, 表现出对柴油机炭烟燃烧的优异催化性能.

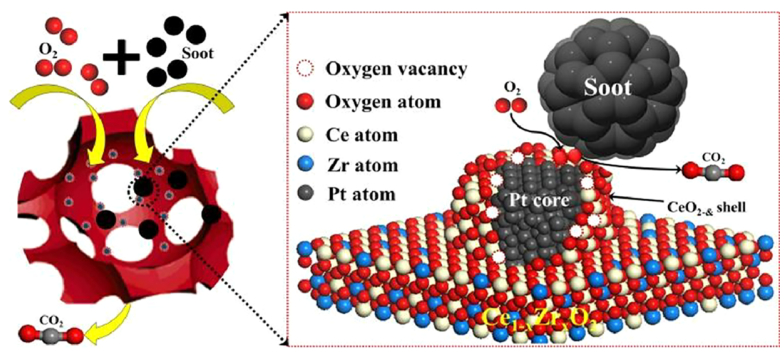

图 23 用于炭烟燃烧的 $3 \mathrm{DOM}-\mathrm{Ce}_{1-x} \mathrm{Zr}_{x} \mathrm{O}_{2}$-负载Pt@ $\mathrm{CeO}_{2-\delta}$ 核一壳NPs的示意图 ${ }^{[204]}$ (网络版彩图)

Figure 23 The catalytic mechanism of $3 \mathrm{DOM}-\mathrm{Ce}_{1-x} \mathrm{Zr}_{x} \mathrm{O}_{2}$-supported $\mathrm{Pt} @ \mathrm{CeO}_{2-\delta}$-rich core-shell NPs for soot combustion [204] (color online).

Zou等 ${ }^{[135]}$ 利用各种技术表征 $\mathrm{Ag} / \mathrm{Co}_{0.93} \mathrm{Ce}_{0.07}$ 催化 剂的性能，并提出了该催化剂在 $\mathrm{O}_{2}$ 氛围下对于炭烟催 化燃烧的机理:

低温阶段: $\mathrm{AgO}_{y}+\mathrm{C} \rightarrow \mathrm{Ag}+\mathrm{C} *[\mathrm{O}]$

$$
\begin{aligned}
& \mathrm{Ag}+\mathrm{O}_{2} \rightarrow \mathrm{O}_{\text {ads }} \\
& \mathrm{Ag}^{\delta+} \rightarrow \mathrm{O}_{2}{ }^{-} / \mathrm{O}^{-}+\mathrm{Ag}^{\delta+} \\
& \mathrm{C}+\mathrm{O}_{2}{ }^{-} \rightarrow \mathrm{C}^{*}[\mathrm{O}] \\
& \mathrm{C}^{*}[\mathrm{O}]+\mathrm{O}_{2}{ }^{-} / \mathrm{O}^{-} \rightarrow \mathrm{CO}_{2} \\
& \mathrm{Ag}+\mathrm{O}_{\mathrm{ads}} \rightarrow \mathrm{AgO}_{y}
\end{aligned}
$$

高温阶段: $\mathrm{O}_{2}+\mathrm{Ag} \rightarrow \mathrm{Ag}^{\delta+}+\mathrm{O}_{2}{ }^{-} / \mathrm{O}^{-}$

$$
\begin{aligned}
& \mathrm{C}+\mathrm{O}_{2}{ }^{-} / \mathrm{O} \rightarrow \mathrm{C}^{*}[\mathrm{O}] \\
& \mathrm{C} *[\mathrm{O}]+\mathrm{O}_{2}{ }^{-} / \mathrm{O}^{-} \rightarrow \mathrm{CO}_{2}
\end{aligned}
$$

所提出的反应机理和途径可以根据温度的不同概 括为两个阶段. 首先, 在低温阶段 $\mathrm{AgO}_{y}$ 分解并形成 $\mathrm{Ag}$ 单质和碳氧中间体. 接着, 气相氧吸附在 $\mathrm{Ag}$ 的表面形 成活性氧物种，同时活性氧侵蚀炭烟以形成碳氧中间， 并造成氧化. 最后, $\mathrm{Ag}$ 上的吸附氧 $\left(\mathrm{O}_{\mathrm{ads}}\right)$ 促进了 $\mathrm{AgO}_{y}$ 再 生过程. 而由于 $\mathrm{AgO}_{y}$ 不能在高温下稳定存在, $\mathrm{Ag}$ 解离 活性氧成为反应的关键，这些活性氧物质会加速炭烟 颗粒燃烧. 因此，在 $\mathrm{O}_{2}$ 存在的情况下银表面的氧化银 是关键的氧化剂, 并且可以在低温下再生. Liu等 ${ }^{[175]}$ 采 用水热法和浸渍法成功合成了比较具有不同形貌的 $\mathrm{Ag} / \mathrm{CeO}_{2}$ 催化剂，并提出了其催化燃烧炭烟颗粒的相 关反应机理, 如图24所示. 在单一 $\mathrm{CeO}_{2}$ 表面, 反应氛围 中的气相氧通过 $\mathrm{CeO}_{2}$ 转变为活性氧的速率较慢, 导致 催化剂的活性较低; 而在 $\mathrm{Ag} / \mathrm{CeO}_{2}$ 表面, $\mathrm{Ag}$ 作为集氧剂 促进了 $\mathrm{O}_{x}{ }^{-}$的形成, 如果 $\mathrm{Ag}$ 纳米颗粒恰巧与炭烟紧密 


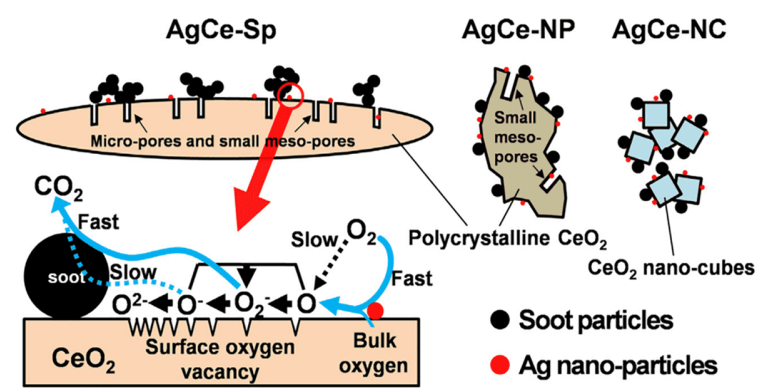

图 $24 \mathrm{Ag} / \mathrm{CeO}_{2}$ 催化剂上炭烟燃烧反应机理 ${ }^{[175]}$ (网络版彩 图)

Figure 24 Scheme of the soot combustion over the $\mathrm{Ag} / \mathrm{CeO}_{2}$ catalysts [175] (color online).

接触，则 $\mathrm{O}_{x}^{-}$可以直接催化燃烧炭烟颗粒，若是炭烟颗 粒与 $\mathrm{Ag}$ 纳米颗粒没有紧密接触，则氧物种通过以下方 式: $2 \mathrm{O} \rightarrow \mathrm{O}^{2-} \rightarrow 2 \mathrm{O}^{-} \rightarrow 2 \mathrm{O}^{2-}$ 来形成活性氧, 最终催化燃 烧炭烟颗粒. 除了上述介绍的机理外, 还有许多贵金属 改性的铈基氧化物催化剂用于炭烟燃烧的机理被研 究, 如 $\mathrm{Pt} / \mathrm{Ce}_{0.27} \mathrm{Zr}_{0.73} \mathrm{O}_{2}^{[205]} 、 \mathrm{Pt} / \mathrm{Ce}_{0.27} \mathrm{Zr}_{0.70} \mathrm{La}_{0.03} \mathrm{O}_{x}^{[205]}$ 、 $\mathrm{Pt} / \mathrm{Ce}_{0.6} \mathrm{Zr}_{0.4} \mathrm{O}_{2}{ }^{[173]} 、 \mathrm{Pt} @ \mathrm{CeO}_{2-x} / \mathrm{ZrO}_{2}{ }^{[126]} 、 \mathrm{Au} / \mathrm{CeO}_{2} / 3 \mathrm{DOM}$ $\mathrm{Al}_{2} \mathrm{O}_{3}{ }^{[127]} 、 \mathrm{Ag} / \mathrm{CeO}_{2}-\mathrm{ZrO}_{2}{ }^{[176]}$ 等. 在这些机理中，贵金 属与铈基氧化物之间的协同作用进一步得到深入的研 究, 为设计和开发高活性的催化剂提供了理论指导.

贵金属改性的铈基氧化物机理主要可以分为两 类: (1) 直接催化氧化路径的反应机理. 贵金属-载体之 间的强相互作用，促使铈基氧化物载体中晶格氧的迁 移能力增加，从而导致催化剂表面活性氧物种的数量 增加，大大提高了催化剂的氧化还原性能，为炭烟颗 粒物的深度氧化提供了充足的活性位点. (2) 间接催 化氧化路径的反应机理. 贵金属纳米颗粒对分子氧的 吸附和活化产生的活性氧物种, 在适当温度下促进 $\mathrm{NO}$ 催化氧化为 $\mathrm{NO}_{2}, \mathrm{NO}_{2}$ 具有比 $\mathrm{O}_{2}$ 强的吸附和氧化性能, 从而提高了炭烟颗粒物的燃烧效率. 而在炭烟燃烧反 应过程中，在直接催化氧化路径和间接催化氧化物路 径的共同作用下进行.

\subsection{4 碱(碱土)金属改性的铈基氧化物催化炭烟燃 烧机理}

炭烟催化反应涉及氧化还原机制，在典型的还原/ 氧化机制中，催化剂表面的氧通过接触点转移到烟尘 中，催化剂部分还原. 催化剂表面产生的氧缺陷分别 通过表面迁移和气相氧的最终再氧化来填充，或者通
过扩散体氧来填充. 晶格的氧不足通过氧从表面或次 表面迁移到催化剂本体来平衡. 碱金属能够加速铈基 氧化物表面超氧化物和过氧化物的形成，引发炭烟的 燃烧. 表面氧作为炭烟颗粒在催化剂表面反应过程中 的主要氧化剂，其迁移率对于催化活性的提高是必不 可少的．通过良好的催化剂/炭烟接触，在碱金属上形 成活性氧的高迁移性有利于促进炭烟燃烧. 而 $\mathrm{Ba} 、 \mathrm{Ca}$ 和 $\mathrm{Mg}$ 等碱土金属相对于碱金属的迁移率低, 因此在碱 土金属改性的催化剂上很难观察到上述对炭烟燃烧的 促进作用 ${ }^{[206]}$.

碱金属化合物由于具有供电子效应，可以提高氧 化铈的催化活性，增加邻近碳位的局部电子密度和与 氧原子结合的亲和力. Gross等 ${ }^{[207]}$ 研究了 $\mathrm{KNO}_{3}$ 担载到 $\mathrm{CeO}_{2}$ 载体上所制备的催化剂应用于炭烟颗粒的催化 燃烧的反应机制, 如图25所示, $\mathrm{KNO}_{3}$ 的引入有利于吸 附态 $\mathrm{CO}_{2}$ 形成 $\mathrm{K}_{2} \mathrm{CO}_{3}$, 随后 $\mathrm{K}_{2} \mathrm{CO}_{3}$ 分解成 $\mathrm{CO}_{2}$ 和 $\mathrm{K}_{2} \mathrm{O}$, $\mathrm{K}_{2} \mathrm{O}$ 与氮氧化物反应生成 $\mathrm{KNO}_{3}$ 完成 $\mathrm{KNO}_{3}$ 在催化循 环中的作用, $\mathrm{CeO}_{2}$ 和 $\mathrm{KNO}_{3}$ 相互循环作用有利于提高 催化剂的活性.Wang等 ${ }^{[208]}$ 通过第一性DFT原理系统 地计算了在有/无氧空位 $\left(\mathrm{O}_{\mathrm{vac}}\right)$ 的炭烟 $/ \mathrm{CeO}_{2}$ (111)界面 上石墨烯型炭烟的分子水平氧化机理，并研究了碱金 属 $\mathrm{K}^{+}$对炭烟燃烧对 $\mathrm{CeO}_{2}$ (111)的促进作用. 结果表明, $\mathrm{K}^{+}$占据阳离子亚晶格会显著降低 $\mathrm{CeO}_{2}(111)$ 的形成能, 从而提高 $\mathrm{CeO}_{2}$ 催化剂的晶格氧 $\left(\mathrm{O}_{\mathrm{lat}}\right)$ 反应活性和 $\mathrm{O}_{\mathrm{vac}}$ 浓 度. 此外, 吸附的钾离子可以提高分子氧在 $\mathrm{K} / \mathrm{CeO}_{2}$ (111)铈界面的吸附. Huang 等 ${ }^{[147]}$ 分析了以 $\mathrm{K}$ 掺杂的 $\mathrm{Ce}_{0.5} \mathrm{Mn}_{0.5} \mathrm{O}_{2}$ 为催化剂对炭烟的催化氧化机理. 对于 $\mathrm{K}$ 掺杂的 $\mathrm{Ce}_{0.5} \mathrm{Mn}_{0.5} \mathrm{O}_{2}$ 催化剂, $\mathrm{K}$ 位点上的活性氧自由基 溢出到炭烟表面，与游离碳位点反应生成具有 $\mathrm{C}=\mathrm{C}=\mathrm{O}$ 结构的烯酮基团. 同时, K位点通过激活周围的气态氧,

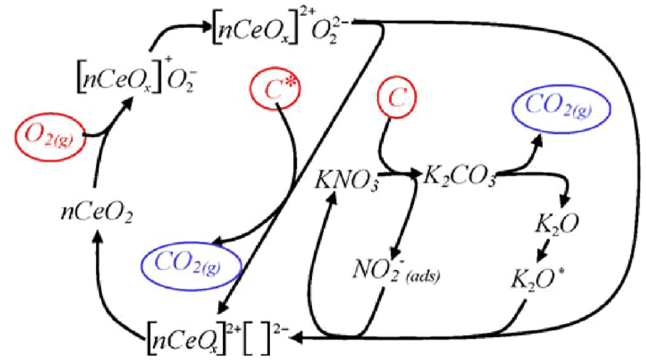

图 $25 \mathrm{~K} / \mathrm{CeO}_{2}$ 催化剂上炭烟燃烧的反应机理 ${ }^{[207]}$ (网络版彩 图)

Figure 25 Reaction mechanism for the soot combustion on $\mathrm{K} / \mathrm{CeO}_{2}$ catalysts [207] (color online). 
增强晶格氧的迁移率, 使催化剂中活性氧的补充, 直到 炭烟被完全催化氧化为 $\mathrm{CO}_{2}$. 而通过对气相氧或表面 晶格氧的化学吸附离解能补充消耗的 $\mathrm{K}$ 表面的活性氧. $\mathrm{Li}^{\text {等 }}{ }^{[141]}$ 结合密度泛函理论计算结果和炭烟燃烧的原 位红外光谱，证实了 $\mathrm{Cs}_{2} \mathrm{O}$ 对 $\mathrm{O}_{2}$ 和炭烟的电子供体比在 $\mathrm{K}_{2} \mathrm{O}$ 上容易, 并提出了 $\mathrm{Cs}-$ 负载型氧化物上炭烟燃烧的 给电子机制. 如下所示, $\mathrm{Cs}-$ 负载型氧化物上的炭烟燃 烧反应可以分为以下三个阶段:

$\mathrm{M}-\mathrm{O}-\mathrm{M}+\mathrm{O}_{2} \rightarrow \mathrm{O}_{2}{ }^{x-}-(\mathrm{M}-\mathrm{O}-\mathrm{M})^{x+}$

$\mathrm{M}-\mathrm{O}-\mathrm{M}+\operatorname{soot} \rightarrow \operatorname{soot}^{x-} \rightarrow \operatorname{soot}^{x-}-(\mathrm{M}-\mathrm{O}-\mathrm{M})^{x+}$

$\mathrm{O}_{2}{ }^{x-}-(\mathrm{M}-\mathrm{O}-\mathrm{M})^{x+}+$ soot $^{x-}-(\mathrm{M}-\mathrm{O}-\mathrm{M})^{x+}+-\mathrm{C}=\mathrm{C}=\mathrm{O}+$

$\rightarrow \mathrm{M}-\mathrm{O}-\mathrm{M}+\mathrm{CO}_{2}$

首先, Cs-O-Cs给予 $\mathrm{O}_{2}$ 电子, 形成活性氧物种 (式11). 与此同时, 类似电子给予过程 $\mathrm{Cs}-\mathrm{O}-\mathrm{Cs}$ 与炭烟 通过含氧基团进行，导致炭烟的激活(式12). 然后，生 成的活性氧与活性炭烟通过和乙烯酮 $(-\mathrm{C}=\mathrm{C}=\mathrm{O})$ 反应 中间体生成 $\mathrm{CO}_{2}$ 产物, 并回收 $\mathrm{Cs}-\mathrm{O}-\mathrm{Cs}$ (式13).

众所周知，碱金属的作用主要基于以下几个因素: (1)碱金属盐的低熔点和流动性大大增加炭烟与催化 剂的接触; (2)碱金属作为强碱性位点，在催化剂上储 存 $\mathrm{NO}_{x}$ 硝酸盐和亚硝酸盐, 并在较高的温度下分解释 放 $\mathrm{NO}_{x}$, 协助炭烟燃烧(在这个过程中氧化还原机理仍 然是主要的反应机理)。然而，尽管含 $\mathrm{K} 、 \mathrm{Cs}$ 催化剂具 有很高的活性，但由于其 $\mathrm{K} 、 \mathrm{Cs}$ 物种的熔点和溶解度 较低, 特别是在存在水的情况下, 其稳定性较低. 碱土 金属如Ba也具有较高的 $\mathrm{NO}_{x}$ 储存能力, 因此在Ba改性 的铈基氧化物催化燃烧机理得到广泛研究. Guan 等 ${ }^{[152]}$ 利用原位红外表征技术提出了 $\mathrm{BaFeCoO}_{2-\delta}$ 催化 剂在 $\mathrm{NO}$ 和 $\mathrm{O}_{2}$ 氛围下对于炭烟催化燃烧的机理:

$$
\begin{aligned}
& 2 \mathrm{C}+3 \mathrm{O}^{-} \rightarrow \mathrm{CO}+\mathrm{CO}_{2} \\
& 4 \mathrm{C}+3 \mathrm{O}^{2-} \rightarrow 2 \mathrm{CO}+\mathrm{CO}_{2} \\
& 2 \mathrm{NO}+\mathrm{O}_{2} \rightarrow 2 \mathrm{NO}_{2} \\
& \mathrm{C}+2 \mathrm{NO}_{2} \rightarrow 2 \mathrm{NO}+\mathrm{CO}_{2} \\
& \mathrm{C}+\mathrm{NO}_{2} \rightarrow \mathrm{NO}+\mathrm{CO} \\
& 2 \mathrm{NO}+\mathrm{O}^{2-} \rightarrow 2 \mathrm{NO}_{2}^{-} \\
& \mathrm{NO}_{2}+\mathrm{O}^{-} \rightarrow \mathrm{NO}_{3}^{-} \\
& \mathrm{NO}^{-} \mathrm{O}^{-} \rightarrow \mathrm{NO}_{2}^{-} \\
& 2 \mathrm{NO}_{3}^{-}+2 \mathrm{C} \rightarrow \mathrm{N}_{2}+\mathrm{CO}+\mathrm{CO}_{2}+3 \mathrm{O}^{-} \\
& 2 \mathrm{NO}_{2}{ }^{-}+2 \mathrm{C} \rightarrow \mathrm{N}_{2}+\mathrm{CO}+\mathrm{CO}_{2}+\mathrm{O}^{-}
\end{aligned}
$$

$4 \mathrm{NO}+3 \mathrm{O}_{2}+2 \mathrm{BaO} \rightarrow 2 \mathrm{Ba}\left(\mathrm{NO}_{3}\right)_{2}$

$4 \mathrm{NO}_{2}+\mathrm{O}_{2}+2 \mathrm{BaO} \rightarrow 2 \mathrm{Ba}\left(\mathrm{NO}_{3}\right)_{2}$

$2 \mathrm{Ba}\left(\mathrm{NO}_{3}\right)_{2} \rightarrow 2 \mathrm{Ba}+4 \mathrm{NO}+3 \mathrm{O}_{2}$

$2 \mathrm{Ba}\left(\mathrm{NO}_{3}\right)_{2} \rightarrow 2 \mathrm{Ba}+4 \mathrm{NO}_{2}+\mathrm{O}_{2}$

$\mathrm{C}+\mathrm{O}_{2} \rightarrow \mathrm{CO}_{2}$

$2 \mathrm{C}+\mathrm{O}_{2} \rightarrow 2 \mathrm{CO}$

通过以上分析讨论，在炭烟- $\mathrm{NO}-\mathrm{O}_{2}$ 反应体系中, 炭烟在 $\mathrm{BaFeCoO}$ - 催化剂上进行的催化燃烧反应存在 四种反应路径. 第一, 铈基催化剂表面的活性氧物种 $\mathrm{O}^{-}$和 $\mathrm{O}^{2-}$ 可以与炭烟颗粒反应并释放 $\mathrm{CO}$ 和 $\mathrm{CO}_{2}$ (式 $14 、 15)$. 第二, $\mathrm{NO}$ 可以很容易地转化为 $\mathrm{NO}_{2}$ (式16), $\mathrm{NO}_{2}$ 对炭烟的燃烧能力远高于 $\mathrm{O}_{2}$ 和 $\mathrm{NO}$, 可引发炭烟燃 烧(式17、18). 第三, 在较低温度下 $\mathrm{NO}$ 和 $\mathrm{NO}_{2}$ 与活性氧 物种反应(式19 21), 生成表面亚硝酸盐和硝酸盐物种 直接与炭烟反应, 并转化为 $\mathrm{N}_{2}$ (式22、23). 在较高温度 下 $\mathrm{NO}$ 和 $\mathrm{NO}_{2}$ 与气相氧反应形成 $\mathrm{Ba}\left(\mathrm{NO}_{3}\right)_{2}$ 物种(式 24 、

25 ), 然后 $\mathrm{Ba}\left(\mathrm{NO}_{3}\right)_{2}$ 的分解产生大量 $\mathrm{NO}_{2}$ 将炭烟燃烧(式 $26 、 27)$. 第四, 气相 $\mathrm{O}_{2}$ 的连续补充的直接贡献不能排 除， $\mathrm{O}_{2}$ 可以在高温下引发炭烟燃烧(式28、29). 此外, Lin等 ${ }^{[151]}$ 研究了通过 $\mathrm{Ba}$ 改性的 $\mathrm{CuO}_{x}-\mathrm{CeO}_{2}$ 催化剂在 $\mathrm{NO}$ 和 $\mathrm{O}_{2}$ 气氛下催化燃烧炭烟颗粒的反应机制. 炭烟在 $\mathrm{BaCuCe}$ 上的催化燃烧反应路线可主要分为三个连续 步骤, 如图 $26 \mathrm{a}, \mathrm{b}$ 所示. 首先, 当温度升高到 $250^{\circ} \mathrm{C}$ 时, $\mathrm{NO}$ 被氧化. 同时硝酸盐物种优先在 $\mathrm{Cu}^{x+}$ 和 $\mathrm{Ce}^{x+}$ 活性位 上形成, 转移到相邻的 $\mathrm{BaCO}_{3}$ 上, 形成 $\mathrm{Ba}\left(\mathrm{NO}_{3}\right)_{2}$

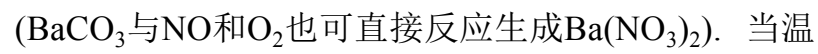
度升至 $350^{\circ} \mathrm{C}$ 时, 储存的硝酸盐通过释放的 $\mathrm{NO}_{2}$ 与炭烟 颗粒反应和/或直接催化分解. 最终, 局部热量引发 $\mathrm{O}_{2}$ 对炭烟颗粒的大量氧化.

在炭烟燃烧反应过程中，碱金属改性除了起到炭 (a)

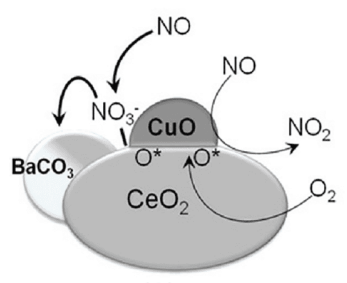

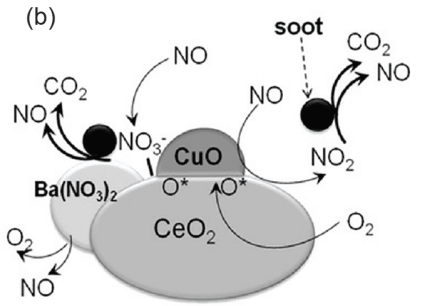

图 26 (a) 低温下的 $\mathrm{NO}_{x}$ 存储, (b) $\mathrm{BaCuCe}$ 催化剂上的 $\mathrm{NO}_{x}$ 辅 助炭烟燃烧 [151]

Figure 26 (a) $\mathrm{NO}_{x}$ storage at low temperatures and (b) $\mathrm{NO}_{x}$-assisted soot combustion on $\mathrm{BaCuCe}$ catalyst [151]. 
烟与催化剂的接触促进剂作用外, 还可能通过“碳酸盐 辅助”机制加速炭烟的燃烧反应. 而碱土金属(Ba)改性 可以实现硝酸盐分解温度和炭烟燃烧温度之间的匹 配, 从而有效的提高柴油机炭烟催化氧化.

\section{4 总结与展望}

近年来, 柴油机尾气炭烟颗粒已经成为城市雾䨪 天气的主要原因之一. 统计表明, 柴油机尾气炭烟颗 粒排放量超过汽车排放总量的 $90 \%$. 因此, 降低和消除 柴油车尾气炭烟颗粒是柴油车尾气催化净化的重要控 制步骤, 开展消除炭烟颗粒的研究具有深远的意义. 中 国是稀土资源大国, 其中 $\mathrm{Ce}$ 的储量最为丰富. 大量研 究表明, 铈基催化剂对炭烟的燃烧有很高的催化活性, 是一类具有应用潜力的催化剂且在汽油车尾气处理方 面已经广泛的应用. 如果将铈基氧化物催化剂广泛应 用于柴油机尾气炭烟颗粒的催化消除, 将极大地开拓 稀土氧化铈的应用市场. 本文详细介绍了氧化铈催化 剂及金属改性的铈基氧化物催化剂对炭烟颗粒的催化 性能以及反应机理. 不同的铈基氧化物催化剂具有其 自身独特的物化性质和优缺点. 如: 单一氧化铈催化 剂活性较好, 但热稳定性差; 稀土改性铈基氧化物催 化剂稳定性好, 但对 $\mathrm{NO}_{x}$ 氧化能力有限; 过渡金属改性 铈基氧化物催化剂活性较好, 但稳定性及抗水耐硫性 有待提高; 贵金属改性铈基氧化物催化剂活性高且选 择性好, 但成本昂贵且易中毒; 碱(碱土)改性的铈基氧 化物催化剂活性大幅度提升, 但稳定性不理想. 因此, 铈基氧化物催化剂在催化炭烟燃烧的研究中虽然已经 取得了一定的进展, 但是还有许多问题仍需解决.

（1）铈基催化剂设计与制备问题. 目前, 多种形貌 以及不同金属改性的铈基氧化物材料已经成功制备出 来且在炭烟颗粒的催化燃烧中展示出较好的催化活 性, 但大部分的制备方法并不能够直接转化为工业化应 用. 为实现铈基催化剂的规模化应用, 亟需开发过程简
单, 耗时短, 且性能保持优良的制备方法. 同时, 基于 炭烟颗粒催化燃烧是一类气 $\left(\mathrm{O}_{2}\right)$-固(炭烟颗粒)-固(催 化剂)三相复杂的深度氧化反应, 铈基氧化物催化剂的 设计和制备还应考虑如何提高催化剂与炭烟颗粒间的 接触效率以及低温活化氧的能力这两个关键的因素.

(2) 低温冷启动问题. 低温冷启动作为柴油车常用 的工况之一, 需要铈基氧化物催化剂的在低温下具有 较高的去除炭烟颗粒的能力, 但报道的催化剂的低温 活性还有待进一步提高. 目前, 贵金属担载型催化剂 具有较高的低温活性, 如何开发非贵金属的铈基氧化 物催化剂, 从铈基催化剂形貌、表面积及氧化还原性 等物化参数方面进行优化, 从而提高铈基氧化物催化 剂低温冷启动活性.

(3) 反应机理问题. 柴油机尾气中涉及到的化学反 应相当复杂有炭烟、VOCs、CO、 $\mathrm{SO}_{2}$ 的氧化反应和 $\mathrm{NO}$ 的还原反应等, 特别是, 由于炭烟为深黑色, 缺乏有 效表征手段对炭烟的催化反应机理进行原位、动态表 征研究. 目前, 有关铈基催化剂催化燃烧炭烟颗粒的反 应机理虽然取得部分成果, 如金属对增加氧空位、形 成活性中心的作用等方面达成共识，但金属种类繁 多、性质各异且存在形式多样, 导致其催化燃烧炭烟 的内在本质认识仍然不够深入. 因此, 下一步开发多 种原位光谱联用技术, 实现炭烟颗粒催化燃烧过程中 原位、动态分析并结合理论计算手段将成为铈基氧化 物催化剂催化炭烟燃烧反应机理的研究重点.

铈元素作为稀土家族中丰度最高的元素, 其在机 动车尾气催化净化领域的广泛研究展示了诱人前景. 随着研究手段的不断提高和深入以及新技术和新方法 的研发, 设计结构合理、性能优异的铈基氧化物催化 剂, 开发新的柴油车尾气催化净化技术, 加快铈基氧 化物催化剂在实际中的应用, 实现该领域的飞跃式发 展, 对提高和改善人们的生活质量并促进我国经济和 科技的发展具有重要的意义.

\section{参考文献}

1 Yu X, Wang L, Zhao Z, Fan X, Chen M, Wei Y, Liu J. ChemistrySelect, 2017, 2: 10176-10185

2 Tan J, Wei Y, Sun Y, Liu J, Zhao Z, Song W, Li J, Zhang X. J Industrial Eng Chem, 2018, 63: 84-94

3 Niessner R. Angew Chem Int Ed, 2014, 53: 12366-12379

4 Chen Y, Shen G, Lang Y, Chen R, Jia L, Yue J, Shen M, Du C, Shan B. J Catal, 2020, 384: 96-105 
5 Feng X, Liu R, Xu X, Tong Y, Zhang S, He J, Xu J, Fang X, Wang X. Chin J Catal, 2021, 42: 396-408

6 Wang M, Zhang Y, Yu Y, Shan W, He H. Environ Sci Technol, 2021, 55: 240-248

7 Wei Y, Zhang P, Xiong J, Yu Q, Wu Q, Zhao Z, Liu J. Environ Sci Technol, 2020, 54: 6947-6956

8 Li M, Bao F, Zhang Y, Sheng H, Chen C, Zhao J. Environ Sci Technol, 2019, 53: 12311-12319

9 Legutko P, Jakubek T, Kaspera W, Stelmachowski P, Sojka Z, Kotarba A. Top Catal, 2017, 60: 162-170

Dhinesh B, Niruban Bharathi R, Isaac JoshuaRamesh Lalvani J, Parthasarathy M, Annamalai K. J Energy Institute, 2017, 90: 634-645

Dhinesh B, Isaac JoshuaRamesh Lalvani J, Parthasarathy M, Annamalai K. Energy Convers Manage, 2016, 117: 466-474 165

41 Papavasiliou J, Vakros J, Avgouropoulos G. Catal Commun, 2018, 115: 68-72

Z ZH, Balasubramanian R. Appl Energy, 2014, 119: 530-536

Agarwal AK, Dhar A, Gupta JG, Kim WI, Lee CS, Park S. Appl Energy, 2014, 130: 212-221

Foo KK, Sun Z, Medwell PR, Alwahabi ZT, Nathan GJ, Dally BB. Combust Flame, 2018, 194: 376-386

Zhao M, Deng J, Liu J, Li Y, Liu J, Duan Z, Xiong J, Zhao Z, Wei Y, Song W, Sun Y. ACS Catal, 2019, 9: 7548-7567

Cao C, Xing L, Yang Y, Tian Y, Ding T, Zhang J, Hu T, Zheng L, Li X. Appl Catal B-Environ, 2017, 218: 32-45

Wu Q, Xiong J, Zhang Y, Mei X, Wei Y, Zhao Z, Liu J, Li J. ACS Catal, 2019, 9: 3700-3715

Yang Y, Zhao D, Gao Z, Tian Y, Ding T, Zhang J, Jiang Z, Li X. Appl Catal B-Environ, 2021, 286: 119932

Mohankumar S, Senthilkumar P. Renew Sustain Energy Rev, 2017, 80: 1227-1238

Wei Y, Zhao Z, Liu J, Xu C, Jiang G, Duan A. Small, 2013, 9: 3957-3963

Mukherjee D, Reddy BM. Catal Today, 2018, 309: 227-235

Liu T, Li Q, Xin Y, Zhang Z, Tang X, Zheng L, Gao PX. Appl Catal B-Environ, 2018, 232: 108-116

Neeft JPA, Makkee M, Moulijn JA. Chem Eng J Biochem Eng J, 1996, 64: 295-302

Yao X, Xiong Y, Zou W, Zhang L, Wu S, Dong X, Gao F, Deng Y, Tang C, Chen Z, Dong L, Chen Y. Appl Catal B-Environ, 2014, 144: 152-

Boningari T, Somogyvari A, Smirniotis PG. Ind Eng Chem Res, 2017, 56: 5483-5494

Gao G, Shi JW, Liu C, Gao C, Fan Z, Niu C. Appl Surf Sci, 2017, 411: 338-346

Zhang G, Han W, Zhao H, Zong L, Tang Z. Appl Catal B-Environ, 2018, 226: 117-126

Li G, Wang B, Resasco DE. ACS Catal, 2020, 10: 5373-5382

Kerkar RD, Salker AV. Mater Chem Phys, 2020, 253: 123326

He X, Looker BG, Dinh KT, Stubbs AW, Chen T, Meyer RJ, Serna P, Román-Leshkov Y, Lancaster KM, Dincă M. ACS Catal, 2020, 10: 7820-

Li P, Fang L, Hou N, Li J, Yao X, Gan T, Fan L, Zhao Y, Li Y. J Electrochem Soc, 2017, 164: F1142-F1148

Walkey C, Das S, Seal S, Erlichman J, Heckman K, Ghibelli L, Traversa E, McGinnis JF, Self WT. Environ Sci-Nano, 2015, 2: 33-53

Li X, Qi M, Sun X, Weir MD, Tay FR, Oates TW, Dong B, Zhou Y, Wang L, Xu HHK. Acta Biomater, 2019, 94: 627-643

Su X, Zhu L, Li W, Liu H, Ye H. RSC Adv, 2020, 10: 4554-4560

Bao X, Zhang Z, Luo T, Wu X, Xie Z, Lan S, Xie S, Zhou D. Hydrometallurgy, 2020, 193: 105317

Lan L, Chen S, Li H, Wang J, Li D, Chen Y. Mater Des, 2018, 147: 191-199

Li WJ, Wey MY. Appl Catal A-General, 2020, 602: 117732

Li L, Zhang N, Huang X, Liu Y, Li Y, Zhang G, Song L, He H. ACS Catal, 2018, 8: 3222-3231

Chen X, Chen X, Yu E, Cai S, Jia H, Chen J, Liang P. Chem Eng J, 2018, 344: 469-479

Lykaki M, Pachatouridou E, Carabineiro SAC, Iliopoulou E, Andriopoulou C, Kallithrakas-Kontos N, Boghosian S, Konsolakis M. Appl Catal

Guo Y, Wang G, Yao X, Liu B. J Solid State Chem, 2020, 292: 121697

Okal J, Zawadzki M, Kraszkiewicz P, Adamska K. Appl Catal A-General, 2018, 549: 161-169

Seo Y, Lee MW, Kim HJ, Choung JW, Jung CH, Kim CH, Lee KY. J Hazard Mater, 2021, 415: 125373

Gao Z, Liu Y, He Q, Ma H, Li Z. Int J Hydrogen Energy, 2016, 41: 4646-4659

Fu G, Mao D, Sun S, Yu J, Yang Z. J Industrial Eng Chem, 2015, 31: 283-290

Tereshchuk P, Freire RLH, Ungureanu CG, Seminovski Y, Kiejna A, Da Silva JLF. Phys Chem Chem Phys, 2015, 17: 13520-13530 

960]

Kümmerle EA, Heger G. J Solid State Chem, 1999, 147: 485-500

Zinkevich M, Djurovic D, Aldinger F. Solid State Ion, 2006, 177: 989-1001

Ray SP, Cox DE. J Solid State Chem, 1975, 15: 333-343

Sørensen OT. J Solid State Chem, 1976, 18: 217-233

Kurian M. J Environ Chem Eng, 2020, 8: 104439

Shan Y, Liu Y, Li Y, Yang W. Separation Purification Tech, 2020, 250: 117181

Montini T, Melchionna M, Monai M, Fornasiero P. Chem Rev, 2016, 116: 5987-6041

Ulrich V, Moroz B, Sinev I, Pyriaev P, Bukhtiyarov V, Grünert W. Appl Catal B-Environ, 2017, 203: 572-581

Skorodumova NV, Simak SI, Lundqvist BI, Abrikosov IA, Johansson B. Phys Rev Lett, 2002, 89: 166601

Ye S, Sun P, Liu CH, Hang H. Chin J Mater Res, 2017, 12: 956-960 (in Chinese) [叶松, 孙平, 刘军恒, 黄河. 材料研究学报, 2017, 12: 956-

Huang H, Liu J, Sun P, Ye S. RSC Adv, 2016, 6: 102028

Kastrinaki G, Lorentzou S, Konstandopoulos AG. Emiss Control Sci Technol, 2015, 1: 247-253

Chen Z, Chen L, Jiang M, Gao X, Huang M, Li Y, Ren L, Yang Y, Yang Z. Appl Surf Sci, 2020, 510 : 145401

Zhang W, Niu X, Chen L, Yuan F, Zhu Y. Sci Rep, 2016, 6: 29062

Miceli P, Bensaid S, Russo N, Fino D. Chem Eng J, 2015, 278: 190-198

Kumar PA, Tanwar MD, Bensaid S, Russo N, Fino D. Chem Eng J, 2012, 207-208: 258-266

Dai Y, Tian J, Fu W. J Mater Sci, 2019, 54: 10141-10152

Bensaid S, Russo N, Fino D. Catal Today, 2013, 216: 57-63

Voskanyan AA, Chan KY, Li CYV. Chem Mater, 2016, 28: 2768-2775

Yang P, Zhou S, Lei J. J Wuhan Univ Technol-Mat Sci Edit, 2016, 31: 113-117

Lee JH, Lee SH, Choung JW, Kim CH, Lee KY. Appl Catal B-Environ, 2019, 246: 356-366

Aneggi E, Wiater D, de Leitenburg C, Llorca J, Trovarelli A. ACS Catal, 2014, 4: 172-181

Aneggi E, Divins NJ, de Leitenburg C, Llorca J, Trovarelli A. J Catal, 2014, 312: 191-194

Jian S, Yang Y, Ren W, Xing L, Zhao D, Tian Y, Ding T, Li X. Chem Eng Sci, 2020, 226: 115891

Sreeremya TS, Krishnan A, Remani KC, Patil KR, Brougham DF, Ghosh S. ACS Appl Mater Interfaces, 2015, 7: 8545-8555

Piumetti M, Bensaid S, Russo N, Fino D. Appl Catal B-Environ, 2015, 165: 742-751

Sahoo TR, Armandi M, Arletti R, Piumetti M, Bensaid S, Manzoli M, Panda SR, Bonelli B. Appl Catal B-Environ, 2017, 211: 31-45

Bueno-López A, Krishna K, Makkee M, Moulijn J. J Catal, 2005, 230: 237-248

Anantharaman AP, Dasari HP, Dasari H, Babu GUB. Asia-Pac J Chem Eng, 2019, 14: e2316

Nascimento LF, Lima JF, de Sousa Filho PC, Serra OA. J Environ Sci, 2018, 73: 58-68

Guillén-Hurtado N, Giménez-Mañogil J, Martínez-Munuera JC, Bueno-López A, García-García A. Appl Catal A-General, 2020,590 : 117339

Guillén-Hurtado N, García-García A, Bueno-López A. Appl Catal B-Environ, 2015, 174-175: 60-66

Krishna K, Bueno-López A, Makkee M, Moulijn JA. Top Catal, 2007, 42-43: 221-228

Vinodkumar T, Durgasri DN, Maloth S, Reddy BM. J Chem Sci, 2015, 127: 1145-1153

Patil SS, Dasari HP, Dasari H. Nano-Struct Nano-Objects, 2019, 20: 100388

Rangaswamy A, Sudarsanam P, Reddy BM. J Rare Earths, 2015, 33: 1162-1169

Małecka MA, Kępiński L, Miśta W. Appl Catal B-Environ, 2007, 74: 290-298

Zhang H, Wang J, Cao Y, Wang Y, Gong M, Chen Y. Chin J Catal, 2015, 36: 1333-1341

Vinodkumar T, Mukherjee D, Subrahmanyam C, Reddy BM. New J Chem, 2018, 42: 5276-5283

Devaiah D, Tsuzuki T, Aniz CU, Reddy BM. Catal Lett, 2015, 145: 1206-1216

Piumetti M, Andana T, Bensaid S, Fino D, Russo N, Pirone R. AIChE J, 2016, 63: 216-225

Deng J, Li S, Xiong L, Jiao Y, Yuan S, Wang J, Chen Y. Appl Surf Sci, 2020, 505: 144301

Dong C, Zong X, Jiang W, Niu L, Liu Z, Qu D, Wang X, Sun Z. Small Struct, 2020, 2: 2000081

Ashikaga R, Murata K, Ito T, Yamamoto Y, Arai S, Satsuma A. Catal Sci Technol, 2020, 10: 7177-7185

Zhao H, Li H, Pan Z, Feng F, Gu Y, Du J, Zhao Y. Appl Catal B-Environ, 2020, 268: 118422 
93 Téllez-Salazar WN, Ovalle-Encinia O, Ramírez-Rosales D, Ma X, Dorantes-Rosales HJ, Lara-García HA, Ortiz-Landeros J. Chem Eng Sci, 2021, 234: 116443

94 Sudarsanam P, Hillary B, Deepa DK, Amin MH, Mallesham B, Reddy BM, Bhargava SK. Catal Sci Technol, 2015, 5: 3496-3500

95 Zhai G, Wang J, Chen Z, Yang S, Men Y. J Hazard Mater, 2019, 363: 214-226

96 Xing L, Yang Y, Ren W, Zhao D, Tian Y, Ding T, Zhang J, Zheng L, Li X. Catal Today, 2020, 351: 83-93

97 Zhao H, Zhou X, Wang M, Xie Z, Chen H, Shi J. RSC Adv, 2017, 7: 3233-3239

98 Zhang H, Zhou C, Galvez ME, Da Costa P, Chen Y. Appl Surf Sci, 2018, 462: 678-684

99 Mori K, Miyauchi Y, Kuwahara Y, Yamashita H. BCSJ, 2017, 90: 556-564

100 Yang Z, Luo L, Tang L, Zhou Z, Zhou Z, Li Y. Fuel, 2020, 278: 118369

101 Lin X, Li S, He H, Wu Z, Wu J, Chen L, Ye D, Fu M. Appl Catal B-Environ, 2018, 223: 91-102

$$
2215
$$
Gao J, Xiong Y, Zhang Q, Jiang Y, Wang J, Zou S, Fu M, Wu J, Hu Y, Ye D. Chem Eng J, 2020, 398: 125448 He H, Lin X, Li S, Wu Z, Gao J, Wu J, Wen W, Ye D, Fu M. Appl Catal B-Environ, 2018, 223: 134-142 Wang J, Yang S, Sun H, Qiu J, Men Y. J Colloid Interface Sci, 2020, 577: 355-367 Huang H, Liu J, Sun P, Ye S, Liu B. RSC Adv, 2017, 7: 7406-7412 Putla S, Amin MH, Reddy BM, Nafady A, Al Farhan KA, Bhargava SK. ACS Appl Mater Interfaces, 2015, 7: 16525-16535 Jampaiah D, Velisoju VK, Devaiah D, Singh M, Mayes ELH, Coyle VE, Reddy BM, Bansal V, Bhargava SK. Appl Surf Sci, 2019, 473: 209-221 Wang M, Zhang Y, Yu Y, Shan W, He H. Catal Sci Technol, 2021, 11: 895-903 Cheng Y, Liu J, Zhao Z, Song W, Wei Y. Chem Eng Sci, 2017, 167: 219-228 Govinda Rao B, Jampaiah D, Venkataswamy P, Reddy BM. ChemistrySelect, 2016, 1: 6681-6691 Ali S, Wu X, Zuhra Z, Ma Y, Abbas Y, Jin B, Ran R, Weng D. Appl Surf Sci, 2020, 512: 145602 Cui B, Yan S, Xia Y, Li K, Li S, Wang D, Ye Y, Liu YQ. Appl Catal A-General, 2019, 578: 20-29 Sudarsanam P, Hillary B, Mallesham B, Rao BG, Amin MH, Nafady A, Alsalme AM, Reddy BM, Bhargava SK. Langmuir, 2016, 32: 2208-

Sudarsanam P, Hillary B, Amin MH, Rockstroh N, Bentrup U, Brückner A, Bhargava SK. Langmuir, 2018, 34: 2663-2673 Singh P, Hegde MS. J Solid State Chem, 2008, 181: 3248-3256

Zhai Z, Cui D, Zhang Y, Hou Y, Cui M, Zhang H, Song J, Wang H. J Rare Earths, 2020, 38: 274-180 Aneggi E, de Leitenburg C, Dolcetti G, Trovarelli A. Catal Today, 2006, 114: 40-47 Neelapala SD, Dasari H. Mater Sci Energy Technol, 2018, 1: 155-159

Cousin R, Capelle S, Abi-Aad E, Courcot D, Aboukaïs A. Appl Catal B-Environ, 2007, 70: 247-253

Sellers-Antón B, Bailón-García E, Cardenas-Arenas A, Davó-Quiñonero A, Lozano-Castelló D, Bueno-López A. Environ Sci Technol, 2020, 54: 2439-2447

Yang Z, Hu W, Zhang N, Li Y, Liao Y. J Catal, 2019, 377: 98-109

Ying Z, Chenjun X, Yeqing S, Qiuliang Z, Yinfei C, Hanfeng L. RSC Adv, 2015, 5: 91734-91741

Andana T, Piumetti M, Bensaid S, Veyre L, Thieuleux C, Russo N, Fino D, Quadrelli EA, Pirone R. Appl Catal B-Environ, 2017, 209: 295-310

Azambre B, Collura S, Darcy P, Trichard JM, Da Costa P, García-García A, Bueno-López A. Fuel Processing Tech, 2011, 92: 363-371

Yu X, Li J, Wei Y, Zhao Z, Liu J, Jin B, Duan A, Jiang G. Ind Eng Chem Res, 2014, 53: 9653-9664

Li Y, Du Y, Wei Y, Zhao Z, Jin B, Zhang X, Liu J. Catal Sci Technol, 2017, 7: 968-981

Jin B, Wei Y, Zhao Z, Liu J, Jiang G, Duan A. Chin J Catal, 2016, 37: 923-933

Wei Y, Zhang Y, Zhang P, Xiong J, Mei X, Yu Q, Zhao Z, Liu J. Environ Sci Technol, 2020, 54: 2002-2011

Wei Y, Liu J, Zhao Z, Duan A, Jiang G. J Catal, 2012, 287: 13-29

Wei Y, Zhao Z, Yu X, Jin B, Liu J, Xu C, Duan A, Jiang G, Ma S. Catal Sci Technol, 2013, 3: 2958-2970

Wei Y, Zhao Z, Jin B, Yu X, Jiao J, Li K, Liu J. Catal Today, 2015, 251: 103-113

Wang W, Liu Y, Wang L, Zhan W, Guo Y, Guo Y. Catal Today, 2020, doi:10.1016/j.cattod.2020.10.043

Lee C, Park JI, Shul YG, Einaga H, Teraoka Y. Appl Catal B-Environ, 2015, 174-175: 185-192

Lee C, Jeon Y, Kim T, Tou A, Park JI, Einaga H, Shul YG. Fuel, 2018, 212: 395-404

Zou G, Fan Z, Yao X, Zhang Y, Zhang Z, Chen M, Shangguan W. Chin J Catal, 2017, 38: 564-572 
Homsi D, Aouad S, El Nakat J, El Khoury B, Obeid P, Abi-Aad E, Aboukaïs A. Catal Commun, 2011, 12: 776-780

Xiong J, Mei X, Liu J, Wei Y, Zhao Z, Xie Z, Li J. Appl Catal B-Environ, 2019, 251: 247-260

Lee JH, Jo DY, Choung JW, Kim CH, Ham HC, Lee KY. J Hazard Mater, 2021, 403: 124085

Castoldi L, Matarrese R, Lietti L, Forzatti P. Appl Catal B-Environ, 2009, 90: 278-285

Aneggi E, de Leitenburg C, Dolcetti G, Trovarelli A. Catal Today, 2008, 136: 3-10

Li Q, Xin Y, Zhang Z, Cao X. Chem Eng J, 2018, 337: 654-660

Sui L, Wang Y, Kang H, Dong H, Dong L, Yu L. ACS Omega, 2017, 2: 6984-6990

Wang M, Zhang Y, Yu Y, Shan W, He H. Appl Catal B-Environ, 2021, 285: 119850

Salinas D, Pecchi G, Rodríguez V, Fierro JLG. $M R C$, 2015, 04: 68-77

Neyertz CA, Miró EE, Querini CA. Chem Eng J, 2012, 181-182: 93-102

Shan W, Yang L, Ma N, Yang J. Chin J Catal, 2012, 33: 970-976

Huang H, Zhang X, Liu J, Ye S. Sci Rep, 2020, 10: 10025

Alinezhadchamazketi A, Khodadadi AA, Mortazavi Y, Nemati A. J Environ Sci, 2013, 25: 2498-2506

Cooper A, Davies TE, Morgan DJ, Golunski S, Taylor SH. Catalysts, 2020, 10: 294-307

Wu X, Lin F, Wang L, Weng D, Zhou Z. J Environ Sci, 2011, 23: 1205-1210

Lin F, Wu X, Weng D. Catal Today, 2011, 175: 124-132

Guan B, Huang Y, Lin H, Huang Z. Ind Eng Chem Res, 2018, 57: 8635-8646

Andana T, Piumetti M, Bensaid S, Russo N, Fino D, Pirone R. Appl Catal B-Environ, 2016, 197: 125-137

Téllez-Salazar WN, Fabián-Anguiano JA, Ovalle-Encinia O, Zeifert BH, Ezeta-Mejía A, Romero-Ibarra IC, Ortiz-Landeros J. Mater Res Express, 2021, 8: 015501

Dulgheru P, Sullivan JA. Top Catal, 2013, 56: 504-510

Andana T, Piumetti M, Bensaid S, Russo N, Fino D, Pirone R. Nanoscale Res Lett, 2016, 11: 278-286

Anantharaman AP, Gadiyar HJ, Surendran M, Rao AS, Dasari HP, Dasari H, Babu GUB. Chem Pap, 2018, 72: 3179-3188

Tang Q, Du J, Xie B, Yang Y, Yu W, Tao C. J Rare Earths, 2018, 36: 64-71

Mori K, Jida H, Kuwahara Y, Yamashita H. Nanoscale, 2020, 12: 1779-1789

Stegmayer MÁ, Milt VG, Miró EE. Catal Commun, 2020, 139: 105984

Jin B, Wu X, Weng D, Liu S, Yu T, Zhao Z, Wei Y. J Colloid Interface Sci, 2018, 532: 579-587

Wang X, Jin B, Feng R, Liu W, Weng D, Wu X, Liu S. Appl Catal B-Environ, 2019, 250: 132-142

He J, Yao P, Qiu J, Zhang H, Jiao Y, Wang J, Chen Y. Fuel, 2021, 286: 119359

Cheng Y, Liu J, Zhao Z, Song W, Wei Y. J Hazard Mater, 2018, 342: 317-325

Liu P, Liang X, Dang Y, He J, Shirazi-Amin A, Achola LA, Dissanayake S, Chen H, Fu M, Ye D, Suib SL. J Environ Sci, 2021, 101: 293-303

Liu J, Zhao Z, Chen Y, Xu C, Duan A, Jiang G. Catal Today, 2011, 175: 117-123

Ai C, Zhang Y, Wang P, Wang W. Catalysts, 2019, 9: 646-664

Cui B, Zhou L, Li K, Liu YQ, Wang D, Ye Y, Li S. Appl Catal B-Environ, 2020, 267: 118670

Feng N, Zhu Z, Zhao P, Wang L, Wan H, Guan G. Appl Surf Sci, 2020, 515: 146013

Yao P, He J, Jiang X, Jiao Y, Wang J, Chen Y. J Energy Institute, 2020, 93: 774-783

Dosa M, Piumetti M, Bensaid S, Russo N, Fino D. Catal Lett, 2019, 149: 107-118

Wang Y, Wang J, Chen H, Yao M, Li Y. Chem Eng Sci, 2015, 135: 294-300

Liu S, Wu X, Lin Y, Li M, Weng D. Chin J Catal, 2014, 35: 407-415

Zeng L, Cui L, Wang C, Guo W, Gong C. Front Mater Sci, 2019, 13: 288-295

Liu S, Wu X, Liu W, Chen W, Ran R, Li M, Weng D. J Catal, 2016, 337: 188-198

Deng X, Li M, Zhang J, Hu X, Zheng J, Zhang N, Chen BH. Chem Eng J, 2017, 313: 544-555

Nascimento LF, Lima JF, de Sousa Filho PC, Serra OA. Chem Eng J, 2016, 290: 454-464

Wen Z, Duan X, Hu M, Cao Y, Ye L, Jiang L, Yuan Y. J Environ Sci, 2018, 64: 122-129

Nascimento LF, Martins RF, Serra OA. J Rare Earths, 2014, 32: 610-620

Weng D, Li J, Wu X, Si Z. J Environ Sci, 2011, 23: 145-150 
181

182 坚. 中国稀土学报, 2016, 34: 694-714] 1922]

Weng D, Li J, Wu X, Si Z. J Rare Earths, 2010, 28: 542-546

Wang L, Fang S, Feng N, Wan H, Guan G. Chem Eng J, 2016, 293: 68-74

Feng N, Chen C, Meng J, Liu G, Fang F, Wang L, Wan H, Guan G. Appl Surf Sci, 2017, 399: 114-122

Neyertz CA, Banús ED, Miró EE, Querini CA. Chem Eng J, 2014, 248: 394-405

Yu XH, Chi CB, Wang LY, Zhao Z, Wei YC, Liu J. J Rare Earths, 2016, 34: 694-714 (in Chinese) [于学华, 迟克彬, 王斓懿, 赵震, 韦岳长, 刘 Bueno-López A. Appl Catal B-Environ, 2014, 146: 1-11

Bueno - López A, Krishna K, Makkee M, Moulijn JA. Catal Lett, 2005, 99: 203-205

Soler L, Casanovas A, Escudero C, Pérez-Dieste V, Aneggi E, Trovarelli A, Llorca J. ChemCatChem, 2016, 8: 2748-2751

Gross MS, Sánchez BS, Querini CA. Chem Eng J, 2011, 168: 413-419

Guillén-Hurtado N, García-García A, Bueno-López A. J Catal, 2013, 299: 181-187

Mukherjee D, Rao BG, Reddy BM. Appl Catal B-Environ, 2016, 197: 105-115

Katta L, Sudarsanam P, Thrimurthulu G, Reddy BM. Appl Catal B-Environ, 2010, 101: 101-108

Zou G, Xu Y, Wang S, Chen M, Shangguan W. Catal Sci Technol, 2015, 5: 1084-1092

Xu J, Lu G, Guo Y, Guo Y, Gong XQ. Appl Catal A-General, 2017, 535: 1-8

Rico-Pérez V, Aneggi E, Bueno-López A, Trovarelli A. Appl Catal B-Environ, 2016, 197: 95-104

Atribak I, Bueno-Lopez A, Garcia-Garcia A. Top Catal, 2009, 52: 2088-2091

Stanmore BR, Brilhac JF, Gilot P. Carbon, 2001, 39: 2247-2268

Yu XH, Wei YC, Zhao Z. Sci Sin Chim, 2014, 44: 1905-1922 (in Chinese) [于学华, 韦岳长, 刘坚, 赵震. 中国科学: 化学, 2014, 44: 1905-

Kašpar J, Fornasiero P, Hickey N. Catal Today, 2003, 77: 419-449

Yang Z, Lu Z, Luo G. Phys Rev B, 2007, 76: 075421

Grabchenko MV, Mamontov GV, Zaikovskii VI, La Parola V, Liotta LF, Vodyankina OV. Appl Catal B-Environ, 2020, 260: 118148

Weng D, Li M. Sci Technol Rev, 2014, 32: 77-83 (in Chinese) [翁端, 李敏. 科技导报, 2014, 32: 77-83]

Bueno-López A, Krishna K, Vanderlinden B, Mul G, Moulijn J, Makkee M. Catal Today, 2007, 121: 237-245

Wei Y, Jiao J, Zhang X, Jin B, Zhao Z, Xiong J, Li Y, Liu J, Li J. Nanoscale, 2017, 9: 4558-4571

Zhang H, Wang J, Zhang Y, Jiao Y, Ren C, Gong M, Chen Y. Appl Surf Sci, 2016, 377: 48-55

Liu S, Wu X, Weng D, Ran R. J Rare Earths, 2015, 33: 567-590

Gross MS, Ulla MA, Querini CA. Appl Catal A-General, 2009, 360: 81-88

Wang C, Yuan H, Lu G, Wang H. Appl Catal B-Environ, 2021, 281: 119468 


\title{
Recent advances in performances and mechanisms of cerium-based oxide catalysts for catalytic combustion of soot particles released from diesel engines
}

\author{
Chao Peng ${ }^{1}$, Di Yu ${ }^{1}$, Lanyi Wang ${ }^{2}$, Chunlei Zhang ${ }^{1}$, Xuehua Yu ${ }^{1 *}$, Zhen Zhao ${ }^{1,2^{*}}$ \\ ${ }^{1}$ Institute of Catalysis for Energy and Environment, College of Chemistry and Chemical Engineering, Shenyang Normal University, Shenyang 110034, \\ China \\ ${ }^{2}$ State Key Laboratory of Heavy Oil Processing, China University of Petroleum, Beijing 102249, China \\ *Corresponding authors (email: yuxuehua1986@163.com; zhenzhao@cup.edu.cn, zhaozhen1586@163.com)
}

\begin{abstract}
With the increasingly strict environmental protection regulations and the improvement of people's awareness of environmental protection, the serious environmental pollution caused by soot particles from diesel vehicle exhaust has attracted people's attention. Catalytic purification technology is one of the most effective ways to eliminate soot particles and the research and development of highly effective catalysts is one of the key factors for determining the application of this technology. In recent years, cerium-based oxide catalysts have been widely used for catalytic combustion of diesel soot particles due to their excellent oxidation-reduction performance, suitable surface acidity, and high oxygen storage/release capacity. The researches focusing on highly active essence of the cerium-based oxide catalysts in soot combustion are helpful to understand the fundamental theories of catalytic processes of soot combustion and provide scientific guidances for the optimization of existing catalysts and design of new-type catalysts. In this review, the recent research progress of cerium-based oxide catalysts for diesel soot combustion is summarized, including single cerium oxide catalyst and cerium-based oxide catalysts modified by rare earth metals, transition metals, noble metals and alkali (alkaline earth) metals. Meanwhile, the reaction mechanisms of above-mentioned catalysts are also summarized. Finally, the problems and development directions of cerium-based oxide catalysts for soot combustion are proposed and prospected.
\end{abstract}

Keywords: cerium-based oxide, catalyst, diesel engines, soot particles

doi: $10.1360 /$ SSC-2021-0093 